Avaliação e seleção de modelos em deteç̧ão não supervisionada de outliers

Henrique Oliveira Marques 



\title{
Avaliação e seleção de modelos em detecção não supervisionada de outliers
}

\author{
Henrique Oliveira Marques
}

Orientador: Prof. Dr. Ricardo José Gabrielli Barreto Campello

Dissertação apresentada ao Instituto de Ciências Matemáticas e de Computação - ICMC-USP, como parte dos requisitos para obtenção do título de Mestre em Ciências - Ciências de Computação e Matemática Computacional. VERSÃO REVISADA 
Ficha catalográfica elaborada pela Biblioteca Prof. Achille Bassi e Seção Técnica de Informática, ICMC/USP, com os dados fornecidos pelo(a) autor(a)

Oliveira Marques, Henrique Avaliação e seleção de modelos em detecção não supervisionada de outliers / Henrique Oliveira Marques; orientador Ricardo José Gabrielli Barreto Campello. -- São Carlos, 2015. $64 \mathrm{p}$.

Dissertação (Mestrado - Programa de Pós-Graduação em Ciências de Computação e Matemática Computacional) -- Instituto de Ciências Matemáticas e de Computação, Universidade de São Paulo, 2015.

1. Mineração de dados. 2. Detecção de outliers. 3. Avaliação não supervisionada. 4. Seleção de modelos. I. José Gabrielli Barreto Campello, Ricardo, orient. II. Título. 
"Standing on the Shoulder of Giants" 



\section{Agradecimentos}

Agradeço a toda minha família, em especial aos meus pais, Abimael e Alaise, que mesmo de longe sempre me motivaram e me deram todo apoio necessário.

Ao meu orientador Ricardo Campello pela dedicação e comprometimento com o trabalho, e por saber nos momentos oportunos cobrar, elogiar e principalmente motivar/incentivar.

Aos professores Arthur Zimek (LMU München) e Jörg Sander (UAlberta) pelas discussões e contribuições que acrescentaram muita qualidade a esta dissertação, além de terem me proporcionado uma excelente experiência internacional.

À professora Claudia Martins (UFMT), que sou muito grato por ter me orientado por quase 4 anos como aluno de iniciação científica na minha graduação e ter me apresentado a mineração de dados, e ao professor Thiago Ventura (UFMT) pelo tempo que trabalhamos juntos, por todo aprendizado e por ainda manter contato, ainda que não tão constante.

À todos meus amigos de São Carlos, em especial os do laboratório BioCom, por terem me recebido tão bem, sempre a disposição para ajudar no que fosse preciso, além dos vários momentos de diversão que me proporcionaram.

À todos os funcionários do ICMC, em especial aos do Serviço de Pós-Graduação, pela paciência e gentileza no atendimento dos inúmeros processos burocráticos.

À Coordenação de Aperfeiçoamento de Pessoal de Nível Superior (CAPES) e ao Conselho Nacional de Desenvolvimento Científico e Tecnológico (CNPq) pelo suporte financeiro para realização do trabalho. 



\section{Resumo}

A área de detecção de outliers (ou detecção de anomalias) possui um papel fundamental na descoberta de padrões em dados que podem ser considerados excepcionais sob alguma perspectiva. Uma importante distinção se dá entre as técnicas supervisionadas e não supervisionadas. O presente trabalho enfoca as técnicas de detecção não supervisionadas. Existem dezenas de algoritmos desta categoria na literatura, porém cada um deles utiliza uma intuição própria do que deve ser considerado um outlier ou não, que é naturalmente um conceito subjetivo. Isso dificulta sensivelmente a escolha de um algoritmo em particular e também a escolha de uma configuração adequada para o algoritmo escolhido em uma dada aplicação prática. Isso também torna altamente complexo avaliar a qualidade da solução obtida por um algoritmo/configuração em particular adotados pelo analista, especialmente em função da problemática de se definir uma medida de qualidade que não seja vinculada ao próprio critério utilizado pelo algoritmo. Tais questões estão inter-relacionadas e se referem respectivamente aos problemas de seleção de modelos e avaliação (ou validação) de resultados em aprendizado de máquina não supervisionado. Neste trabalho foi desenvolvido um índice pioneiro para avaliação não supervisionada de detecção de outliers. O índice, chamado IREOS (Internal, Relative Evaluation of Outlier Solutions), avalia e compara diferentes soluções (top- $n$, i.e., rotulações binárias) candidatas baseando-se apenas nas informações dos dados e nas próprias soluções a serem avaliadas. O índice também é ajustado estatisticamente para aleatoriedade e extensivamente avaliado em vários experimentos envolvendo diferentes coleções de bases de dados sintéticas e reais. 



\section{Abstract}

Outlier detection (or anomaly detection) plays an important role in the pattern discovery from data that can be considered exceptional in some sense. An important distinction is that between the supervised and unsupervised techniques. In this work we focus on unsupervised outlier detection techniques. There are dozens of algorithms of this category in literature, however, each of these algorithms uses its own intuition to judge what should be considered an outlier or not, which naturally is a subjective concept. This substantially complicates the selection of a particular algorithm and also the choice of an appropriate configuration of parameters for a given algorithm in a practical application. This also makes it highly complex to evaluate the quality of the solution obtained by an algorithm or configuration adopted by the analyst, especially in light of the problem of defining a measure of quality that is not hooked on the criterion used by the algorithm itself. These issues are interrelated and refer respectively to the problems of model selection and evaluation (or validation) of results in unsupervised learning. Here we developed a pioneer index for unsupervised evaluation of outlier detection results. The index, called IREOS (Internal, Relative Evaluation of Outlier Solutions), can evaluate and compare different candidate (top- $n$, i.e., binary labelings) solutions based only upon the data information and the solution to be evaluated. The index is also statistically adjusted for chance and extensively evaluated in several experiments involving different collections of synthetic and real data sets. 



\section{Sumário}

Agradecimentos

Resumo iii

Abstract v v v v v v v

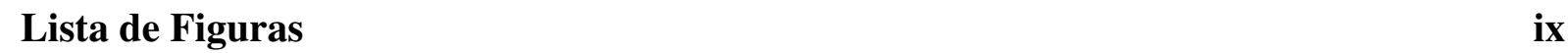

Lista de Abreviações $\quad$ xi

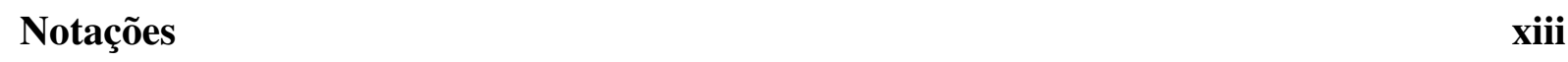

\begin{tabular}{lll}
\hline 1 & Introdução & 1
\end{tabular}

1.1 Hipótese . . . . . . . . . . . . . . . . . . . . . 5 5

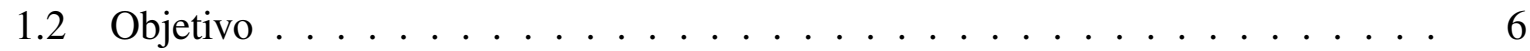

1.3 Contribuições . . . . . . . . . . . . . . . . . 6

1.4 Organização do Trabalho $\ldots \ldots \ldots \ldots \ldots$. . . . . . . . . . . 6

2 Detecção de Outliers 9

$2.1 \quad$ Algoritmos Supervisionados e Semissupervisionados de Detecção de Outliers . 9

2.2 Algoritmos Não Supervisionados de Detecção de Outliers $\quad$. . . . . . . . . . . 10

2.2 .1 Técnicas Estatísticas . . . . . . . . . . . . . . . . . . . 11

2.2 .2 Técnicas Baseadas em Distância . . . . . . . . . . . . . . . . . . 12

2.2 .3 Técnicas Baseadas em Densidade . . . . . . . . . . . . . . . . 13

2.2 .4 Técnicas Baseadas em Ângulo . . . . . . . . . . . . . . . . . . . . 14

2.2.5 Avaliação de Resultados de Detecção Não Supervisionada de Outliers • 15

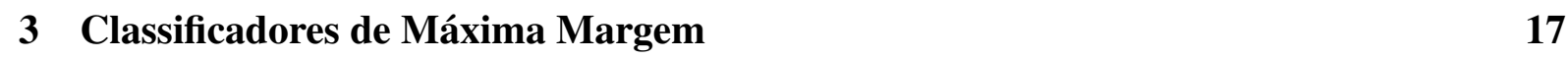

3.1 Classificador Linear de Máxima Margem . . . . . . . . . . . . . . . 17

3.2 Margem Suave . . . . . . . . . . . . . . . . . . . . . 22

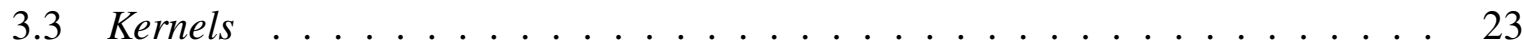


3.4 Classificadores Não Lineares de Máxima Margem . . . . . . . . . . . . . . . 26

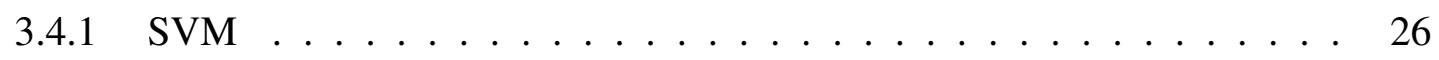

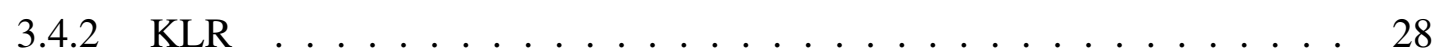

4 IREOS: Um Índice de Validação Interna para Detecção de Outliers 31

4.1 Introdução . . . . . . . . . . . . . . . . . . 31

4.1 .1 Apresentação do Problema . . . . . . . . . . . . . . . . . . . . . . . . . . . . . . . . . . . 32

4.2 Intuição Básica . . . . . . . . . . . . . . . . . . . . . . . . . 32

4.3 Além da Intuição Básica $\ldots \ldots \ldots$. . . . . . . . . . . . . . . 35

4.4 Ajuste para Aleatoriedade . . . . . . . . . . . . . . . . . . 38

$4.4 .1 \quad$ Ajuste Exato . . . . . . . . . . . . . . . . . . . . 38

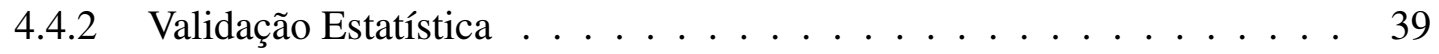

4.4 .3 Ajuste Aproximado via Monte Carlo . . . . . . . . . . . . . . . . 41

4.5 Algoritmo e Complexidade . . . . . . . . . . . . . . . . . . . 42

5 Resultados 45

5.1 Bases de Dados . . . . . . . . . . . . . . . . . . . . 45

5.1 .1 Bases Sintéticas . . . . . . . . . . . . . . . . 45

5.1 .2 Bases Reais . . . . . . . . . . . . . . . . . . . . . 46

5.2 Metodologia . . . . . . . . . . . . . . . . . . . . . 48

5.3 Experimentos . . . . . . . . . . . . . . . . . 50

$5.3 .1 \quad$ Correlação entre Precision-at- $n$ e IREOS . . . . . . . . . . . . . . . . . . . . . . . . 50

5.3 .2 Seleção de Modelos . . . . . . . . . . . . . . . . . 52

6 Conclusões $\quad 53$

6.1 Limitações e Trabalhos Futuros . . . . . . . . . . . . . . . . . . . . . 54

A Medidas de Avaliação Externa de Detecção de Outliers 55

A.1 Precision-at- $\ldots \ldots \ldots \ldots \ldots \ldots \ldots$

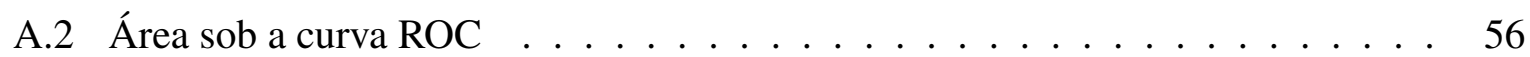

\begin{tabular}{ll}
\hline Referências & 64
\end{tabular} 


\section{Lista de Figuras}

$2.1 \quad$ Base de dados gerada por dois mecanismos diferentes (inspirado em (Breunig et al., 2000) . . . . . . . . . . . . . . . . . . 11

2.2 Ângulos formados por pontos da base (inspirado em (Kriegel et al. [2008)). . . 15

3.1 Base de dados linearmente separável . . . . . . . . . . . . . . . . . 18

3.2 Comparação entre o hiperplano de ótima separação (linha contínua preta) e Regressão Logística (linha tracejada vermelha). Na Figura 3.2(c)| devido a inserção das novas observações, a sobreposição entre os hiperplanos é a menor . . . 20

3.3 Margem rígida e suave . . . . . . . . . . . . . . . . 22

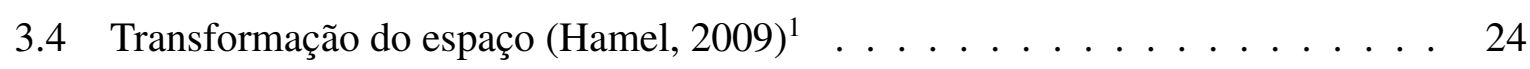

3.5 Efeito dos parâmetros dos kernels polinomial e radial . . . . . . . . . . . 25

3.6 Função de Custo . . . . . . . . . . . . . . . . . . . . . . . . . 29

4.1 Dificuldade em separar uma observação das demais . . . . . . . . . . . . . 33

4.2 Separabilidade. . . . . . . . . . . . . . . . . . . 34

4.3 Presença de clump na base de dados da Figura $4.1 \ldots \ldots$. . . . . . . . . . . 36

$4.4 \quad$ Fronteira de decisão do classificador para avaliação da observação em losango . 37

4.5 Soluções Aleatórias . . . . . . . . . . . . . . . . . . . . . 40

5.1 Curva de separabilidade para soluções controladas: cores refletem o ground truth (cores quentes com maior precision-at-n) . . . . . . . . . 51

A.1 Ambas soluções com precision-at- $n=0$ de acordo com o ground truth . . . . . 56 



\section{Lista de Abreviações}

ABOD Angle-Based Outlier Detection .................................... 4

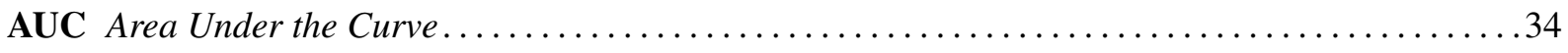

COF Connectivity-based Outlier Factor ....................................... 4

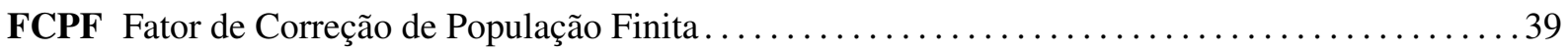

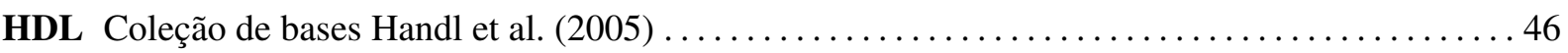

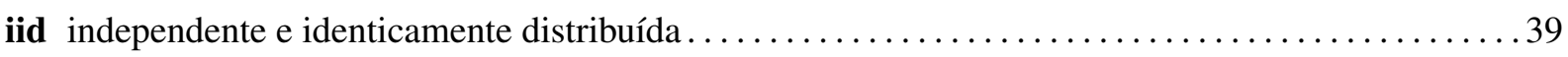

INFLO Influenced Outlierness .................................................

IREOS Internal, Relative Evaluation of Outlier Solutions

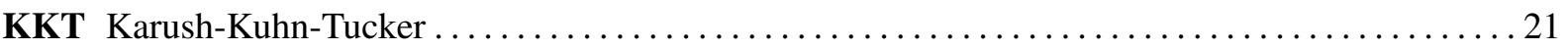

KLR Kernel Logistic Regression ............................................ 28

LDOF Local Distance-based Outlier Factor .....................................

LOCI Local Correlation Integral................................................ 4

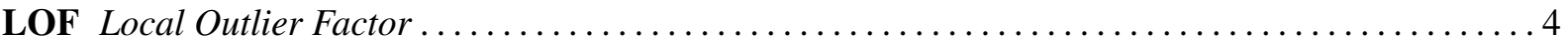

LoOP Local Outlier Probabilities ................................................

OCC One Class Classification ............................................ 10

ROC Receiver Operating Characteristic ...................................... 56

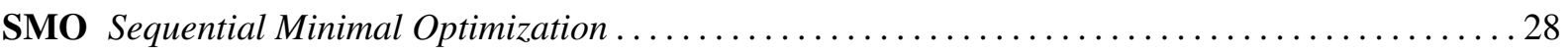

SVM Support Vector Machines................................................ 26

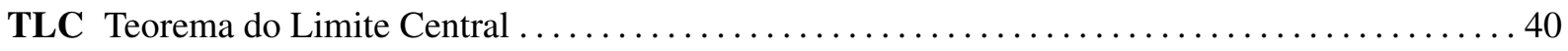


WBC Wisconsin Breast Cancer .............................................

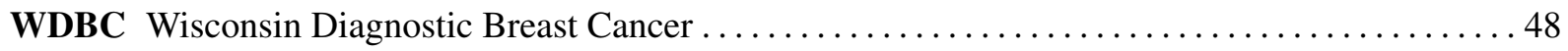

WKNN Weighted $k$-Nearest Neighbors........................................

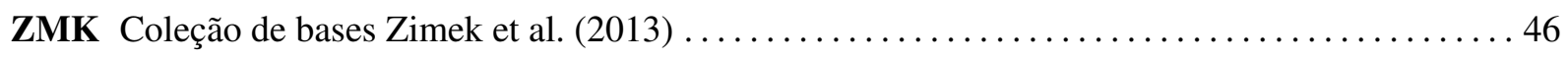




\section{Notações}

$\mathrm{X}$

S

$\mathbf{X}$

$y$

$N$

$\vec{X}$

$|\cdot|$

$\|\cdot\|$

$k$-distance $(\cdot)$

$V_{k}(\cdot)$

$\overline{A B}$

$\mathbf{X} \cdot \mathbf{X}$

$x \times x$
Letras maiúsculas em negrito denotam matrizes, $\mathrm{X}$ em específico denota uma base de dados

Denota uma solução de detecção de outliers, formalizada na seção 4.1

Letras minúsculas em negrito denotam vetores, $\mathrm{x}$ em específico denota uma observação

Letras minúsculas ou maiúsculas em itálico denotam escalares, $y$ em específico denota classe, usualmente +1 ou -1

Denota o número de observações na base de dados

Denota o número de outliers na base de dados

Denota um ponto no espaço euclidiano

Denota a cardinalidade

Denota a norma ou módulo do vetor

Denota a distância para o $k$-ésimo vizinho

Denota a vizinhança que contém os $k$ vizinhos mais próximos $\vec{B}-\vec{A}$

Denota o produto interno entre dois vetores

Denota a multiplicação entre escalares, na maior parte do texto este operador é omitido, sendo utilizado apenas em situações que se deseja evidenciar a operação 



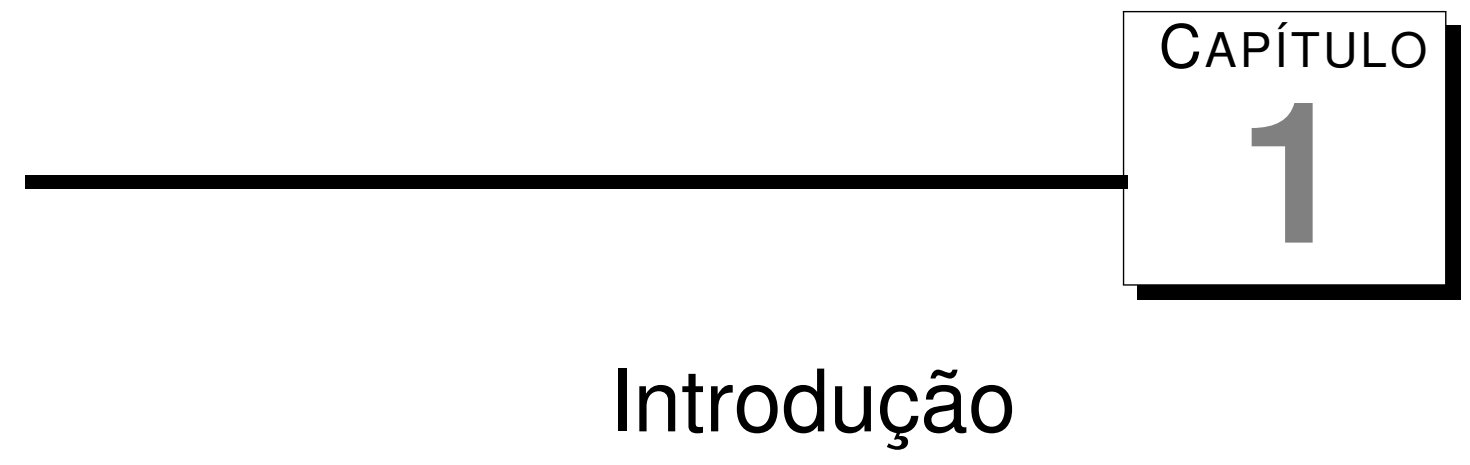

A tecnologia da informática tem evoluído de forma extraordinária. A capacidade de processamento dos computadores tem aumentado nos últimos 50 anos seguindo a chamada lei de Moore, que de forma geral diz que a capacidade de processamento aumenta 100\% aproximadamente a cada 18 meses (Moore, 1964, 1965, 1975). Concomitantemente, a capacidade de armazenamento tem aumentado ainda mais rápido. Em consequência desses avanços tecnológicos, o custo da tecnologia tem diminuído, facilitando o acesso a tecnologias como smartphones, RFID, sistemas de vigilância, entre outras tecnologias que produzem uma quantidade enorme de dados. A capacidade de analisar e extrair informação útil desses dados tem sido utilizada de forma estratégica por empresas na intenção de aumentar sua produtividade (Brynjolfsson et al. 2011). Porém extrair informação a partir de uma grande quantidade de dados não é uma tarefa trivial. Nesse contexto, Naisbitt (1982) disse: “we are drowning in information and starved for knowledge", sendo que o cenário de superabundância de dados tem aumentado cada vez mais nos últimos anos, na medida em que a capacidade de coletar e armazenar dados já ultrapassou em muito a capacidade humana para analisar e extrair conhecimento a partir deles (Fayyad et al. 1996). A impossibilidade de analisar esses dados de forma manual proporcionou um ambiente adequado para a aplicação de tecnologias emergentes de informação capazes de sintetizar, processar e transformar dados em conhecimento útil de uma forma inteligente e automatizada. Por essa razão, pesquisadores de diversas áreas têm se empenhado no estudo de métodos para o que tem sido chamado de mineração de dados ou data mining.

O termo mineração de dados (Fayyad et al., 1996; Han and Kamber, 2006) refere-se amplamente a técnicas estatísticas, matemáticas e computacionais de análise para extrair conhecimento útil de grandes conjuntos de dados de forma eficiente. Há algumas vertentes principais em mineração de dados que juntas cobrem a maioria dos problemas existentes em aplicações práticas (Tan et al., 2006): agrupamento de dados, classificação de padrões, análise de associação, análise de regressão e detecção de outliers. Dentre tais vertentes, a área de detecção 
de outliers (ou detecção de anomalias, como também é conhecida) possui um papel fundamental na descoberta de padrões que podem ser considerados excepcionais sob alguma perspectiva (Hodge and Austin, 2004; Patcha and Park, 2007; Hadi et al., 2009; Chandola et al., 2009, 2012; Zimek et al., 2012). Detectar tais padrões em dados é relevante por diversas razões, entre as principais estão: (i) em algumas aplicações, tais padrões representam dados espúrios que se deseja eliminar em uma etapa de pré-processamento de dados, por exemplo, falhas ou ruídos em sensores; (ii) existem aplicações em que se deseja disparar um alarme quando um evento anômalo é detectado, como em detecção de ataques virtuais e detecção de falhas em sensores; ou, ainda mais importante, (iii) em muitas aplicações tais padrões representam comportamentos extraordinários que merecem algum tipo de atenção especial. Eles podem revelar, por exemplo, genes associados a determinadas doenças, fraudes em sistemas financeiros, funcionários/clientes com perfis não usuais de produtividade/consumo, etc. Nesse contexto, diz-se que “one person's noise is another person's signal" (Knorr and Ng, 1998; Han and Kamber, 2006).

A maneira pela qual uma observação é julgada inconsistente ou suspeita não é definida de maneira geral, ao contrário, existem várias definições de outlier na literatura, cada uma sendo mais (ou menos) apropriada dependendo do cenário de aplicação e do método de detecção utilizado. Entre as definições mais amplamente citadas estão:

"An outlying observation, or outlier, is one that appears to deviate markedly from other members of the sample in which it occurs" (Grubbs, 1969).

"An observation that deviates so much from other observations as to arouse suspicion that it was generated by a different mechanism" (Hawkins, 1980).

"An observation (or subset of observations) which appears to be inconsistent with the remainder of that set of data" (Barnett and Lewis, 1994).

Devido ao fato de que não existe apenas uma única definição de outlier, dezenas de algoritmos têm sido desenvolvidos, cada um utilizando uma intuição própria do que deve ser considerado um outlier ou não. Tais técnicas podem ser categorizadas de diferentes maneiras. Por exemplo, uma distinção usual se dá entre as técnicas globais e locais (Ramaswamy et al., 2000; Breunig et al., 2000), que se refere ao escopo dos dados a ser considerado quando um método decide se uma determinada observação deve ser interpretada como um outlier e com qual grau ou probabilidade. Outra distinção se dá entre as técnicas de rotulação (labeling) (Jin et al., 2001; Fan et al., 2006; Angiulli and Pizzuti, 2005) e pontuação (scoring ou ranking) (Breunig et al., 2000; Zhang et al., 2009; Tang et al., 2002). As técnicas de rotulação categorizam binariamente as observações como outliers ou não outliers (inliers), as $n$ observações mais prováveis serem outliers são categorizadas como tais e as restantes são categorizadas como inliers, tais técnicas são conhecidas como técnicas top- $n$ de detecção de outliers. As técnicas de pontuação, ao invés de categorizar binariamente as observações, pontuam e/ou ordenam as observações de acordo com o grau ou probabilidade com que cada uma delas deve ser categorizada como tal. Uma 
terceira e importante distinção se dá entre as técnicas supervisionadas, semissupervisionadas e não supervisionadas de detecção (Tan et al., 2006). As técnicas supervisionadas pressupõem que se dispõe a priori de um conjunto suficiente e apropriado de observações previamente sabidas serem inliers e também um conjunto de observações previamente sabidas serem outliers de fato. Isso permite o treinamento de classificadores, caso um conjunto apropriado de atributos que descreva as observações esteja disponível. Devido aos outliers serem normalmente raros, em alguns cenários se dispõe de um conjunto suficiente e apropriado apenas de inliers, neste cenário técnicas semissupervisionadas podem ser utilizadas para construir um modelo a partir dos inliers e as observações que não se encaixarem neste modelo são classificadas como outlier. Quando não se tem qualquer informação a priori sobre quais observações são de fato outliers ou inliers, faz-se necessário utilizar técnicas não supervisionadas, que não pressupõem qualquer conhecimento prévio sobre observações que de fato são ou não outliers. O presente trabalho enfoca as técnicas top- $n$ de detecção não supervisionadas.

O campo da estatística surgiu inicialmente como a principal área de pesquisa em detecção não supervisionada de outliers. Dezenas de testes estatísticos foram desenvolvidos para detectar discordância/anomalia nos dados (Hawkins, 1980; Barnett and Lewis, 1994; Grubbs, 1969). Entretanto, esses testes se suportam em uma série de suposições. Por exemplo, o teste pode fazer suposição quanto à distribuição dos dados, que geralmente não é conhecida a priori, sendo necessário realizar extensivos testes para encontrar uma distribuição conhecida que descreva bem os dados. Outra suposição comum é quanto aos parâmetros da distribuição (e.g. média e variância), porém os parâmetros da distribuição em geral não são conhecidos e precisam portanto ser estimados a partir dos próprios dados, mas tal estimação é geralmente sensível e distorcida pela presença dos próprios outliers que se deseja detectar. Tais distorções geram efeitos indesejados conhecidos como masking, quando a presença de outliers é mascarada por outros outliers, e swamping, quando inliers são incorretamente rotulados como outliers devido à distorção causada pelos outliers (Hadi,1992). Além da maioria dos testes serem paramétricos, ou seja, assumirem que os dados seguem uma determinada distribuição (e.g. Normal) em que os parâmetros podem ou não ser conhecidos, a maioria deles podem ser aplicados apenas em base de dados numéricas e unidimensionais. Por exemplo, uma regra prática comum é tomar como outliers observações que desviam mais do que 3 vezes o desvio padrão a partir da média de uma distribuição Normal (unidimensional); no caso multidimensional limiares equivalentes podem ser estabelecidos e impostos à distância de Mahalanobis (Aggarwal, 2013; , Hair et al., 2005).

Devido à série de limitações apresentada pelas técnicas estatísticas, métodos alternativos de detecção de outliers passaram a ser desenvolvidos. Técnicas baseadas em profundidade (Johnson et al., 1998; Ruts and Rousseeuw, 1996) conseguiram solucionar parte dessas limitações. Por exemplo, suposições quanto à distribuição dos dados não são necessárias e conceitualmente essas técnicas podem ser aplicadas em base de dados multidimensionais, apesar de na prática serem computacionalmente inviáveis para base de dados com mais de 4 dimensões Knorr and Ng, 1998). A partir do trabalho pioneiro de Knorr and Ng (1998); Knorr et al. (2000), pas- 
sam a surgir técnicas não paramétricas computacionalmente escaláveis de detecção de outliers em grandes bases de dados, que ao mesmo tempo generalizam e unificam abordagens estatísticas paramétricas quando certas hipóteses são satisfeitas. Várias novas abordagens surgiram a partir desse trabalho (Orair et al., 2010), tais como os algoritmos KNNOutlier (Ramaswamy et al., 2000), Weighted $k$-Nearest Neighbors (WKNN) ou HilOut (Angiulli and Pizzuti, 2002, 2005), OPTICS-OF (Breunig et al., 1999) Local Outlier Factor (LOF) (Breunig et al., 2000), Local Distance-based Outlier Factor (LDOF) (Zhang et al., 2009), Connectivity-based Outlier Factor (COF) (Tang et al., 2002), Influenced Outlierness (INFLO) (Jin et al., 2006), Local Outlier Probabilities (LoOP) (Kriegel et al., 2009), Angle-Based Outlier Detection (ABOD) (Kriegel et al., 2008), Local Correlation Integral (LOCI) (Papadimitriou et al., 2003), dentre outros. Cada um desses algoritmos, entretanto, utiliza um critério próprio para julgar de forma quantitativa o nível de aderência de cada observação com o conceito de outlier, que é naturalmente subjetivo no contexto não supervisionado. Isso dificulta sensivelmente a escolha de um algoritmo em particular e também a escolha de uma configuração adequada para o algoritmo escolhido em uma dada aplicação prática. Isso também torna altamente complexo avaliar a qualidade da solução obtida por um algoritmo/configuração em particular adotados pelo analista, especialmente em função da problemática de se definir uma medida de qualidade que não seja vinculada ao próprio critério utilizado pelo algoritmo. Tais questões estão inter-relacionadas e se referem respectivamente aos problemas de seleção de modelos e avaliação (ou validação) de resultados em aprendizado não supervisionado. Esses problemas têm sido investigados ao longo de décadas na área de agrupamento não supervisionado de dados (data clustering) (Jain and Dubes, 1988; Gan et al., 2007), mas são raramente mencionados e estão praticamente intocados na área de detecção de outliers.

As áreas de agrupamento de dados e detecção de outliers estão intimamente relacionadas. De fato, ao se referir a um outlier como "an observation that deviates so much from other observations as to arouse suspicion that it was generated by a different mechanism", assume-se implicitamente a existência de um ou mais mecanismos responsáveis por gerar as observações consideradas não suspeitas. Intuitivamente, grupos de dados (clusters) são candidatos naturais para modelar tais mecanismos. Além disso, um outlier não é necessariamente sempre considerado como uma observação que desvia muito de todas as demais. De fato, em alguns domínios de aplicação outliers são vistos como observações que se assemelham umas às outras por serem possivelmente geradas por um mecanismo comum, embora desviem e sejam geralmente menos frequentes do que as demais observações (por exemplo, certos tipos de fraude ou mutações genéticas seguindo um padrão comum).

Dada a relação supramencionada entre as áreas de agrupamento de dados e detecção não supervisionada de outliers, é surpreendente que os problemas de avaliação e seleção de modelos já tenham sido extensivamente investigados na primeira (embora ainda sejam temas desafiadores e atuais de pesquisa) porém ainda estejam tão em aberto nesta última. De fato, o procedimento de avaliação de algoritmos de detecção de outliers usualmente adotado na literatura é baseado na utilização de bases de dados previamente rotuladas, nas quais os outliers (segundo alguma 
intuição particular) são previamente conhecidos. No contexto não supervisionado, os rótulos não são utilizados pelo algoritmo em si, mas para avaliar os resultados produzidos por este. Especificamente, a categorização binária ou o ranking das observações produzidos pelo algoritmo são comparados com a rotulação considerada correta e previamente conhecida (ground truth). O resultado quantitativo desta comparação, por exemplo utilizando precision-at- $n$ ou área sob a curva ROC (Schubert et al., 2012) (uma breve explicação sobre essas medidas é apresentada no Apêndice A), é tomado como medida de qualidade do algoritmo de detecção em questão. Entretanto, a disponibilidade de uma base de dados pré-rotulada é obviamente inconsistente com a hipótese fundamental do aprendizado não supervisionado. Logo, embora o procedimento de avaliação descrito acima seja útil durante o desenvolvimento de novos algoritmos, ele não é viável em aplicações práticas no contexto não supervisionado.

No contexto de agrupamento de dados, o problema de avaliação e seleção de modelos quando não se tem qualquer informação sobre quais são de fato os rótulos das observações é usualmente abordado utilizando os chamados índices de validação interna (Jain and Dubes, 1988). Tais índices são denominados internos pois não fazem uso de nenhuma informação externa (como rótulos) na avaliação. A avaliação é feita baseada apenas na informação dos dados e das soluções a serem avaliadas. A maioria desses índices são também relativos no sentido que eles podem ser utilizados para comparar diferentes soluções e apontar qual delas é melhor em termos relativos. Tais índices têm se mostrado ferramentas efetivas e úteis para avaliação e seleção de modelos em agrupamentos de dados (Milligan and Cooper, 1985; Vendramin et al., 2010).

O presente trabalho de pesquisa propõe investigar formas pelas quais algumas ideias fundamentais utilizadas para avaliação interna de qualidade e seleção de modelos em agrupamento de dados poderiam ser estendidas, adaptadas e/ou redefinidas para aplicações no contexto de detecção não supervisionada de outliers.

\subsection{Hipótese}

Critérios internos para validação de soluções produzidas por algoritmos não supervisionados de agrupamentos de dados têm sido amplamente estudado na área de agrupamento de dados. Vendramin et al. (2010), por exemplo, fizeram um amplo estudo envolvendo 40 diferentes medidas de validação interna de agrupamento. Porém medidas que utilizem critérios internos para avaliar uma solução são raramente mencionados e estão praticamente intocados na área de detecção de outliers. Isso motiva a seguinte hipótese:

Hipótese: É possível avaliar soluções de algoritmos de detecção de outliers utilizando critérios internos e utilizar essas avaliações para a seleção de modelos, ou seja, para a escolha de parametrizações ou de algoritmos em particular. 


\subsection{Objetivo}

O objetivo deste trabalho consiste no desenvolvimento de uma medida para avaliação/validação de soluções de algoritmos de detecção de outliers. A medida deverá ser baseada apenas na utilização de critérios internos e não poderá ser vinculada à qualquer critério utilizado por algum algoritmo de detecção de outliers em particular. A medida ainda deverá ser extensivamente avaliada em coleções de base de dados sintéticas e reais, devendo refletir a qualidade da solução no valor do índice.

\subsection{Contribuições}

A principal contribuição deste trabalho é o desenvolvimento de um índice interno e relativo para avaliação de soluções de detecção não supervisionada de outliers. O índice, nomeado IREOS (Internal, Relative Evaluation of Outlier Solutions), é apresentado no Capítulo 4 e possui diversas propriedades desejáveis para uma medida independente de avaliação interna. Como contribuições específicas deste trabalho com relação ao índice proposto, pode-se citar:

- O índice pode ser calculado mas não otimizado de forma trivial. Isso significa que IREOS pode avaliar soluções dadas, mas procurar no espaço de soluções utilizando a própria medida como base de um algoritmo de detecção seria impraticável.

- Foi elaborada uma versão melhorada de \REOS que é ajustada para aleatoriedade, removendo do índice o valor esperado para uma solução aleatória, fazendo com que soluções aleatórias recebam valores em torno de 0 . Além disso, é fornecido um $p$-value assumindo como hipótese nula uma solução aleatória.

- Sabendo que em grandes bases de dados o procedimento de ajuste para aleatoriedade pode ser computacionalmente custoso, foi desenvolvido um procedimento mais rápido baseado em simulações de Monte Carlo.

- IREOS foi extensivamente avaliado em diferentes coleções de base de dados sintéticas e reais, envolvendo experimentos controlados assim como experimentos práticos de seleção de modelos.

\subsection{Organização do Trabalho}

Este trabalho está organizado da seguinte forma:

No Capítulo 2 são apresentados conceitos básicos sobre detecção de outliers. Uma breve visão geral é fornecida para os algoritmos que utilizam paradigma supervisionado ou semissupervisionado. Introduz-se então quatro representantes das diversas abordagens não supervisionadas, assim como exemplos de algoritmos e o desafio que representa a avaliação de seus resultados. 
No Capítulo 3 são apresentados inicialmente conceitos básicos sobre classificadores de máxima margem, que são utilizados como base para a medida de avaliação desenvolvida neste trabalho. Em seguida são apresentados dois classificadores ditos de máxima margem, SVM e KLR.

No Capítulo 4 , IREOS, o índice interno e relativo proposto neste trabalho para avaliação de soluções de detecção não supervisionada de outliers, é apresentado. Inicialmente, o problema de avaliação interna de soluções de detecção de outliers é formalmente descrito. Em seguida, o índice é discutido em detalhes. São discutidos sua intuição básica, duas outras intuições adicionais desejadas e suas propriedades, tais como ajuste para aleatoriedade e validação estatística. Por fim, um pseudocódigo em alto nível e a análise de complexidade do índice são apresentados.

No Capítulo 5 são discutidos os resultados dos experimentos envolvendo avaliação e seleção de modelos em diferentes coleções de bases de dados sintéticas e reais para avaliação de IREOS. As coleções de bases sintéticas e reais que foram utilizadas nos experimentos são apresentadas, assim como a descrição da metodologia e dos experimentos realizados. Por fim, os resultados dos experimentos realizados são apresentados e discutidos.

No Capítulo 6 são fornecidas as conclusões deste trabalho, discutidas suas limitações e perspectivas para trabalhos futuros.

No Apêndice $\mathbf{A}$ duas das medidas mais utilizadas na literatura de detecção de outliers são apresentadas, uma medida externa para avaliação de soluções top- $n$ de detecção de outliers (precision-at-n) e uma medida externa para avaliação de rankings (área sob a curva $\mathrm{ROC}$ ). 



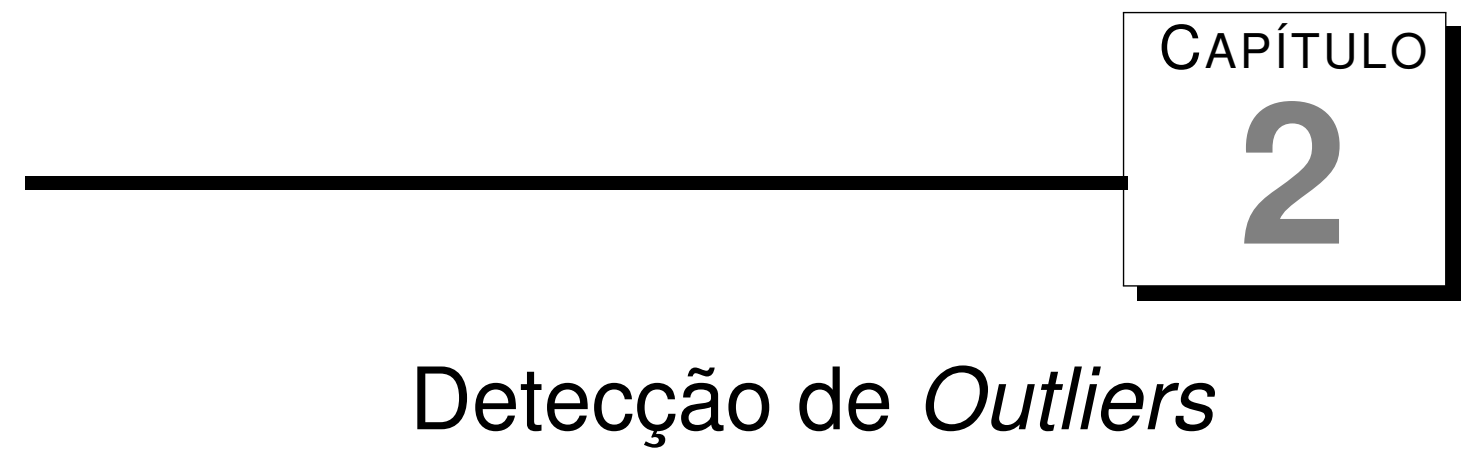

Neste Capítulo são apresentados conceitos básicos sobre detecção de outliers. Uma breve visão geral dos algoritmos que utilizam o paradigma supervisionado ou semissupervisionado é fornecida na seção 2.1. Existem diversas abordagens utilizadas pelos algoritmos de detecção não supervisionada de outliers, quatro delas são introduzidas na seção 2.2, assim como exemplos de algoritmos que utilizam essas abordagens e o desafio que representa a avaliação dos resultados produzidos por esses algoritmos.

\subsection{Algoritmos Supervisionados e Semissupervisionados de Detecção de Outliers}

Diferentes técnicas de detecção de outliers têm sido propostas no contexto de mineração de dados, tais técnicas podem utilizar os paradigmas de aprendizado supervisionado, semissupervisionado ou não supervisionado. As técnicas que utilizam aprendizado supervisionado pressupõem que se dispõe de um conjunto apropriado de observações rotuladas como outlier e inlier para criar um modelo de classificação a partir dos dados rotulados. A detecção supervisionada de outliers pode ser vista como um caso especial de classificação binária (classes outlier e inlier). O problema de classificação tem sido amplamente estudado, com uma enorme quantidade de técnicas disponíveis na literatura (Tan et al., 2006; Han et al., 2011; Duda et al., 2001). Tais técnicas têm sido adaptadas para o contexto de detecção de outliers (Tang et al., 2009; Zhang and Mani, 2003), pois neste contexto elas frequentemente precisam lidar com alguns dos seguintes problemas:

- Trata-se de um problema em que a classe outlier geralmente é muito desbalanceada em relação à classe inlier, dificultando a criação de um modelo que generalize bem a classe de interesse; 
- Os outliers em algumas aplicações podem tentar simular o comportamento de um inlier, por exemplo no contexto de detecção de fraude, em que o outlier (fraude) tenta se passar por uma observação normal, para que não seja facilmente detectada;

- Devido ao fato dos outliers serem normalmente raros, em algumas aplicações o conjunto de treinamento não tem observações rotuladas como outlier, logo os algoritmos devem trabalhar de forma semissupervisionada, em que se cria um modelo a partir dos dados rotulados como inliers e as observações que não se encaixam no modelo são rotuladas como outlier (Amer et al., 2013, Roth, 2006). Este problema também é estudado pela área de classificação de padrões e conhecido como problema de aprendizado de classe única (One Class Classification (OCC) (Tax, 2001; Khan and Madden, 2010).

Apesar das técnicas supervisionadas e semissupervisionados possuírem tais desafios, elas partem do princípio que possuem um conjunto apropriado de observações rotuladas, logo este conjunto pode ser utilizado para construção e avaliação do modelo, utilizando técnicas bem estabelecidas na área de classificação, tais como hold-out, validação cruzada e bootstrap para a formação do conjunto de treinamento e de validação, e medidas como área sob a curva ROC, medida-F e acurácia para a avaliação do modelo (Tan et al., 2006, Han et al., 2011).

\subsection{Algoritmos Não Supervisionados de Detecção de Out- liers}

Quando não se tem qualquer conhecimento prévio sobre quais observações são de fato outliers ou não, faz-se necessário a utilização de técnicas de aprendizado não supervisionado. Cada técnica, entretanto, utiliza um critério próprio para julgar de forma quantitativa o nível de aderência de cada observação ao conceito de outlier, que é naturalmente subjetivo no contexto não supervisionado.

Cada uma dessas técnicas pode adotar diferentes abordagens para determinar se uma observação é um outlier. De forma geral, pode-se categorizar tais técnicas em: (i) técnicas de detecção global, que determinam se uma observação é outlier com respeito a toda base de dados, ou (ii) técnicas de detecção local, que determinam se uma observação é um outlier com respeito à região do espaço dos dados em que a observação está localizada.

A Figura 2.1 ajuda a ilustrar a diferença entre as técnicas de detecção local e global. A base de dados apresentada na Figura 2.1 é formada por dois mecanismos diferentes, o grupo $C_{1}$ e o grupo $C_{2}$, sendo que o grupo $C_{1}$ é bem mais esparso que o grupo $C_{2}$. Nesta base de dados também estão presentes dois outliers, a observação $o_{1}$ considerada um outlier global e a observação $o_{2}$ considerada um outlier local. A ideia central dos algoritmos de detecção local é assumir que a base de dados pode ser gerada por mais de um mecanismo. Logo, no momento de detectar outliers nesta base, as técnicas de detecção local irão tratar de forma diferente as observações da vizinhança do grupo $C_{1}$ e as observações da vizinhança do grupo $C_{2}$. Desta forma, a observação $o_{2}$ localizada próxima ao grupo $C_{2}$ poderá ser considerada outlier, pois 
ela desvia significantemente em relação às demais observações da sua vizinhança. Entretanto, com a utilização de um algoritmo de detecção global a observação $o_{2}$ não seria detectada como outlier, pois a mesma desvia tanto quanto as observações do grupo $C_{1}$ em relação a toda a base de dados, de forma que, para a observação $o_{2}$ ser classificada como outlier, muita das observações do grupo $C_{1}$ também teriam que ser classificadas como outliers.

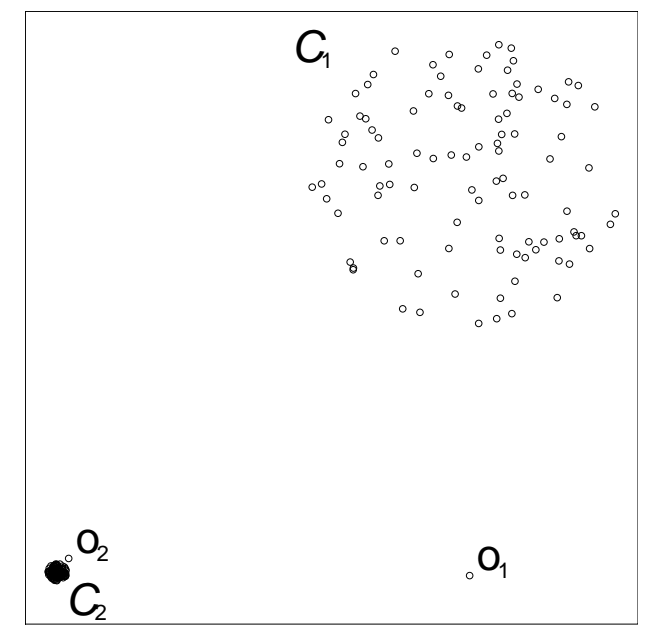

Figura 2.1: Base de dados gerada por dois mecanismos diferentes (inspirado em (Breunig et al., 2000))

Uma forma mais específica de se categorizar as diferentes técnicas de detecção não supervisionada de outliers é quanto ao paradigma utilizado. As diferentes técnicas existentes podem utilizar diferentes paradigmas para definir se uma observação é um outlier, tais como os paradigmas baseados em estatísticas (Barnett and Lewis, 1994; Hawkins, 1980), distância (Ramaswamy et al., 2000; Angiulli and Pizzuti, 2002, Zhang et al., 2009), densidade (Breunig et al., 2000; Jin et al., 2006), ângulo (Kriegel et al., 2008; Pham and Pagh, 2012) e dentre outros.

\subsubsection{Técnicas Estatísticas}

O campo da estatística surgiu inicialmente como a principal área de pesquisa em detecção não supervisionada de outliers. Dezenas de testes estatísticos têm sido desenvolvidos para detectar discordância/anomalia nos dados (Hawkins, 1980; Barnett and Lewis, 1994; Grubbs, 1969). Tais testes diferem na hipótese sobre o tipo de distribuição dos dados, na hipótese sobre o tipo dos dados propriamente ditos, na natureza dos outliers esperados, dentre outros. Eles possuem em comum, entretanto, o fato de necessitarem fazer uma série de suposições. Por exemplo, o teste pode precisar fazer suposição quanto à distribuição dos dados, que geralmente não é conhecida a priori, sendo necessário realizar extensivos testes para encontrar uma distribuição conhecida que descreva bem os dados. Outra suposição comum é quanto aos parâmetros da distribuição (e.g. média e variância), porém os parâmetros da distribuição em geral não são conhecidos e precisam portanto ser estimados a partir dos próprios dados. Tal estimação é geralmente sensível e distorcida pela presença dos próprios outliers que se deseja detectar. Essas distorções geram efeitos indesejados conhecidos como masking, quando a presença de outliers é mascarada por outros outliers, e swamping, quando inliers são incorretamente rotulados como 
outliers devido à distorção causada pelos outliers (Hadi, 1992). Além da maioria dos testes serem paramétricos, ou seja, assumirem que os dados seguem uma determinada distribuição (e.g. Normal) em que os parâmetros podem ou não ser conhecidos, a maioria deles pode ser aplicado apenas em base de dados numéricas e unidimensionais. Nesse caso, uma regra prática comum é tomar como outliers observações que desviam mais do que 3 vezes o desvio padrão a partir da média de uma distribuição Normal (unidimensional); no caso multidimensional limiares equivalentes podem ser estabelecidos e impostos à distância de Mahalanobis, como apresentado em maiores detalhes a seguir.

\section{Distância de Mahalanobis}

A distância de Mahalanobis (Mahalanobis, 1936) é uma generalização da distância Euclidiana que captura a correlação entre as variáveis. No contexto de detecção de outliers, a distância de Mahalanobis é utilizada para calcular a distância de cada observação x para o centro de seu grupo $(\mu)$ baseado na sua matriz de covariância $(\Sigma)$ (Equação $(2.1)$ ). A utilização desta técnica implica em suposições quanto à distribuição dos dados e seus parâmetros. A técnica é aplicada a dados que seguem distribuição Normal quando se sabe seus parâmetros ( $\mu$ e $\Sigma$ ). Variações da distância de Mahalanobis no contexto de detecção de outliers foram propostas para evitar os problemas de masking e swamping (Rousseeuw and Zomeren, 1990; Hadi, 1992).

$$
\operatorname{mahalanobis}(\mathbf{x})=\sqrt{(\mathbf{x}-\mu)^{T} \Sigma^{-1}(\mathbf{x}-\mu)}
$$

Como resultado o algoritmo retorna um score para cada observação, para definir quais observações deverão ser rotuladas binariamente como outliers comumente é utilizado um resultado estatístico bem conhecido: quando a distância de Mahalanobis é aplicada a dados que seguem uma distribuição Normal $d$-dimensional, as distâncias resultantes seguem uma distribuição $\chi^{2}$ com $d$ graus de liberdades (Hair et al. 2005). A partir da distribuição $\chi^{2}$ é possível definir o limiar para rotulação das observações. Caso seja de interesse, por exemplo, a rotulação de 2,5\% das observações que mais desviam da distribuição teórica, pode-se utilizar o quartil teórico de 0.975 da distribuição $\chi^{2}$ para rotulação dos outliers.

\subsubsection{Técnicas Baseadas em Distância}

As técnicas baseadas em distância assumem que outliers são observações que estão distantes de suas observações mais próximas (tais observações são definidas aqui como vizinhos mais próximos). Para isso, é necessário definir uma distância ou medida de similaridade entre duas observações. Existem diferentes distâncias e medidas de similaridades. Enquanto para atributos contínuos a distância Euclidiana é a mais utilizada, para atributos categóricos é comumente utilizado o coeficiente de casamento simples. Dois algoritmos bem conhecidos que utilizam esta abordagem são o KNNOutlier e o HilOut, ambos apresentados a seguir. 


\section{KNNOutlier e HilOut (WKNN)}

O algoritmo KNNOutlier é um dos algoritmos baseados em distância existentes. Foi proposto por Ramaswamy et al.(2000) e é um algoritmo de detecção de outliers globais. O KNNOutlier atribui um score para cada observação da base de dados para medir o quanto cada uma delas se caracteriza como outlier. Para calcular o score de uma determinada observação é utilizada simplesmente a distância desta observação ao seu $k$-ésimo vizinho mais próximo, definida aqui como $k$-distance $(\cdot)$ (Equação $(2.2)$ ).

$$
\operatorname{KNNOutlier}_{k}(\mathbf{x})=k \text {-distance }(\mathbf{x})
$$

Uma variante do KNNOutlier é o HilOut, ou Weighted $k$-Nearest Neighbors (WKNN), que foi proposto por Angiulli and Pizzuti (2002). Diferente do KNNOutlier, que utiliza apenas a distância do $k$-ésimo vizinho da observação para produzir seu score, HilOut utiliza a soma das distâncias aos $k$ vizinhos mais próximos da observação para produzir seu score (Equação (2.3)).

$$
\operatorname{HilOut}_{k}(\mathbf{x})=\sum_{i=1}^{k} i \text {-distance }(\mathbf{x})
$$

Caso seja de interesse obter uma classificação binária de $n$ observações como outliers e as demais como inliers, são rotuladas as $n$ observações com maior score como outliers e as demais como inliers.

\subsubsection{Técnicas Baseadas em Densidade}

Para julgar quantitativamente se uma observação deve ser considerada outlier, as técnicas baseadas em densidade estimam a densidade de cada observação $\mathrm{x}$ com respeito à sua vizinhança $V_{k}(\mathbf{x})$, vizinhança aqui definida como o conjunto de observações cuja distância para a observação $\mathbf{x}$ não seja maior que a $k$-distance $(\mathbf{x}) ; \operatorname{logo}\left|V_{k}(\mathbf{x})\right| \geq k$ (as observações pertencentes à vizinhança de $\mathbf{x}$ são ditos seus $k$ vizinhos mais próximos, embora possam ser um número maior que $k$ em caso de empates). Essas técnicas então assumem que observações que estejam em vizinhanças de baixa densidade são consideradas outliers, enquanto observações localizadas em regiões densas são consideradas inliers. Para estimativa da densidade da vizinhança de uma determinada observação, várias técnicas utilizam as distâncias da observação aos seus $k$ vizinhos mais próximos como base para uma estimativa do inverso da densidade daquela vizinhança. Um dos algoritmos mais bem conhecidos que utiliza esta abordagem é o LOF, apresentado em mais detalhes a seguir.

\section{$L O F$}

Uma das técnicas baseadas em densidade existentes é o Local Outlier Factor ( $\overline{\mathrm{LOF}}$ ) que foi proposto por Breunig et al. (2000) e foi o algoritmo pioneiro entre os algoritmos de detecção de outlier locais. A partir deste algoritmo surgiram muitos outros (Tang et al., 2002; Jin et al., 2006; Zhang et al., 2009) que de alguma forma seguem a mesma intuição. 
Assim como os algoritmos KNNOutlier e HilOut, LOF também retorna um score para cada observação. O score produzido é baseado na densidade da observação em relação à densidade dos seus $k$ vizinhos mais próximos, quanto maior este score maior a evidência de que a observação seja um outlier.

Como estimativa de densidade local de uma observação, LOF utiliza o inverso da média das distâncias da observação aos seus $k$ vizinhos mais próximos. Entretanto, para evitar efeitos similares aos de masking e swamping, Breunig et al. (2000) propõem utilizar a distância de alcançabilidade (reachability distance) em vez de utilizar simplesmente a distância. A distância de alcançabilidade de uma observação $\mathrm{x}$ em relação à observação $\mathbf{y}$ é definida como reach-dist ${ }_{k}(\mathbf{x}, \mathbf{y})=M A X\{k$-distance $(\mathbf{y}), d(\mathbf{x}, \mathbf{y})\}$, em que $d(\mathbf{y}, \mathbf{x})$ é a distância da observação x para a observação $\mathbf{y}$. Repare que apesar de ser chamada de distância de alcançabilidade, essa medida não é uma distância em sua definição formal, uma vez que ela não é simétrica. A estimativa de densidade local $e d l$ de uma observação $\mathrm{x}$ é matematicamente apresentada na Equação (2.4).

$$
e d l_{k}(\mathbf{x})=\left(\frac{\sum_{\mathbf{y} \in V_{k}(\mathbf{x})} \text { reach-dist }_{k}(\mathbf{x}, \mathbf{y})}{\left|V_{k}(\mathbf{x})\right|}\right)^{-1}
$$

Para cada observação, o score produzido pelo LOFé a média da razão entre a estimativa de densidade local dos seus $k$ vizinhos mais próximos e a estimativa de densidade local da própria observação (Equação (2.5)). Sendo assim, se o score de determinada observação for igual a 1, significa que a observação possui em média a mesma densidade que seus $k$ vizinhos mais próximos. Em caso do score for menor que 1, a observação possui em média uma densidade maior que seus $k$ vizinhos mais próximos. Em ambos os casos a observação pode ser considerada inlier. Entretanto, um valor alto de score mostra que a observação está em uma região de baixa densidade comparada aos seus $k$ vizinhos mais próximos, assim quanto maior este score maior a evidência de que a observação seja um outlier.

$$
\operatorname{LOF}_{k}(\mathbf{x})=\frac{\sum_{\mathbf{y} \in V_{k}(\mathbf{x})} \frac{e d l_{k}(\mathbf{y})}{e d l_{k}(\mathbf{x})}}{\left|V_{k}(\mathbf{x})\right|}
$$

\subsubsection{Técnicas Baseadas em Ângulo}

As técnicas baseadas em ângulo representam cada observação da base de dados como um ponto no espaço euclidiano, o que restringe estes métodos apenas a bases de dados com atributos numéricos. Para determinar o quanto cada ponto se caracteriza como um outlier, elas avaliam a variância do ângulo que cada ponto forma com os demais pares de pontos. Essas técnicas assumem que a maioria dos pontos estarão concentrados em alguma direção a partir de um outlier, sendo assim espera-se outliers não tenham grande variação de ângulo, como por exemplo o ponto $\gamma$ da Figura 2.2. Para um inlier, espera-se que os demais pontos estejam distribuídos em todas as direções, tendo grande variação de ângulo, como por exemplo o ponto 
$\alpha$ da Figura 2.2. Logo, espera-se que pontos que tenham baixa variação de ângulo sejam outliers. Uma grande vantagem desta abordagem em relação às demais é o fato de não utilizar uma medida baseada em distância, uma vez que as distâncias tendem a se deteriorarem com o aumento dimensionalidade. As técnicas que utilizam esta abordagem são mais robustas quando aplicadas a base de dados de alta dimensionalidade.

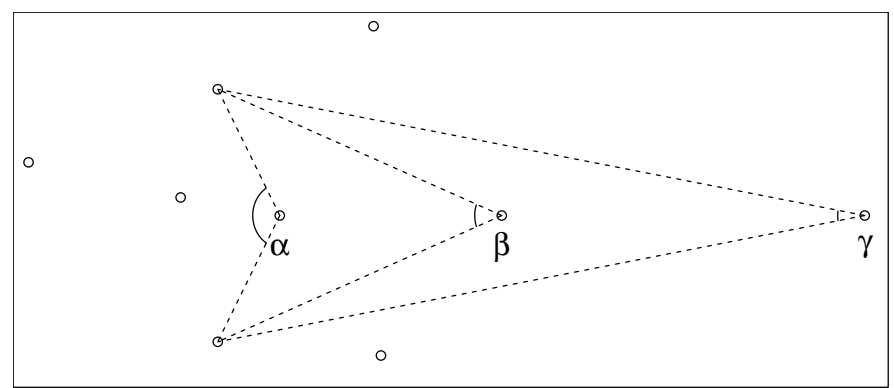

Figura 2.2: Ângulos formados por pontos da base (inspirado em (Kriegel et al., 2008))

\section{$A B O D$}

O algoritmo Angle-Based Outlier Detection (ABOD) foi proposto por Kriegel et al. (2008). A ideia fundamental deste algoritmo está em utilizar também a variância do ângulo formado por um ponto com os demais pares de pontos, em vez de utilizar somente a distância desse ponto para os demais pontos da base de dados. Para computar o score de um ponto $\vec{A}, A B O F(\vec{A})$, ABOD computa a variância ao longo dos ângulos entre o ponto $\vec{A}$ e todos os demais pontos na base de dados $\mathbf{X}$, sendo os ângulos ponderados pelo inverso das distâncias dos respectivos pontos (Equação (2.6)). Devido à ponderação, observações mais distantes terão menos peso no cálculo do score, essa ponderação é importante pelo fato do ângulo entre pares de pontos mais distantes variarem naturalmente mais.

$$
\operatorname{ABOF}(\vec{A})=V A R_{\vec{B}, \vec{C} \in \mathbf{X}}\left(\frac{\overline{A B} \cdot \overline{A C}}{\|\overline{A B}\|^{2}\|\overline{A C}\|^{2}}\right)
$$

Diferente das outras técnicas apresentadas, é esperado que outliers tenham valores baixos de scores, uma vez que é esperada baixa variância de ângulo para os pontos considerados outliers.

\subsubsection{Avaliação de Resultados de Detecção Não Supervisionada de Outliers}

Nas subseções anteriores foram citadas algumas abordagens utilizadas pelos algoritmos não supervisionados e existem outras que poderiam ser citadas, como, por exemplo, as abordagens baseadas em agrupamento (Zhang et al., 1996; Ester et al., 1996), baseadas em conectividade (Tang et al., 2002, Pokrajac et al., 2008) e baseadas em profundidade (Johnson et al., 1998; Ruts and Rousseeuw, 1996). Existem diferentes algoritmos baseados em cada uma delas. Por exemplo, além do KNNOutlier e HilOut, outra técnica que utiliza a abordagem baseada em 
distância é o LDOF (Zhang et al., 2009), mas os dois algoritmos citados anteriormente são algoritmos de detecção global, enquanto LDOFé um algoritmo de detecção local.

Cada algoritmo de detecção de outliers utiliza um critério diferente para considerar o quanto uma observação se caracteriza como outlier. Cada critério pode ser mais ou menos apropriado dependendo da base de dados em que o algoritmo é aplicado. Para avaliação dos resultados obtidos por esses algoritmos, utiliza-se normalmente na literatura técnicas de validação externa (Schubert et al., 2012), ou seja, técnicas que assumem que os rótulos das observações são previamente conhecidos, para então comparar a solução fornecida pelo algoritmo com os rótulos conhecidos. Entretanto, a disponibilidade de uma base de dados pré-rotulada é obviamente inconsistente com a hipótese fundamental do aprendizado não supervisionado. Logo, embora o procedimento de avaliação descrito acima seja útil para experimentos controlados durante o desenvolvimento de novos algoritmos, ele não é viável em aplicações práticas no contexto não supervisionado. Nessas aplicações, faz-se necessário procedimentos de avaliação que utilizem critérios internos, ou seja, independentes de rótulos pré-conhecidos (externos), tais como os procedimentos de validação interna existentes na área de agrupamento de dados. O desenvolvimento deste tipo de procedimento também na área de detecção de outliers constitui o objetivo central deste trabalho, para isto é proposta uma medida de validação interna para detecção de outliers que utiliza como base classificadores de máxima margem. Tais classificadores serão discutidos em maiores detalhes no próximo Capítulo e a medida proposta será apresentada no Capítulo 4. 


\section{$-3$ \\ Classificadores de Máxima Margem}

Neste Capítulo são apresentados conceitos gerais sobre classificadores de máxima margem que são utilizados como base para medida de avaliação desenvolvida neste trabalho. Conceitos básicos sobre esses classificadores são introduzidos nas seções 3.1] e 3.2, sem fazer referência a um classificador em específico. Na seção 3.3 é apresentada a abordagem utilizada para transformá-los em classificadores não lineares. Na seção 3.4 são apresentados dois classificadores ditos de máxima margem, SVM $\mathrm{e}$ KLR

\subsection{Classificador Linear de Máxima Margem}

Dado o problema de classificação binária da Figura 3.1(a), em que uma das classes é representada pelos quadrados e a outra pelos círculos, é possível traçar infinitos hiperplanos que separem as duas classes de forma que não ocorra nenhum erro de classificação. Cada classificador pode traçar um diferente hiperplano e um mesmo classificador pode ainda traçar diferentes hiperplanos dependendo de seus parâmetros e/ou configurações inicias, entretanto, não existe nenhuma garantia que todos esses hiperplanos se comportarão da mesma forma na medida que exemplos ainda não vistos pelo classificador surjam para serem classificados.

O classificador de máxima margem utiliza ideias oriundas da área de Aprendizado Estatístico (Vapnik, 1998) para construir o hiperplano que separará as observações em suas respectivas classes, tal hiperplano é definido como hiperplano de ótima separação. Vapnik (1995) define o hiperplano de ótima separação como sendo aquele que maximiza a margem de separação entre as classes, esse hiperplano não apenas fornece uma solução única para o problema de classificação, como também é o hiperplano que melhor generaliza o problema (Hastie et al., 2013). O hiperplano de ótima separação do problema apresentado na Figura 3.1(b) é representado pelo hiperplano $B_{1}$, embora nenhuma das observações esteja dentro da margem, isto não implica que o mesmo ocorrerá a medida que novos exemplos surjam. 


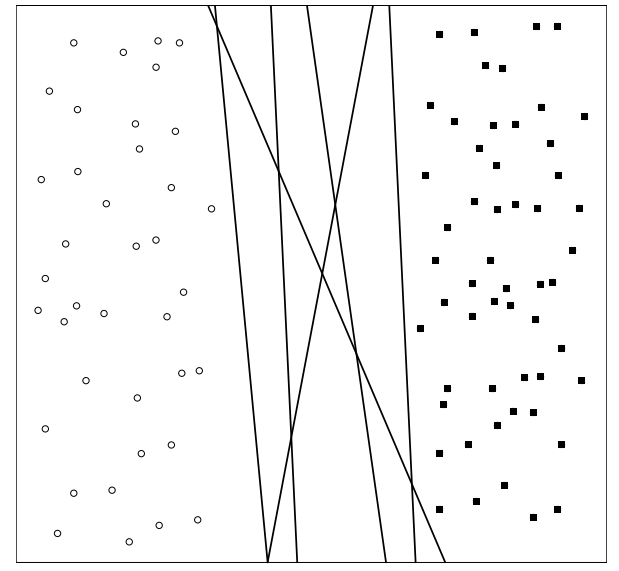

(a) Possibilidades de separação

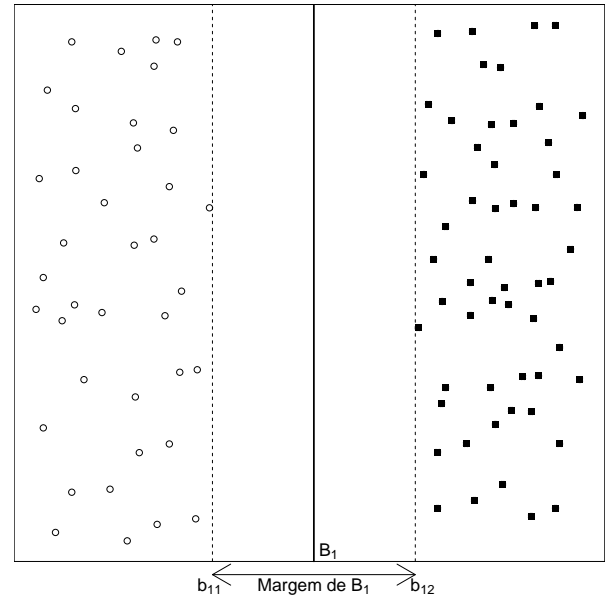

(b) Hiperplano de ótima separação

Figura 3.1: Base de dados linearmente separável

No problema de classificação binária apresentado na Figura 3.1(b), cada observação $\mathrm{x}=$ $\left(x_{1}, \cdots, x_{d}\right)$ é associada a uma classe $y$ (círculo ou quadrado). O hiperplano de ótima separação $B_{1}$ pode ser escrito como um hiperplano linear da seguinte forma:

$$
B_{1}: \mathbf{x} \cdot \mathbf{w}+b=0
$$

em que $\mathbf{w}=\left(w_{1}, \cdots, w_{d}\right)^{T}$ e $b$ são os parâmetros do modelo que se deve encontrar de forma que a margem de $B_{1}$ seja maximizada. Para qualquer quadrado $\mathbf{x}_{q}$ localizado ao lado direito do hiperplano separador $B_{1}$, pode-se mostrar que:

$$
\mathbf{x}_{q} \cdot \mathbf{w}+b=r
$$

em que $r>0$. Similarmente, para qualquer círculo localizado ao lado esquerdo do hiperplano separador $B_{1}$, pode-se mostrar que:

$$
\mathbf{x}_{c} \cdot \mathbf{w}+b=r^{\prime}
$$

em que $r^{\prime}<0$. Caso rotular todos os quadrados como classe +1 e todos os círculos como classe -1, então poderá predizer a classe $y$ para qualquer nova observação $\mathbf{z}$ da seguinte forma:

$$
y=\left\{\begin{array}{cc}
+1, & \text { Se } \mathbf{z} \cdot \mathbf{w}+b>0 \\
-1, & \text { Se } \mathbf{z} \cdot \mathbf{w}+b<0
\end{array}\right.
$$

Na Figura 3.1(b), considere apenas o quadrado e o círculo mais próximo do hiperplano separador $B_{1}$, denominados de support points. Desde que o quadrado esteja à direta do hiperplano separador $B_{1}$, a Equação (3.2) deve ser satisfeita para algum valor positivo de $r$, da mesma forma o círculo deve satisfazer a Equação (3.3) para algum valor negativo de $r^{\prime}$. Pode-se reescalar os parâmetros w e $b$ do hiperplano separador $B_{1}$ para que os hiperplanos paralelos ao hiperplano separador $B_{1}$ e associado à margem máxima de separação entre as classes, deno- 
minados de margin boundary e representados na Figura 3.1(b) como os hiperplanos $b_{11}$ e $b_{12}$, sejam expressos da seguinte forma:

$$
\begin{aligned}
& b_{11}: \mathbf{x} \cdot \mathbf{w}+b=-1 \\
& b_{12}: \mathbf{x} \cdot \mathbf{w}+b=+1
\end{aligned}
$$

A margem do hiperplano de decisão é dada pela distância entre esses dois hiperplanos. Seja $\mathbf{x}_{1}$ o support point localizado em cima do hiperplano $b_{11}$ e $\mathbf{x}_{2}$ o support point localizado em cima do hiperplano $b_{12}$. Substituindo esses pontos na Equação (3.5) e (3.6), a margem $d$ pode ser computada subtraindo a segunda equação pela primeira:

$$
\begin{array}{r}
\left(\mathbf{x}_{2}-\mathbf{x}_{1}\right) \cdot \mathbf{w}=2 \\
d \times\|\mathbf{w}\|=2 \\
d=\frac{2}{\|\mathbf{w}\|}
\end{array}
$$

A formulação do problema em função apenas dos support points sugere que apenas tais observações são importantes para definir o hiperplano de ótima separação, mesmo que para identificá-los seja necessário todo o conjunto de dados. Regressão logística (Hosmer and Lemeshow, 2000; Hastie et al., 2013) é um modelo discriminativo linear que utiliza uma função logística para estimar diretamente a probabilidade de determinada observação $\mathrm{x}$ pertencer à classe $y$, isto é $P(y \mid \mathbf{x})$. Para traçar o hiperplano separador, esse classificador utiliza uma abordagem contrária em que todas as observações são consideradas para traçar o hiperplano separador, embora as observações próximas ao hiperplano separador influenciem muito mais que aquelas distante dele.

A Figura 3.2 representa três diferentes bases de dados onde são traçados o hiperplano de ótima separação (linha contínua preta) e o hiperplano gerado pela Regressão Logística (linha tracejada vermelha). Na Figura 3.2(a) os dois hiperplanos possuem alto grau de sobreposição. Com a inserção de duas novas observações (losango vermelho), resultando na Figura 3.2(b), o hiperplano gerado pela Regressão Logística é levemente alterado em relação ao hiperplano anterior, mas devido às observações terem sido inseridas atrás dos support points o hiperplano de ótima separação não se altera. Na Figura 3.2(c) as novas observações são aproximadas do hiperplano separador, porém ainda permanecem atrás dos support points, desta forma o hiperplano de ótima separação continua inalterado, mas pelo fato delas estarem mais próximas do hiperplano separador, a alteração do hiperplano gerado pela Regressão Logística é maior. 


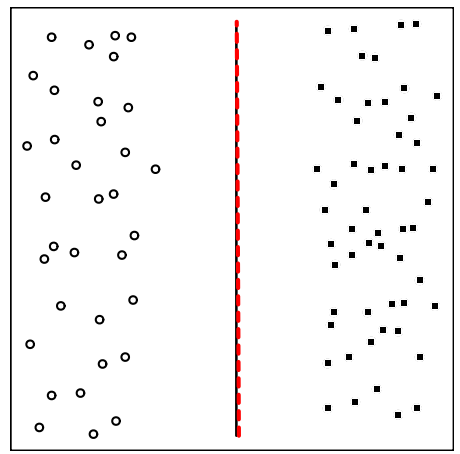

(a) Hiperplano de ótima sep. $\mathbf{w}=\{9.037,-0.276,0.000\}$; Regressão Logística $\mathbf{w}=\{9.119,-0.272,-0.003\}$

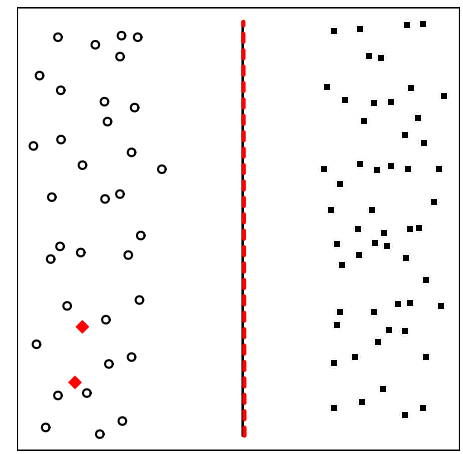

(b) Hiperplano de ótima sep. $\mathbf{w}=\{9.037,-0.276,0.000\}$; Regressão Logística $\mathbf{w}=\{9.006,-0.272,-0.002\}$

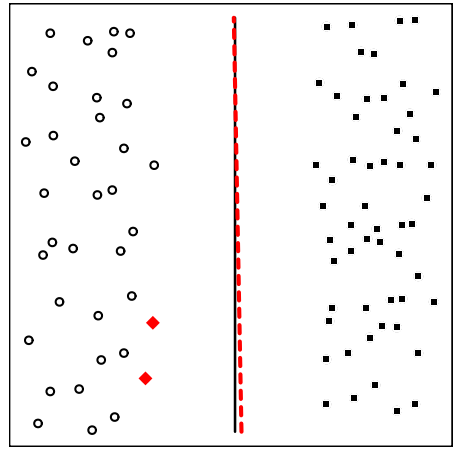

(c) Hiperplano de ótima sep. $\mathbf{w}=\{9.037,-0.276,0.000\}$; Regressão Logística $\mathbf{w}=\{9.766,-0.274,-0.010\}$

Figura 3.2: Comparação entre o hiperplano de ótima separação (linha contínua preta) e Regressão Logística (linha tracejada vermelha). Na Figura 3.2(c), devido a inserção das novas observações, a sobreposição entre os hiperplanos é a menor

\section{Estimação dos Parâmetros}

Para estimação dos parâmetros w e $b$ do modelo as seguintes condições devem ser satisfeitas:

$$
\begin{array}{ll}
\mathbf{x}_{i} \cdot \mathbf{w}+b \geq+1 & \text { Se } y_{i}=+1 \\
\mathbf{x}_{i} \cdot \mathbf{w}+b \leq-1 & \text { Se } y_{i}=-1
\end{array}
$$

Essas condições garantem que todas as observações $\mathbf{x}_{i}$ não violem a margin boundary da sua classe. Ambas condições podem ser sumarizadas na seguinte condição:

$$
y_{i}\left(\mathbf{x}_{i} \cdot \mathbf{w}+b\right) \geq 1, \quad i=1, \cdots, N
$$

Essas condições podem ser aplicadas a qualquer classificador linear, entretanto para encontrar o hiperplano de ótima separação uma condição adicional deve ser aplicada para que a margem do hiperplano de decisão seja maximizada. A maximização da margem significa maximizar a Equação (3.7), que é equivalente a minimizar a seguinte equação:

$$
f(\mathbf{w})=\frac{\|\mathbf{w}\|^{2}}{2}
$$

O problema então pode ser formalizado como:

$$
\begin{array}{ll}
\min _{\mathbf{w}} & \frac{\|\mathbf{w}\|^{2}}{2} \\
\text { s. a. } & y_{i}\left(\mathbf{x}_{i} \cdot \mathbf{w}+b\right) \geq 1, \quad i=1, \cdots, N
\end{array}
$$

Este problema possui função objetivo quadrática e as restrições lineares nos parâmetros w e $b$. Tais problemas são conhecidos como problemas de otimização convexa, que podem ser resolvidos utilizando o método dos multiplicadores de Lagrange. Primeiro, deve-se reescre- 
ver a função objetivo de forma que as restrições sejam consideradas. A nova função objetivo conhecida como Lagrangiana é apresentada na Equação (3.12).

$$
L_{P}=\frac{1}{2}\|\mathbf{w}\|^{2}-\sum_{i=1}^{N} \alpha_{i}\left(y_{i}\left(\mathbf{x}_{i} \cdot \mathbf{w}+b\right)-1\right),
$$

em que os parâmetros $\alpha_{i}$ são chamados de multiplicadores de Lagrange. O primeiro termo da nova função objetivo é o mesmo a função objetivo original, enquanto o segundo termo captura as restrições.

Para minimizar a função objetivo, deve-se derivar $L_{P}$ com relação aos parâmetros w e $b$ e igualá-las a 0 , conforme realizado nas seguintes equações:

$$
\begin{gathered}
\frac{\partial L_{P}}{\partial \mathbf{w}}=0 \Rightarrow \mathbf{w}=\sum_{i=1}^{N} \alpha_{i} y_{i} \mathbf{x}_{i}, \\
\frac{\partial L_{P}}{\partial b}=0 \Rightarrow \sum_{i=1}^{N} \alpha_{i} y_{i}=0 .
\end{gathered}
$$

Fazendo o uso das condições Karush-Kuhn-Tucker (KKT) (Nocedal and Wright, 2006), as seguintes restrições devem ser aplicadas:

$$
\begin{gathered}
\alpha_{i} \geq 0 \\
\alpha_{i}\left(y_{i}\left(\mathbf{x}_{i} \cdot \mathbf{w}+b\right)-1\right)=0
\end{gathered}
$$

A Equação 3.16 mostra que o multiplicador de Lagrange $\alpha_{i}$ deve ser 0 ao menos que a observação $\mathbf{x}_{i}$ satisfaça a equação $y_{i}\left(\mathbf{x}_{i} \cdot \mathbf{w}+b\right)=1$. Tais observações, com $\alpha>0$, são aquelas que estão em cima da margin boundary de sua classe, os support points. As observações que não estiverem em cima da margin boundary terão $\alpha_{i}=0$.

A função objetivo pode ser simplificada transformando-a em função apenas dos multiplicadores de Lagrange, conhecida como problema dual. Para fazer isso, basta substituir as Equações (3.13) e (3.14) na Equação 3.12). Isto levará à seguinte equação:

$$
L_{D}=\sum_{i=1}^{N} \alpha_{i}-\frac{1}{2} \sum_{i, j}^{N} \alpha_{i} \alpha_{j} y_{i} y_{j} \mathbf{x}_{i} \cdot \mathbf{x}_{j}
$$

A otimização da função pode resolvida utilizando técnicas de programação quadrática. Uma vez encontrado os $\alpha_{i}$, os parâmetros w podem ser encontrados utilizando a Equação 3.13 e o parâmetro $b$ com a Equação (3.16). Encontrado o modelo, uma nova observação z pode ser classificada com a Equação (3.4).

Quando os dados não são linearmente separáveis, não haverá uma solução possível e uma formulação alternativa será necessária. Na seção a seguir será apresentada uma abordagem que permite a sobreposição das classes. 


\subsection{Margem Suave}

A presença de ruído na base de dados pode prejudicar a generalização do modelo, pois o hiperplano de ótima separação pode ser inapropriadamente modificado para classificar o ruído. A Figura 3.3(a) mostra o hiperplano $B_{1}$ que separa as duas classes após a inserção de um ruído na base de dados da Figura 3.1. Os classificadores com margem suave permitem que certos exemplos sejam classificados de forma incorreta na fase de treinamento para que o hiperplano de decisão traçado pelo classificador seja mais suave e tenda a generalizar melhor.

O princípio dos classificadores de máxima margem é maximar a margem. Caso o conjunto de treinamento contenha ruídos, a margem pode ser limitada por eles. Entretanto, esse efeito pode ser reduzido quando se permite que algumas observações fiquem "do lado errado" da sua margin boundary. Para isso se utiliza uma variável de relaxamento $\left(\xi_{i}\right)$, que mede o quanto determinada observação distancia-se do lado correto da sua margin boundary. Na Figura 3.3(b) pode-se observar que o ruído inserido na base dados está do lado errado da sua margin boundary $\left(b_{12}\right)$ e $\xi_{i}$ mede o quanto ela se distancia.

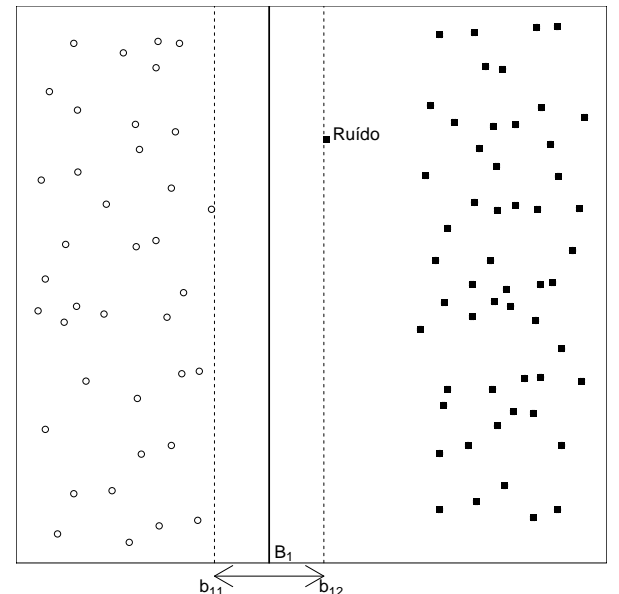

(a) Margem rígida

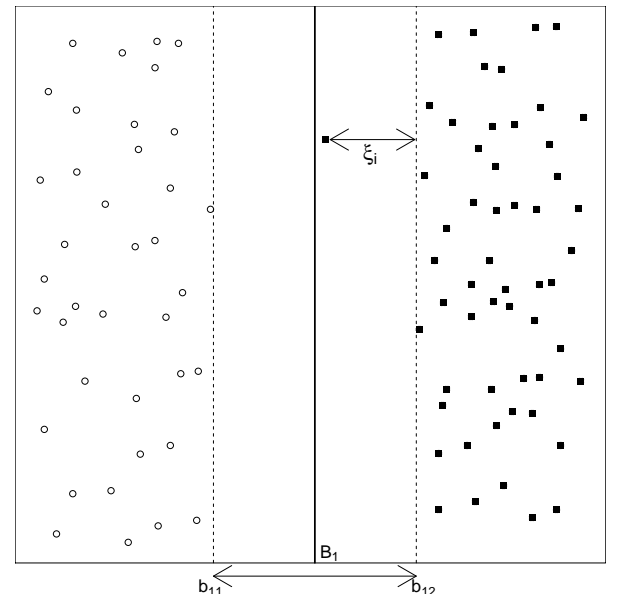

(b) Margem suave

Figura 3.3: Margem rígida e suave

Para evitar uma solução trivial que maximiza a margem fazendo que todas as observações fiquem do lado errado das suas margin boundary, as variáveis de relaxamento $\xi_{i}$ são incorporadas à função objetivo (do classificador) que se deseja otimizar, na forma de uma penalidade dada em função de $\xi_{i}$. A função objetivo modificada é dada pela seguinte equação:

$$
f(\mathbf{w})=\frac{\|\mathbf{w}\|^{2}}{2}+C \sum_{i=1}^{N} g\left(\xi_{i}\right)
$$

O primeiro termo da Equação (3.18) representa a maximização da margem, enquanto o segundo termo é a soma dos valores em função de $\xi_{(\cdot)}$ de cada observação da base de dados, multiplicada por uma constante de custo $(C)$ positiva. Tal constante controla o trade-off entre o tamanho da margem e o montante de erros (e respectiva penalidade). Quando o valor de $C$ for alto, será necessário encontrar uma solução com vários $\xi_{(\cdot)}$ pequenos ou iguais a zero, pois 
será muito custoso ter $\xi_{(\cdot)}$ diferentes de zero. Isso significa que, quanto maior $C$, menor será a margem, o que implica reduzir as possibilidades de erros nos dados de treinamento aumentando o risco de sobre-treinamento (overfitting ou generalização pobre). Por outro lado, quanto menor o valor de $C$, maior poderá ser a margem, aumentando as possibilidades de erros nos dados de treinamento mas reduzindo os riscos de overfitting.

A inserção das variáveis de relaxamento faz com que a restrição da Equação (3.9) não seja mais satisfeita, sendo assim é necessário a inclusão destas variáveis na restrição, como mostrado na seguinte equação:

$$
y_{i}\left(\mathbf{x}_{i} \cdot \mathbf{w}+b\right) \geq 1-\xi_{i}, \quad i=1, \cdots, N
$$

onde $\forall i: \xi_{i} \geq 0$. Para encontrar o hiperplano de ótima separação utilizando a abordagem de margem suave, o problema passa a ser então minimizar a Equação (3.18) dada a restrição da Equação 3.19.

Uma generalização desta abordagem é atribuir valores diferentes para a constante $C$ dependendo da classe da observação (Osuna et al., 1997). Isso pode ser aplicado, por exemplo, em problemas de classes desbalanceadas, tornando a classificação errada de observações de uma classe durante a fase de treinamento mais cara do que da outra. A função objetivo torna-se então:

$$
f(\mathbf{w})=\frac{\|\mathbf{w}\|^{2}}{2}+C^{+} \sum_{\forall i \in+} g\left(\xi_{i}\right)+C^{-} \sum_{\forall i \in-} g\left(\xi_{i}\right)
$$

Essa abordagem pode ser generalizada ainda mais, no cenário em que cada observação tem um valor de $C$ diferente. Isso pode ser aplicado em cenários em que se sabe que a rotulação de certas observações são mais confiáveis que de outras. A função objetivo torna-se nesse caso:

$$
f(\mathbf{w})=\frac{\|\mathbf{w}\|^{2}}{2}+\sum_{i=1}^{N} C_{i} g\left(\xi_{i}\right)
$$

\subsection{Kernels}

No mundo real poucas bases de dados são linearmente separáveis, o que torna os classificadores lineares de máxima margem pouco eficientes. Entretanto, a utilização de funções kernels podem transformar a base de dados em um conjunto linearmente separável. A ideia fundamental por trás das funções kernels é transformar o espaço de entrada da base de dados, que é possivelmente não linearmente separável, em um espaço chamado de espaço de características em que os dados são linearmente separáveis.

Para esta tarefa são definidas funções $\Phi(\cdot)$ no domínio do espaço de entrada que mapeiam o conjunto de dados no espaço de características. Essas funções podem ser não lineares e transformam o espaço de características em um espaço com dimensão muito maior que o espaço de entrada. 
Na Figura 3.4(a) é apresentada uma base de dados que não é possível separar os objetos positivos dos objetos negativos com apenas um hiperplano de decisão. Porém, com a utilização de uma função $\Phi(\cdot)$, é possível mapear o espaço de entrada no espaço de características apresentado na Figura 3.4(b), que é linearmente separável, transformando $\mathbb{R}^{2} \rightarrow \mathbb{R}^{3}$ através da seguinte função:

$$
\Phi(\mathbf{x})=\Phi\left(x_{1}, x_{2}\right)=\left(x_{1}^{2}, x_{2}^{2}, \sqrt{2} x_{1} x_{2}\right)=\left(z_{1}, z_{2}, z_{3}\right)
$$

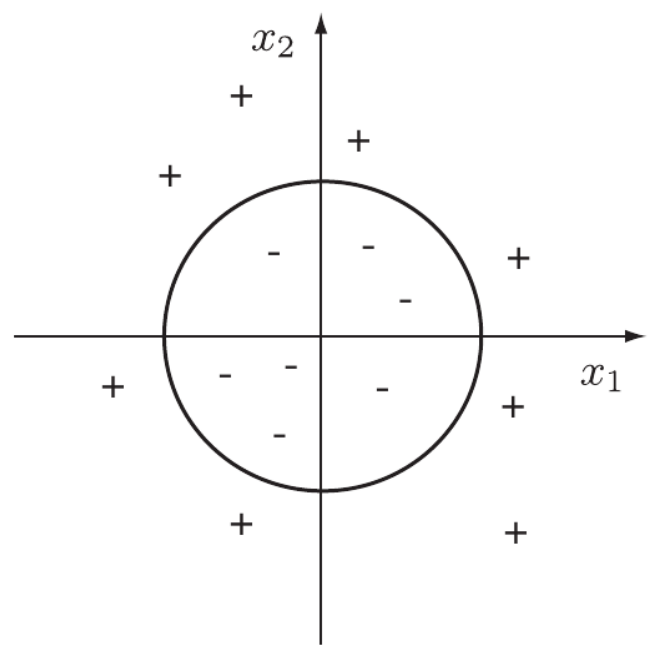

(a) Não linearmente separável

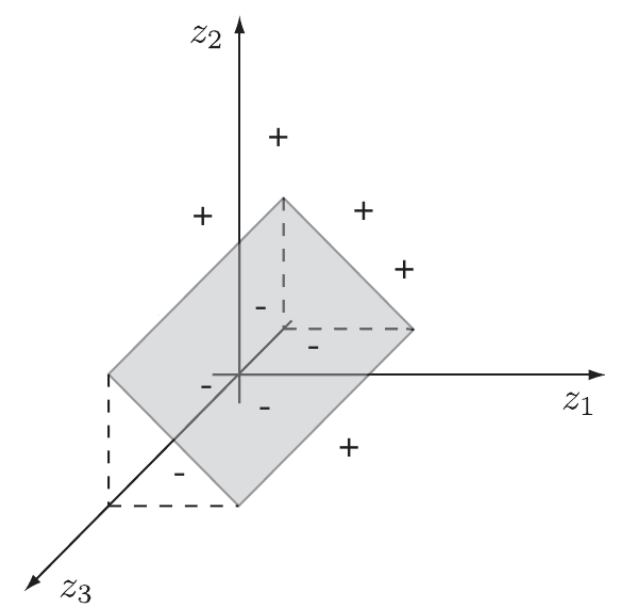

(b) Linearmente separável

Figura 3.4: Transformação do espaço (Hamel, 2009)

Existem classificadores que de fato transformam o espaço de entrada no espaço de características para então classificar os dados, tais como os classificadores polinomiais (Duda et al., 2001). Apesar da transformação funcionar bem no exemplo da Figura 3.4, essa abordagem pode não funcionar bem em bases de dados reais, pois a transformação dos dados pode levar a um novo espaço de dimensões muito maiores. Trabalhar nesse novo espaço pode ser computacionalmente muito caro e pode-se sofrer com o problema da alta dimensionalidade, chamado de maldição da dimensionalidade (Tan et al., 2006, Zimek et al., 2012). Para evitar tais problemas, pode-se utilizar o chamado "kernel trick", que permite calcular o produto interno no espaço de características sem ter que explicitar o mapeamento das funções $\Phi(\cdot)$, ou seja, o produto interno no espaço transformado é computado utilizando o conjunto de atributos do espaço original que possui menor dimensionalidade. O produto interno de dois vetores $\mathbf{x}$ e $\mathrm{x}^{\prime}$ no espaço de características pode ser escrito da seguinte forma no espaço de entrada:

$$
\begin{array}{r}
K\left(\mathbf{x}, \mathbf{x}^{\prime}\right)=\Phi(\mathbf{x}) \cdot \Phi\left(\mathbf{x}^{\prime}\right)=\left(x_{1}^{2}, x_{2}^{2}, \sqrt{2} x_{1} x_{2}\right) \cdot\left(x_{1}^{\prime 2}, x_{2}^{\prime 2}, \sqrt{2} x_{1}^{\prime} x_{2}^{\prime}\right) \\
=x_{1}^{2} x_{1}^{\prime 2}+x_{2}^{2} x_{2}^{\prime 2}+2 x_{1} x_{2} x_{1}^{\prime} x_{2}^{\prime} \\
=\left(\mathbf{x} \cdot \mathbf{x}^{\prime}\right)\left(\mathbf{x} \cdot \mathbf{x}^{\prime}\right) \\
=\left(\mathbf{x} \cdot \mathbf{x}^{\prime}\right)^{2}
\end{array}
$$

A função kernel apresentada na Equação (3.22) é o kernel polinomial que pode ser genera-

\footnotetext{
${ }^{1}$ Figura reproduzida sob número de licença: 3310870924938
} 
lizado na seguinte função:

$$
K\left(\mathbf{x}, \mathbf{x}^{\prime}\right)=\left(\mathbf{x} \cdot \mathbf{x}^{\prime}\right)^{p}
$$

em que o parâmetro $p$ representa o grau da função, sendo que quanto maior o grau, maior será a dimensão do espaço de características e maior o risco de overfitting. Por outro lado, se o valor de $p$ for muito pequeno, o tamanho do espaço de características pode não ser suficiente para separar os dados. Outra função kernel amplamente utilizada é o kernel radial:

$$
\begin{array}{r}
K\left(\mathbf{x}, \mathbf{x}^{\prime}\right)=e^{\left(-\gamma\left|\mathbf{x}-\mathbf{x}^{\prime}\right|^{2}\right)} \\
\gamma=\frac{1}{2 \sigma^{2}}
\end{array}
$$

em que o parâmetro $\sigma$ representa o espalhamento da radial. Se $\sigma$ for muito pequeno, o número de radiais cresce e, no extremo, obtém-se uma radial para cada observação da base de dados (Figura 3.5(f)], causando overfitting. Por outro lado, tem-se que conforme $\sigma$ cresce $(\gamma$ tende a zero), tende-se a um classificador linear (Figura 3.5(c)). Na Figura 3.5 é possível visualizar o efeito dos parâmetros dos kernels polinomial e radial.

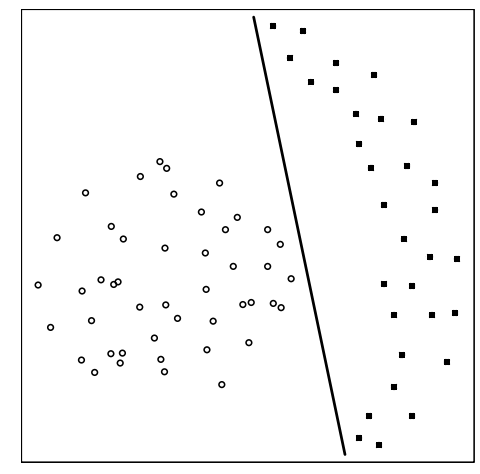

(a) Kernel polinomial, $p=1$

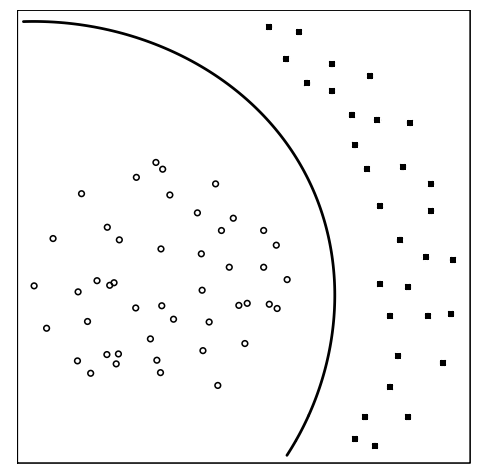

(d) Kernel radial $\sigma=2.25(\gamma=0.1)$

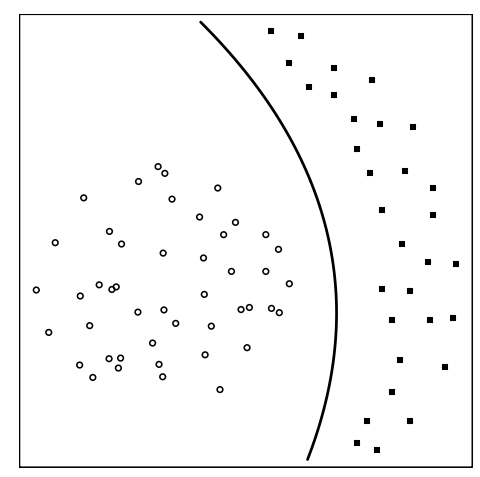

(b) Kernel polinomial, $p=2$

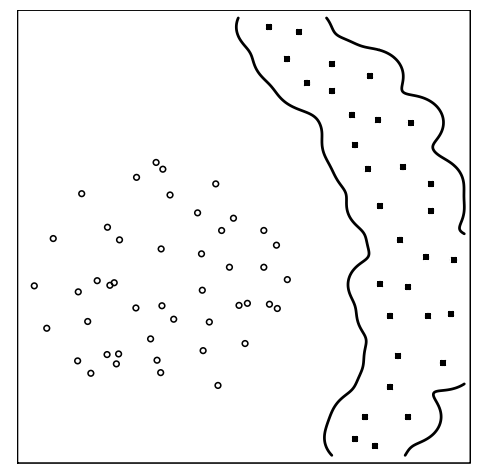

(e) Kernel radial $\sigma=0.125(\gamma=32)$

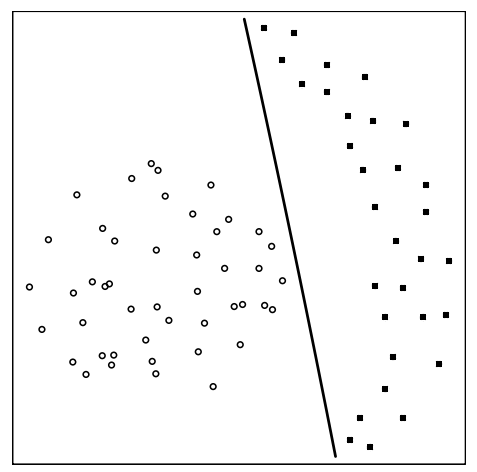

(c) Kernel radial $\sigma=70.75(\gamma=0.0001)$

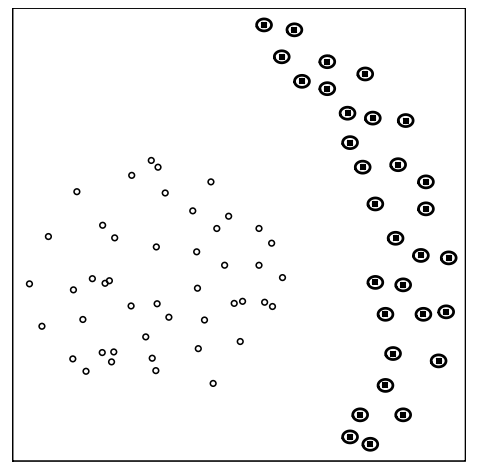

(f) Kernel radial $\sigma=0.025(\gamma=800)$

Figura 3.5: Efeito dos parâmetros dos kernels polinomial e radial 


\subsection{Classificadores Não Lineares de Máxima Margem}

Para problemas reais onde os dados normalmente não são linearmente separáveis e as informações são sujeitas a apresentar imperfeições como erros/ruído, é importante que se utilize classificadores robustos. Baseado nisso, os classificadores não lineares de máxima margem combinam as estrategias do "kernel trick" e a abordagem de margem suave para transformar o espaço original e assim construir fronteiras lineares e capazes de separar as observações em suas respectivas classes. A seguir, os classificadores SVM KLR serão melhor descritos.

\subsubsection{SVM}

Support Vector Machines (SVM) (Vapnik, 1995; Bennett and Campbell, 2000, Hastie et al., 2013) é um classificador que, após definir o hiperplano separador que maximiza a margem de separação das classes, classifica as observações binariamente em uma das classes. Para definir tal hiperplano, o classificador utiliza os conceitos apresentados neste Capítulo para atingir o hiperplano de ótima separação, tendo então como objetivo minimizar a Equação (3.18), onde a função de custo $g\left(\xi_{i}\right)$ é dada por $M A X\left(0, \xi_{i}\right)$, ou seja, a penalização é simplesmente a distância da observação para sua margin boundary $\left(g\left(\xi_{i}\right)=\xi_{i}\right)$, entretanto, não há penalização para aquelas que não violarem a margin boundary $\left(g\left(\xi_{i}\right)=0\right)$. O problema então pode ser formalizado como apresentado na Equação 3.25).

$$
\begin{array}{ll}
\min _{\mathbf{w}} & \frac{\|\mathbf{w}\|^{2}}{2}+C \sum_{i=1}^{N} \xi_{i} \\
\text { s. a. } & y_{i}\left(\mathbf{x}_{i} \cdot \mathbf{w}+b\right) \geq 1-\xi_{i}
\end{array}
$$

Note que apesar da formulação apresentar um mesmo custo $C$ para todas observações, abordagens com custo diferente para cada classe, ou ainda, com custo diferente para cada observação pode ser aplicada, como discutido na seção 3.2 .

Utilizando os multiplicadores de Lagrange para inserir as restrições do problema de otimização na função objetivo, a função Lagrangiana pode ser escrita como:

$$
L_{P}=\frac{1}{2}\|\mathbf{w}\|^{2}+C \sum_{i=1}^{N} \xi_{i}-\sum_{i=1}^{N} \alpha_{i}\left(y_{i}\left(\mathbf{x}_{i} \cdot \mathbf{w}+b\right)-1+\xi_{i}\right)-\sum_{i=1}^{N} \mu_{i} \xi_{i}
$$

sendo que os dois primeiros termos representam a função objetivo que deseja minimizar, o terceiro termo representa a restrição associada as variáveis de relaxamento e o último termo garante a não negatividade dos $\xi_{i}$ 's. Utilizando as condições KKT temos que:

$$
\begin{gathered}
\xi_{i} \geq 0, \quad \alpha_{i} \geq 0, \quad \mu_{i} \geq 0 \\
\alpha_{i}\left(y_{i}\left(\mathbf{x}_{i} \cdot \mathbf{w}+b\right)-1+\xi_{i}\right)=0
\end{gathered}
$$




$$
\mu_{i} \xi_{i}=0
$$

Note que pela Equação (3.28), tem-se que os $\alpha_{i}$ 's serão iguais a 0 não apenas para as observações que estejam em cima da margin boundary de sua classe, mas também para toda observação que violá-la. Agora toda observação que tiver $\alpha>0$ será considerada support point. No contexto do $\mathrm{SVM}$ os support points também são conhecidos como support vectors.

Igualando a derivada de $L_{P}$ em relação a w, $b$ e $\xi_{i}$ a 0 tem-se:

$$
\begin{gathered}
\frac{\partial L_{P}}{\partial \mathbf{w}}=0 \Rightarrow \mathbf{w}=\sum_{i=1}^{N} \alpha_{i} y_{i} \mathbf{x}_{i}, \\
\frac{\partial L_{P}}{\partial b}=0 \Rightarrow \sum_{i=1}^{N} \alpha_{i} y_{i}=0 . \\
\frac{\partial L_{P}}{\partial \xi_{i}}=0 \Rightarrow \alpha_{i}+\mu_{i}=C
\end{gathered}
$$

Substituindo as Equações (3.30), (3.31) e (3.32) na Equação 3.26 tem-se a forma dual em função dos multiplicadores de Lagrange:

$$
\begin{array}{r}
L_{D}=\frac{1}{2} \sum_{i, j}^{N} \alpha_{i} \alpha_{j} y_{i} y_{j} \mathbf{x}_{i} \cdot \mathbf{x}_{j}+C \sum_{i=1}^{N} \xi_{i} \\
-\sum_{i=1}^{N} \alpha_{i}\left(y_{i}\left(\sum_{j=1}^{N} \alpha_{j} y_{j} \mathbf{x}_{i} \cdot \mathbf{x}_{j}+b\right)-1+\xi_{i}\right) \\
-\sum_{i=1}^{N}\left(C-\alpha_{i}\right) \xi_{i} \\
=\sum_{i=1}^{N} \alpha_{i}-\frac{1}{2} \sum_{i, j}^{N} \alpha_{i} \alpha_{j} y_{i} y_{j} \mathbf{x}_{i} \cdot \mathbf{x}_{j}
\end{array}
$$

A forma dual apresentada na Equação (3.33) é idêntica a dual apresentada na Equação (3.17) da seção 3.1, entretanto, as restrições são levemente diferentes. Além dos $\alpha_{i}>0$ para todas as observações que violarem a margem, como discutido acima, a Equação (3.32) sugere que $0 \leq \alpha_{i} \leq C$ devido a não negatividade de $\alpha_{i}$ e $\mu_{i}$.

Para resolver problemas não linearmente separáveis, pode-se utilizar o "kernel trick" apresentado anteriormente. O "kernel trick" pode ser aplicado diretamente na Equação (3.33), tendo agora como objetivo minimizar a seguinte equação:

$$
L_{D}=\sum_{i=1}^{N} \alpha_{i}-\frac{1}{2} \sum_{i, j}^{N} \alpha_{i} \alpha_{j} y_{i} y_{j} \Phi\left(\mathbf{x}_{i}\right) \cdot \Phi\left(\mathbf{x}_{j}\right)=\sum_{i=1}^{N} \alpha_{i}-\frac{1}{2} \sum_{i, j}^{N} \alpha_{i} \alpha_{j} y_{i} y_{j} K\left(\mathbf{x}_{i}, \mathbf{x}_{j}\right)
$$


Os $\alpha_{i}$ 's podem ser obtidos por meio de técnicas de programação quadrática. Um algoritmo eficiente e bem conhecido é o Sequential Minimal Optimization (SMO) (Platt, 1999), que divide um problema de programação quadrática em vários outros problemas menores. Uma vez encontrados os $\alpha_{i}$ 's, os parâmetros w e $b$ podem ser encontrados utilizando as seguintes equações:

$$
\begin{gathered}
\mathbf{w}=\sum_{i=1}^{N} \alpha_{i} y_{i} \Phi\left(\mathbf{x}_{i}\right) \\
\alpha_{i}\left(y_{i}\left(\sum_{j=1}^{N} \alpha_{j} y_{j} \Phi\left(\mathbf{x}_{j}\right) \cdot \Phi\left(\mathbf{x}_{i}\right)+b\right)-1\right)=\alpha_{i}\left(y_{i}\left(\sum_{j}^{N} \alpha_{j} y_{j} K\left(\mathbf{x}_{j}, \mathbf{x}_{i}\right)+b\right)-1\right)=0
\end{gathered}
$$

essas equações são análogas as Equações 3.30) e 3.31). Por fim, uma nova observação z pode ser classificada utilizando a seguinte equação:

$f(\mathbf{z})=\operatorname{sign}(\mathbf{w} \cdot \Phi(\mathbf{z})+b)=\operatorname{sign}\left(\sum_{i=1}^{N} \alpha_{i} y_{i} \Phi\left(\mathbf{x}_{i}\right) \cdot \Phi(\mathbf{z})+b\right)=\operatorname{sign}\left(\sum_{i=1}^{N} \alpha_{i} y_{i} K\left(\mathbf{x}_{i}, \mathbf{z}\right)+b\right)$

em que sign indica que a observação z será classificada de acordo com o sinal da função, isto é, classe positiva em caso de sinal positivo ou classe negativa em caso de sinal negativo.

\subsubsection{KLR}

Kernel Logistic Regression (KLR) (Zhu and Hastie, 2001; Keerthi et al., 2005, Hastie et al., 2013), assim como SVM, é um classificador de máxima margem suave. Entretanto, ao contrário do SVM que classifica as observações binariamente, KLR fornece a probabilidade associada de cada classe. Outra importante diferença entre os classificadores está na função de custo $\left(g\left(\xi_{i}\right)\right)$ utilizada. Enquanto SVM utiliza uma função de custo linear, conhecida como hinge loss, em que apenas as observações que violam a margem recebem penalização, [KLR utiliza uma função de custo logarítmica, $g\left(\xi_{i}\right)=\log \left(1+e^{\xi_{i}}\right)$, conhecida como log loss, em que todas as observações são penalizadas, embora a penalidade para as observações que violem sejam maiores. A utilização das funções de custo hinge loss e log loss pelos seus respectivos classificadores garantem com que as margens de seus modelos sejam maximizadas (Rosset et al., 2003).

Uma comparação entre as funções de custo utilizada pelos classificadores SVM e KLR pode ser visualizada na Figura 3.6. Assim como brevemente discutido na seção 3.1, o modelo gerado pelo classificador KLR faz com que todas as observações influenciem na construção do hiperplano separador, ao contrário do modelo gerado pelo SVM. Note que devido a função de custo utilizada pelo classificador KLR, a propriedade de que apenas os support points possuam $\alpha>0$ não é válida para este classificador.

O objetivo do KLR também é minimizar a Equação (3.18), entretanto, aqui a função de 


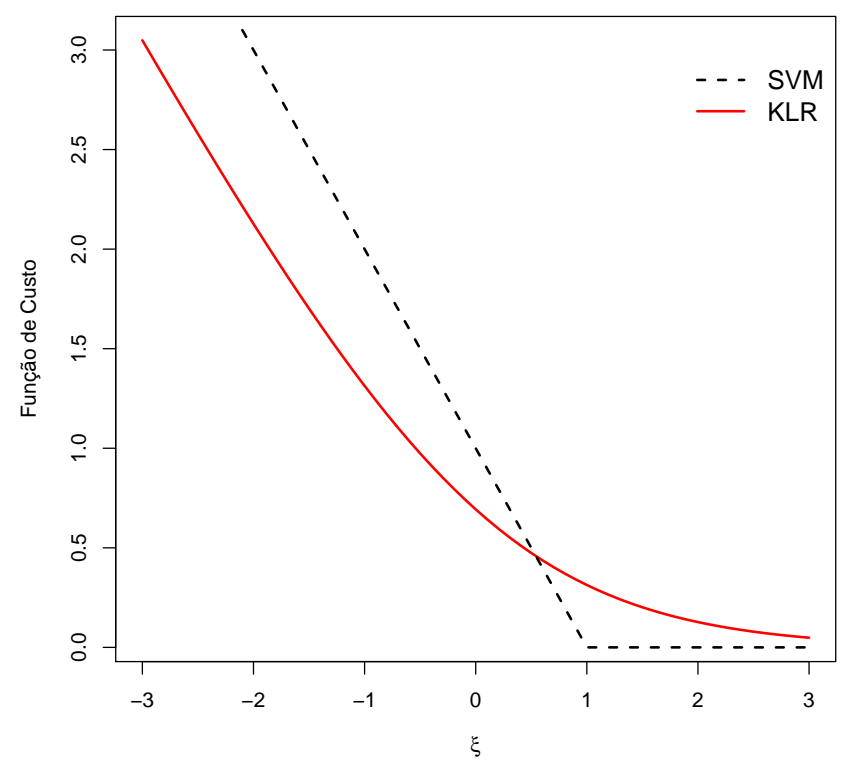

Figura 3.6: Função de Custo

custo $g\left(\xi_{i}\right)$ é dada por $\log \left(1+e^{\xi_{i}}\right)$, sendo assim o problema de otimização pode ser formalizado conforme a Equação (3.38). Novamente, a formulação apresentada aqui utiliza o mesmo custo $C$ para todas observações por questão de simplicidade, porém abordagens que utilizam custo variado podem ser aplicadas.

$$
\begin{array}{ll}
\min _{\mathbf{w}} & \frac{\|\mathbf{w}\|^{2}}{2}+C \sum_{i=1}^{N} \log \left(1+e^{\xi_{i}}\right) \\
\text { s. a. } & y_{i}\left(\mathbf{x}_{i} \cdot \mathbf{w}+b\right) \geq 1-\xi_{i},
\end{array}
$$

Aplicando os multiplicadores de Lagrange para que as restrições sejam inseridas na função objetivo, tem-se a seguinte equação:

$$
L_{P}=\frac{1}{2}\|\mathbf{w}\|^{2}+C \sum_{i=1}^{N} \log \left(1+e^{\xi_{i}}\right)-\sum_{i=1}^{N} \alpha_{i}\left(y_{i}\left(\mathbf{x}_{i} \cdot \mathbf{w}+b\right)+\xi_{i}\right)
$$

novamente os dois primeiros termos são da função objetivo que se deseja minimizar, enquanto o último é a restrição. Igualando a derivada da função Lagrangiana em relação a w e $b$ a 0 , tem-se respectivamente as Equações (3.30) e (3.31). Quando igualada a derivada da Lagrangiana em relação a $\xi_{i}$ a 0 , tem-se:

$$
\frac{\partial L_{P}}{\partial \xi_{i}}=0 \Rightarrow e^{\xi_{i}}=\frac{\delta}{1-\delta} \Rightarrow \xi_{i}=\log \left(\frac{\delta}{1-\delta}\right)
$$


onde $\delta=\frac{\alpha_{i}}{C}$. Tendo que:

$$
\begin{array}{r}
\delta \xi_{i}-g\left(\xi_{i}\right)=\delta \log \left(\frac{\delta}{1-\delta}\right)-\log \left(1+\frac{\delta}{1-\delta}\right) \\
=\delta \log \left(\frac{\delta}{1-\delta}\right)-\log \left(\frac{1}{1-\delta}\right) \\
=\delta \log (\delta)-\delta \log (1-\delta)+\log (1-\delta) \\
=\delta \log (\delta)+(1-\delta) \log (1-\delta)
\end{array}
$$

Para obter a forma dual em função dos multiplicadores de Lagrange, pode-se substituir as Equações 3.30), 3.31), 3.40) e (3.41) na Equação (3.39), tendo então a seguinte forma dual:

$$
\begin{array}{r}
L_{D}=\frac{1}{2} \sum_{i, j}^{N} \alpha_{i} \alpha_{j} y_{i} y_{j} \mathbf{x}_{i} \cdot \mathbf{x}_{j}+C \sum_{i=1}^{N}\left(\delta \xi_{i}-g\left(\xi_{i}\right)\right) \\
=\frac{1}{2} \sum_{i, j}^{N} \alpha_{i} \alpha_{j} y_{i} y_{j} \mathbf{x}_{i} \cdot \mathbf{x}_{j}+C \sum_{i=1}^{N}(\delta \log (\delta)+(1-\delta) \log (1-\delta))
\end{array}
$$

O "kernel trick" pode ser trivialmente aplicado na forma dual, resultando na seguinte equação:

$$
\begin{array}{r}
L_{D}=\frac{1}{2} \sum_{i, j}^{N} \alpha_{i} \alpha_{j} y_{i} y_{j} \Phi\left(\mathbf{x}_{i}\right) \cdot \Phi\left(\mathbf{x}_{j}\right)+C \sum_{i=1}^{N}(\delta \log (\delta)+(1-\delta) \log (1-\delta)) \\
=\frac{1}{2} \sum_{i, j}^{N} \alpha_{i} \alpha_{j} y_{i} y_{j} K\left(\mathbf{x}_{i}, \mathbf{x}_{j}\right)+C \sum_{i=1}^{N}(\delta \log (\delta)+(1-\delta) \log (1-\delta))
\end{array}
$$

Os $\alpha_{i}$ 's podem ser encontrados utilizando um algoritmo baseado no SMO proposto por Keerthi et al. (2005). Assim como no SVM, após encontrados os $\alpha_{i}$ 's, os parâmetros w e $b$ podem ser obtidos utilizando as Equações 3.35 e 3.36). Após encontrado os parâmetros, a probabilidade de uma determinada observação $\mathbf{z}$ pertencer a classe positiva $(y=+1)$ ou negativa $(y=-1)$ pode ser calculada utilizando a seguinte função logística:

$$
P(y \mid \mathbf{z})=\frac{1}{1+e^{-y(\mathbf{w} \cdot \Phi(\mathbf{z})-b)}}=\frac{1}{1+e^{-y\left(\sum_{i=1}^{N} \alpha_{i} y_{i} \Phi\left(\mathbf{x}_{i}\right) \cdot \Phi(\mathbf{z})-b\right)}}=\frac{1}{1+e^{-y\left(\sum_{i=1}^{N} \alpha_{i} y_{i} K\left(\mathbf{x}_{i}, \mathbf{z}\right)-b\right)}}
$$




\section{CAPÍTULO 4 \\ IREOS: Um Índice de Validação Interna para Detecção de Outliers}

Neste Capítulo é apresentado o índice interno e relativo proposto para avaliação de soluções de detecção não supervisionada de outliers, nomeado IREOS, Na seção 4.1 é feita uma introdução sobre o índice e apresentado formalmente o problema de avaliação interna de soluções de detecção de outliers. A intuição básica utilizada pela medida é apresentada na seção 4.2 e duas outras intuições adicionais importantes na avaliação das soluções são apresentadas na seção 4.3. Na seção 4.4 são apresentados o índice ajustado para aleatoriedade e a validação estatística, além de uma versão aproximada, porém mais rápida do ajuste. Por fim, na seção 4.5 é apresentado um pseudocódigo do índice em alto nível, assim como a análise de complexidade.

\subsection{Introdução}

O principal objetivo deste trabalho é investigar os problemas de seleção de modelos e avaliação (ou validação) de resultados em detecção não supervisionada de outliers, isto é, automaticamente e sem utilizar informações externas (tais como rótulos), selecionar soluções mais promissoras, que correspondem a modelos (algoritmos, parâmetros) mais adequados, e avaliar a qualidade dos resultados produzidos. Para isso, foi desenvolvido um índice interno e relativo para avaliação de soluções de detecção não supervisionada de outliers, nomeado IREOS (Internal, Relative Evaluation of Outlier Solutions).

Os índices denominados internos não fazem uso de nenhuma informação externa na avaliação. A avaliação é feita baseada apenas nas informações dos dados e das soluções a serem avaliadas. A maioria desses índices é também relativo no sentido que eles podem ser utilizados para comparar diferentes soluções e apontar qual delas é melhor em termos relativos. IREOS pode ser visto como um índice de avaliação interna e relativa, uma vez que ele avalia e com- 
para diferentes soluções (top- $n$, i.e., rotulações binárias) candidatas baseando-se apenas nas informações dos dados e nas próprias soluções a serem avaliadas. A seguir é apresentado formalmente o problema de avaliação interna de soluções de detecção de outliers e nas próximas seções IREOS é apresentado em detalhes.

\subsubsection{Apresentação do Problema}

Seja $\mathbf{X}=\left\{\mathbf{x}_{1}, \ldots, \mathbf{x}_{N}\right\}$ uma base de dados contendo $N$ observações não rotuladas, cada observação descrita por um vetor de atributos $d$-dimensional, $\mathbf{x}_{(.)}$, e assume-se que um ou mais algoritmos de detecção não supervisionada de outliers produzirá, para essa base de dados, soluções candidatas que se deseja avaliar na indisponibilidade de observações rotuladas. Soluções são $n$ observações rotuladas como outliers, consequentemente as $N-n$ observações restantes são consideradas inliers. As rotulações podem serem sugeridas diretamente a partir de algoritmos de detecção que rotulam as $n$ observações mais prováveis serem outliers como tais e as $N-n$ restantes como inliers, ditos algoritmos top- $n$ de detecção de outliers (Jin et al., 2001; Fan et al., 2006, Angiulli and Pizzuti, 2005), ou ainda, as rotulações podem serem sugeridas a partir de algoritmos de detecção que pontuam (scoring) e/ou ordenam (ranking) as $N$ observações de acordo com o grau ou probabilidade com que cada uma delas deve ser categorizada como tal (Breunig et al., 2000; Zhang et al., 2009; Tang et al., 2002). Entretanto, neste caso as $n$ observações que mais se caracterizam como outliers, de acordo com os scorings e/ou ranking, são rotuladas como outliers e as $N-n$ restantes são rotuladas como inliers, processo conhecido como binarização. Sendo assim, uma solução pode ser vista formalmente como um subconjunto $\mathbf{S} \subset \mathbf{X},|\mathbf{S}|=n$, contendo as observações rotuladas como outliers. Dada uma coleção de soluções candidatas, deseja-se independentemente e quantitativamente medir a qualidade de cada solução candidata de forma individual para, por exemplo, i) avaliar sua significância estatística quando comparada à hipotese nula de uma solução aleatória; ou ii) compará-las em termos relativos, de forma que soluções mais promissoras, correspondentes aos modelos (algoritmos, parâmetros) mais adequados, poderiam ser selecionadas.

\subsection{Intuição Básica}

A intuição básica por trás do índice \REOS é que um outlier é uma observação que de certa forma está mais distante e então pode ser mais facilmente separada das demais observações que um inlier. Essa intuição não é vinculada a qualquer critério específico utilizado por algoritmos de detecção de outliers. Além disso, isso se encaixa na intuição que a maioria dos algoritmos deseja capturar.

A rotulação de $n$ observações como outliers em uma solução boa deveria então ser mais consistente com essa intuição do que a rotulação de $n$ observações em uma solução ruim. Sendo assim, é esperado que as observações rotuladas como outliers em soluções boas sejam em média mais fáceis de serem separadas do que as observações rotuladas como tal em soluções ruins. O problema passa ser então quantificar o quão difícil é separar das demais observações cada 
observação $\mathbf{x}_{(.)} \in \mathbf{S}$, ou seja, cada observação rotulada como outlier na solução que está sendo avaliada.

IREOS utiliza classificadores de máxima margem (Capítulo 3), tais como SVM ou KLR, para avaliar a separabilidade de cada observação. O índice utiliza do fato de que tais classificadores são capazes de quantificar de alguma forma o quão distante cada observação está da fronteira de decisão e toma esta grandeza como base para uma medida de separabilidade da observação. Esta ideia é ilustrada na Figura 4.1.

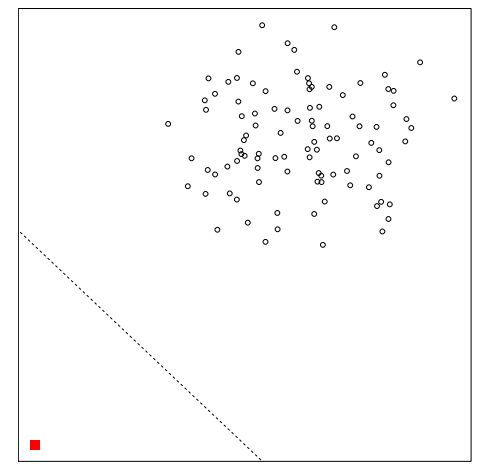

(a) Outlier Global

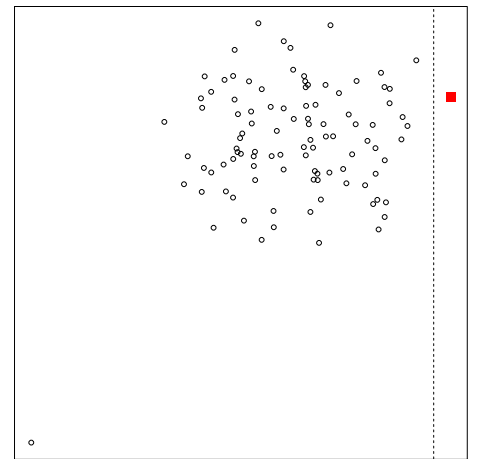

(b) Outlier Local

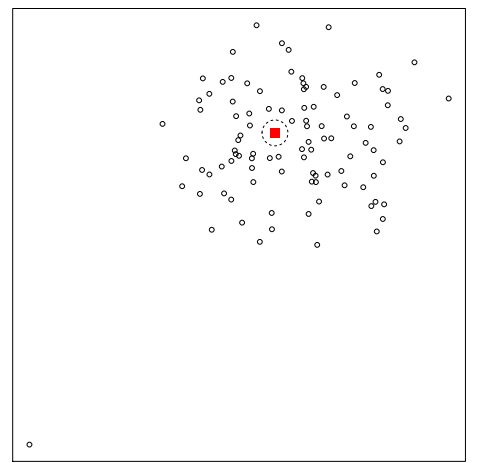

(c) Inlier

Figura 4.1: Dificuldade em separar uma observação das demais

As Figuras 4.1(a), 4.1(b) e 4.1(c) destacam diferentes observações rotuladas como outlier (quadrado vermelho) em hipotéticas soluções de detecção de outliers a serem avaliadas. Na Figura 4.1(a) pode-se ver que a observação destacada é um outlier global, que está bem distante do hiperplano (linha tracejada) do classificador que a separa das demais observações. Na Figura 4.1(b), por se tratar de um outlier local, a margem do classificador é menor, mas ainda assim é mais larga que a da Figura 4.1(c). Neste último caso, a observação rotulada é sem dúvida um inlier e não apenas a margem é bem pequena como também é necessária uma fronteira de decisão complexa (i.e. não linear).

O fato da fronteira de decisão poder ser não linear (como no exemplo da Figura 4.1(c)), implica na necessidade de classificadores de máxima margem não lineares que utilizam funções kernels, como, por exemplo, os classificadores apresentados na seção 3.4 . As funções kernels transformam o espaço de entrada (possivelmente não linearmente separável) em um espaço linearmente separável. Entretanto, a maioria dos kernels demanda a configuração de um parâmetro. Um dos kernels mais utilizado é o kernel radial, dado por $K\left(\mathbf{x}_{i}, \mathbf{x}_{j}\right)=e^{-\gamma\left\|\mathbf{x}_{i}-\mathbf{x}_{j}\right\|^{2}}$ (Equação (3.24), em que o parâmetro $\gamma$ representa a largura da gaussiana, que é positivamente relacionado ao grau de não linearidade da fronteira de decisão, isto é, quanto maior o valor de $\gamma$ mais complexa será a fronteira de decisão. Isso indica que observações para as quais o classificador precisa de um $\gamma$ maior para separá-la das demais são mais difíceis de serem separadas.

Em problemas de classificação, $\gamma$ pode ser visto como um parâmetro de controle entre a performance no conjunto de treinamento e a performance no conjunto de teste (conforme já discutido na seção 3.3). Entretanto, na avaliação de soluções de detecção de outliers não é de interesse a capacidade de generalização do classificador, o interesse está meramente em medir 
o grau de dificuldade para separar uma observação das demais. Sendo assim, a premissa básica "quanto mais outlier uma observação é, mais fácil de separá-la das demais" é esperada que se mantenha verdadeira para diferentes valores de $\gamma$, embora a diferença relativa entre o grau de dificuldade de separação de observações fáceis e observações difíceis possa se alterar com diferentes valores de $\gamma$. Essa ideia é ilustrada na Figura 4.2, em que é utilizado um classificador de máxima margem com kernel para separar as três observações rotuladas como outliers na Figura 4.1. No eixo horizontal o valor de $\gamma$ é variado de 0 até $\gamma_{\max }$ (que é o valor necessário para que todas observações rotuladas como outliers sejam individualmente separadas das demais observações na base de dados), enquanto o eixo vertical apresenta uma medida $p\left(\mathbf{x}_{i}, \gamma\right)$ que quantifica em um intervalo normalizado o quão longe cada observação $\mathbf{x}_{i}$ está da fronteira de decisão. Observe que, não importa o valor de $\gamma, p\left(\mathbf{x}_{i}, \gamma\right)$ é sempre maior para $\mathbf{x}_{i}$ dado pelo outlier global (Figura 4.1(a) do que para o outlier local (Figura 4.1(b)), que por sua vez é maior do que para o inlier (Figura 4.1(c)), embora as diferenças relativas se alterem.

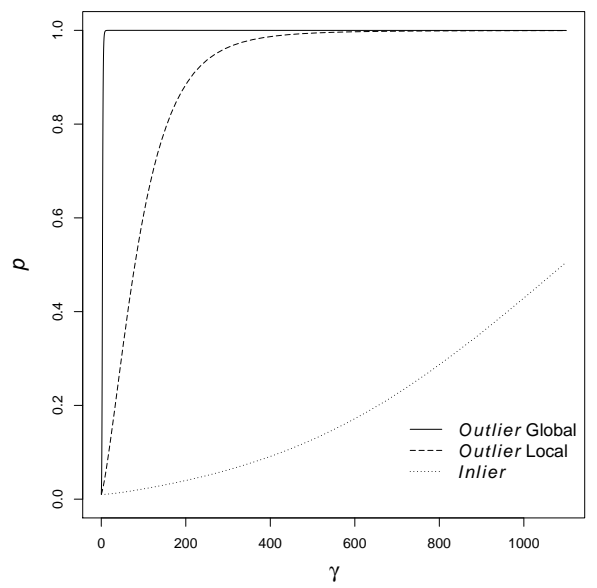

Figura 4.2: Separabilidade

A observação acima nos permite eliminar a necessidade de escolha de um valor particular de $\gamma$, o que seria um parâmetro indesejado no índice de avaliação. De fato, não é necessária a escolha de um valor particular de $\gamma$, em vez disso, a separabilidade da observação $\mathbf{x}_{i}$ pode ser medida computando a área sob a curva (Area Under the Curve (AUC)) do intervalo de valores de $\gamma$, i.e. $\int_{\gamma=0}^{\gamma_{\max }} p\left(\mathbf{x}_{i}, \gamma\right)$. Para avaliar a qualidade de uma dada solução $\mathbf{S}$, é tomada a média das curvas de separabilidade de cada observação $\mathbf{x}_{i} \in \mathbf{S}$, i.e. $\bar{p}(\gamma)=\frac{1}{n} \sum_{\mathbf{x}_{i} \in \mathbf{S}} p\left(\mathbf{x}_{i}, \gamma\right)$, então computa-se a área sob essa curva como o índice, i.e. $\int_{\gamma=0}^{\gamma_{\max }} \bar{p}(\gamma)$. Esta AUC pode ser trivialmente normalizada em $[0,1]$ dividindo-a pela área máxima $\left(\gamma_{\max } \times 1\right)$, o que leva a um índice preliminar:

$$
\frac{1}{\gamma_{\max }} \int_{\gamma=0}^{\gamma_{\max }} \bar{p}(\gamma)
$$

A integral do índice pode ser aproximada utilizando técnicas de integração numérica (Faires and Burden, 2012), tais como Regra do Ponto Médio, Regra Trapezoidal e Regra de Simpson. Por questão de simplicidade será utilizada a Regra do Ponto Médio, entretanto, pode-se chegar às mesmas conclusões sobre o índice utilizando qualquer dos outros métodos. Para calcular $\int_{\gamma=0}^{\gamma_{\max }} \bar{p}(\gamma), \gamma$ precisa ser discretizado em um número finito de valores de $\gamma$ no intervalo de 
$\left[0, \gamma_{\max }\right]$ para que seja possível treinar o classificador e então computar $\bar{p}(\gamma)$ para cada $\gamma$. Caso o intervalo de $\gamma$ seja uniformemente discretizado em $n_{\gamma}$ valores, este índice preliminar pode ser computado aplicando a Regra do Ponto Médio da seguinte forma:

$$
I(\mathbf{S})=\frac{1}{\gamma_{\max }} \int_{\gamma=0}^{\gamma_{\max }} \bar{p}(\gamma) \approx \frac{1}{\gamma_{\max }} \frac{\left(\gamma_{\max }-0\right)}{n_{\gamma}} \sum_{l=1}^{n_{\gamma}} \bar{p}\left(\gamma_{l}\right)=\frac{1}{n_{\gamma}} \sum_{l=1}^{n_{\gamma}} \bar{p}\left(\gamma_{l}\right)
$$

\subsection{Além da Intuição Básica}

O índice preliminar apresentado na seção anterior funciona bem na maioria dos cenários de aplicações. Entretanto, conceitualmente o índice preliminar não captura duas intuições adicionais julgadas importantes na avaliação de soluções de detecção de outliers. Ambas são relacionadas com a possível presença de clumps na base de dados. Clumps são conjunto de observações próximas umas às outras, mas muito pequenos para serem considerados clusters. Eles podem aparecer por diferentes razões: i) devido à aleatoriedade, e.g., em base de dados com ruído de fundo que segue uma distribuição Poison; ou ii) anomalias que são relativamente raras, mas tendem a ser de alguma forma similar umas às outras, e.g., algumas mutações genéticas ou certo tipos de fraudes. Embora a semântica por trás da interpretação de tais clumps como outliers sejam diferentes nesses dois cenários, ruído no primeiro caso e micro-clusters no segundo, em ambos casos o analista pode querer que os clumps sejam rotulados como potenciais outliers para uma análise mais cuidadosa.

Um problema com a ideia de considerar clumps como parte do modelo de avaliação é que a interpretação deste conceito depende fortemente do domínio de aplicação e da expectativa do usuário. Sem um mecanismo que permita que diferentes usuários em diferentes cenários de aplicações possam expressar o que eles julgam muito pequeno para ser interpretado como cluster, a medida de avaliação ficará presa em uma única e muito particular perspectiva rígida de avaliação. Portanto, em contraste com a prática comum de evitar utilizar qualquer parâmetro em índices de avaliação não supervisionada, na avaliação de detecção de outliers é na verdade importante fornecer ao usuário um mecanismo de controle para ajustar suas expectativas sobre o tamanho de um clump. Dada uma certa expectativa sobre o que considerar o tamanho máximo de um clump, que o usuário acredita ser o número de observações a partir do qual um grupo de observações seja mais um cluster do que um aglomerado de potenciais outliers, o índice deve ser capaz de diferenciar entre fracos candidatos a outliers, como observações dentro de um cluster, de moderados candidatos a outliers, como observações em clumps isolados, além de forte candidatos a outliers, como observações bem separadas das demais. Esta primeira intuição não estava presente no índice preliminar apresentado na seção 4.2, e para capturá-la, é definido o tamanho máximo do clump, $m_{\text {clSize }}$, como um parâmetro opcional de controle para análise exploratória dos dados, a ser incorporado ao índice.

A segunda intuição não capturada pelo índice preliminar também está relacionada com a presença de clumps. Enquanto é claro que a avaliação de cada observação rotulada como outlier deveria ser negativamente afetada pela presença de outra observação próxima (e.g. em um 
clump), é intuitivo que o impacto negativo deveria ser maior se a observação próxima estiver com rótulo diferente (i.e., rotulada como inlier). Considerando o exemplo da Figura 4.3, que corresponde basicamente à Figura 4.1 porém com uma observação adicional perto da observação originalmente rotulada como outlier global na Figura 4.1(a). A diferença entre as figuras da esquerda e da direita é a rotulação da observação adicional (inlier e outlier, respectivamente). Na Figura 4.3(a) a rotulação parece ser inconsistente com a rotulação da observação original e o índice deveria ser negativamente afetado. Na Figura 4.3(b) embora a observação original agora seja menos outlier devido à presença da observação adicional, a rotulação de ambas como outliers é mais consistente e ambos podem ser vistos como se estivessem formando um clump, então o impacto negativo devido à presença da nova observação deveria ser menor que o impacto do primeiro caso.

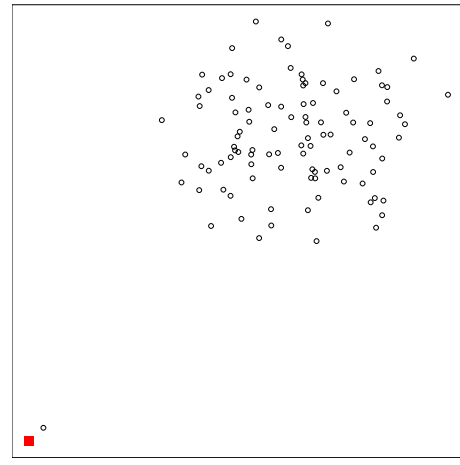

(a) Observação adicional rotulada como inlier

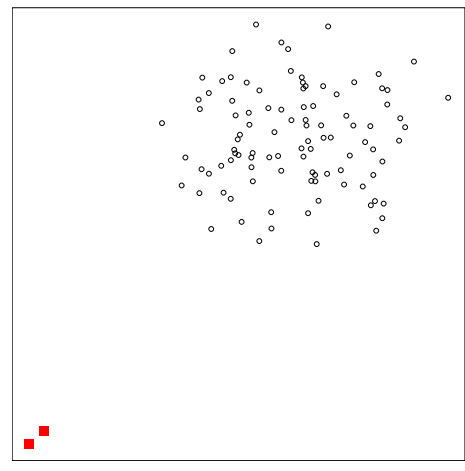

(b) Observação adicional rotulada como outlier

Figura 4.3: Presença de clump na base de dados da Figura 4.1

Ambas intuições discutidas acima podem ser incorporadas ao índice com a utilização de classificadores de margem suave com penalidade individual para cada observação (seção 3.2). Para isso, basta que na Equação (3.21) os valores de $C_{i}$ associados às observações $\mathbf{x}_{i}$ dependa das suas rotulações: caso a observação seja rotulada como inlier, o custo (penalidade) para violação da margem é integral; entretanto, se a observação for rotulada como outlier, apenas uma fração $\beta \in[0,1]$ de $C$ é utilizada, ou seja, na Equação (3.21), $C_{i}=C$ ou $\beta C$ dependendo da rotulação de $\mathbf{x}_{i}$. Repare que, no problema original de classificação, $C$ controla o compromisso entre overfitting e underfitting; aqui, entretanto, não é de interesse a generalização do classificador, então $C$ precisa apenas ser grande o suficiente para que o classificador consiga classificar as observações $\mathbf{x}_{i} \in \mathbf{S}$. Quando $\beta=1$, o índice se reduz ao índice preliminar conforme discutido na seção 4.2, em que todas observações são tratadas igualmente independente dos seus rótulos. Para $\beta=0$, as observações rotuladas como outliers não são penalizadas por violação da margem. Repare que, neste outro extremo, quando se avalia a separabilidade de uma observação específica, isto equivale a remover todas as outras observações rotuladas como outliers da base de dados. A Figura 4.4 ilustra esta intuição. Na Figura 4.4(a), quando avaliada a separabilidade da observação original (aqui rotulada em losango) utilizando $\beta=1$, a violação da margem pela observação adicional, também rotulada como outlier, será tão cara quanto a violação de uma observação rotulada como inlier, funcionando como o índice preliminar. Na Figura 4.4(b), 
a avaliação da mesma observação, mas agora utilizando $\beta=0.5$, faz com que a violação da margem pela observação adicional seja menos penalizada, fazendo com que passe valer a pena violar a margem para a observação adicional fazer que a observação avaliada fique mais distante da fronteira de decisão, consequentemente aumentando seu grau de separabilidade. Na Figura 4.4(c), a observação original é avaliada para $\beta=0$, neste cenário a violação da margem pela observação adicional não será penalizada e a fronteira de decisão será a mesma da Figura 4.1(a), como se a observação adicional não estivesse presente na base de dados. A escolha de $\beta$ controla então a influência que a rotulação das outras observações terão no momento da avaliação de uma determinada observação, capturando a segunda intuição desejada.

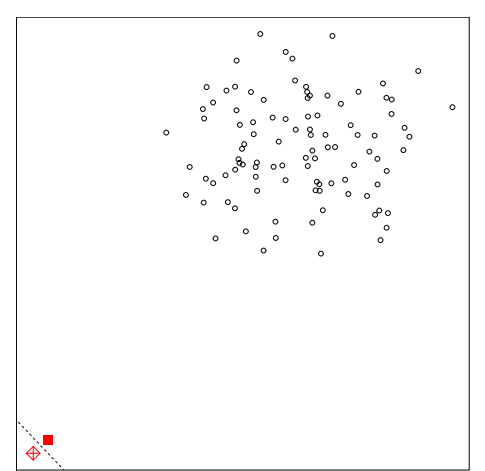

(a) Avaliação da observação em losango para $\beta=1$

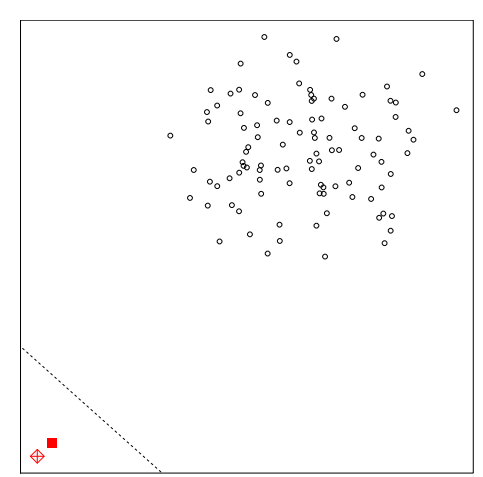

(b) Avaliação da observação em losango para $\beta=0.5$

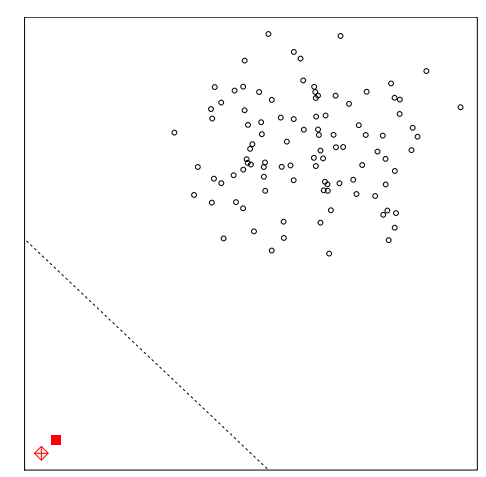

(c) Avaliação da observação em losango para $\beta=0$

Figura 4.4: Fronteira de decisão do classificador para avaliação da observação em losango

Para capturar a primeira intuição desejada e discutida anteriormente, i.e., a modelagem de possíveis clumps dado um tamanho máximo de clump $\left(m_{\text {clSize }}\right)$, pode-se configurar a fração da penalidade $C$ discutida acima como $\beta=1 / m_{c l \text { Size }}$. Desta forma, $m_{c l \text { Size }}$ será o único parâmetro opcional na medida de avaliação. O parâmetro é opcional porque, pela utilização de $m_{\text {clSize }}=1$, o método reduz-se ao caso particular $(\beta=1)$ em que os clumps não são modelados e a mesma penalidade de custo é utilizada para todas observações (índice preliminar da seção 4.2). Conforme $m_{\text {clSize }}$ aumenta, $\beta$ diminui e as observações rotuladas como outliers no clump vão individualmente afetar cada vez menos as outras ao se medir a separabilidade dessas, de forma que um número maior de observações próximas será necessário para conseguir um certo impacto negativo (penalidade). Note que utilizando $\beta=1 / m_{c l \text { Size }}$ são necessárias $m_{c l \text { Size }}$ observações rotuladas como outliers para conseguir o mesmo impacto de apenas um inlier, ou seja, uma penalidade $\beta C m_{\text {clSize }}$ vezes, portanto igual a $m_{\text {clSize }} \times \frac{1}{m_{\text {clSize }}} \times C=C$. Note também que em problemas top- $n$ de detecção de outliers seria contraditório utilizar $m_{c l \text { Size }}>n$, pelo fato de haver somente $n$ observações rotuladas como outliers nas soluções sendo avaliadas, utilizar $m_{\text {clSize }}>n$ seria sugerir que aglomerados com mais de $n$ observações devam ser considerados como possíveis outliers em um clump, mesmo sabendo da presença de apenas $n$ outliers na base de dados. Sendo assim, conceitualmente este parâmetro deveria ser utilizado entre $1 \leq m_{\text {clSize }} \leq n$. Exceto quando $m_{\text {clSize }}=1$, a separabilidade de cada observação depende dos rótulos das demais observações e, assim, procurar por uma solução que maximize o índice proposto (em vez de utilizá-lo para avaliar uma solução) torna-se uma tarefa complexa. 
Em resumo, assim como o índice preliminar apresentado na seção 4.2, IREOS é calculado utilizando a Equação (4.2), entretanto, para o cálculo do termo $p\left(\mathbf{x}_{i}, \gamma\right)$, os outliers recebem apenas uma fração $\beta=1 / m_{\text {clSize }}$ da penalidade atribuída aos inliers em caso de violação da margem.

\subsection{Ajuste para Aleatoriedade}

O índice IREOS descrito na seção anterior pode ser utilizado na prática se for de interesse a comparação em termos relativos de um conjunto de diferentes soluções candidatas, por exemplo, para seleção de modelos. Entretanto, a avaliação em termos absolutos do índice para soluções individuais, por exemplo, para validação estatística, pode ser mal interpretada pelo fato do índice fornecer valores não nulos até mesmo quando as soluções são puramente aleatórias. Para piorar, estes valores dependem dos dados. Na Figura 4.2 pode-se notar que até mesmo o inlier da Figura 4.1(c) terá um valor não nulo para a AUC de separabilidade. Para interpretação e avaliação das soluções em termos absolutos é necessário ajustar o índice para aleatoriedade. Para isso, foi utilizado o clássico framework estatístico de ajuste para aleatoriedade (Hubert and Arabie, 1985):

$$
I_{a d j}(\mathbf{S})=\frac{I(\mathbf{S})-E\{I\}}{I_{\max }-E\{I\}}
$$

em que $I_{a d j}(\mathbf{S})$ é o índice ajustado, $I(\mathbf{S})$ é o índice original da Equação 4.2 , $I_{\max }=1$ é o valor máximo que o índice pode atingir, e $E\{I\}$ é o valor esperado do índice assumindo que as $n$ observações rotuladas como outliers na solução a ser avaliada foram escolhidas de forma completamente aleatória. Em soluções aleatórias é portanto esperado valores próximos de 0 para $I_{a d j}$. O valor máximo para o índice continua sendo 1, mas agora é possível que a solução receba valores negativos, o que indica que a solução é ainda pior que uma solução aleatória, o que deve ocorrer ao se rotular sistematicamente observações indiscutivelmente inliers (sob a ótica de separabilidade) como outliers.

\subsubsection{Ajuste Exato}

O termo $E\{I\}$ na Equação 4.3 é dado a partir da Equação 4.2 como:

$$
E\{I\}=\frac{1}{n_{\gamma}} \sum_{l=1}^{n_{\gamma}} E\left\{\bar{p}\left(\gamma_{l}\right)\right\}
$$

em que $\bar{p}\left(\gamma_{l}\right)$ é a variável aleatória associada a uma solução aleatória $\mathbf{S}_{R} . E\left\{\bar{p}\left(\gamma_{l}\right)\right\}$ pode ser computada de forma exata quando utilizado $m_{\text {clSize }}=1$. Quando $m_{\text {clSize }}=1$, o classificador apenas tenta separar cada observação rotulada como outlier $\mathbf{x}_{i}$ das demais observações, não fazendo diferença os rótulos dessas demais observações. Isso mostra que $p\left(\mathbf{x}_{i}, \gamma_{l}\right)$ depende apenas dos dados e não de alguma rotulação particular de possíveis candidatos a outliers para $\mathbf{S}_{R}$, então pode-se independentemente pré-computar a separabilidade de cada observação $\mathbf{x}_{i} \in$ $\mathbf{X}$ para $\gamma_{l}\left(l=1, \ldots, n_{\gamma}\right)$. 
Sendo $\left|\mathbf{S}_{R}\right|=n$, o valor esperado $E\left\{\bar{p}\left(\gamma_{l}\right)\right\}$ pode ser obtido a partir de um resultado bem conhecido que diz que o valor esperado da média de uma amostra independente e identicamente distribuída (iid) de tamanho $n$ é a média da própria população, conforme mostrado na Equação (4.5). Aqui, para um dado $\gamma_{l}$, a população (finita) consiste dos $N$ valores pré-computados de $p\left(\mathbf{x}_{i}, \gamma_{l}\right)$ para todas observações $\mathbf{x}_{i}$ na base de dados $\mathbf{X}$, logo a sua média $E\left\{\bar{p}\left(\gamma_{l}\right)\right\}$ é conhecida de forma exata.

$$
\begin{array}{r}
E\left\{\bar{p}\left(\gamma_{l}\right)\right\}=E\left\{\frac{1}{n} \sum_{\mathbf{x}_{i} \in \mathbf{S}} p\left(\mathbf{x}_{i}, \gamma_{l}\right)\right\} \\
=\frac{1}{n} \sum_{\mathbf{x}_{i} \in \mathbf{S}} E\left\{p\left(\mathbf{x}_{i}, \gamma_{l}\right)\right\} \\
=\frac{1}{n} n E\left\{p\left(\mathbf{x}_{i}, \gamma_{l}\right)\right\} \\
=E\left\{p\left(\mathbf{x}_{i}, \gamma_{l}\right)\right\}
\end{array}
$$

\subsubsection{Validação Estatística}

Embora o valor esperado do índice para uma solução aleatória $\mathbf{S}_{R}$ possa ser calculado a partir da Equação (4.4), espera-se que exista uma variância em torno deste valor. Na Figura 4.5 é mostrado em azul a curva de separabilidade de várias soluções aleatórias, em vermelho a curva de separabilidade esperada e em vermelho tracejado o desvio padrão a partir da curva esperada. O desvio padrão não é necessário para o cálculo do índice ou para seu ajuste, porém pode ser útil para validação estatística. Conforme mostrado na Equação (4.6), a variância pode ser calculada de forma similar ao valor esperado, isto é, a variância da média da amostra é a variância da população sobre o tamanho da amostra, que pode ser exatamente computado uma vez que se tem pré-computado toda população $p(\cdot, \cdot)$. Aqui entretanto, por se tratar de uma população de tamanho finita $(N)$, pode ser necessário utilizar o Fator de Correção de População Finita (FCPF) (Triola, 2007) para ajuste da variância caso o número de outliers represente mais que $5 \%$ da base de dados $(N)$.

$$
\begin{array}{r}
V A R\left\{\bar{p}\left(\gamma_{l}\right)\right\}=V A R\left\{\frac{1}{n} \sum_{\mathbf{x}_{i} \in \mathbf{S}} p\left(\mathbf{x}_{i}, \gamma_{l}\right)\right\} \\
\frac{1}{n^{2}} \sum_{\mathbf{x}_{i} \in \mathbf{S}} V A R\left\{p\left(\mathbf{x}_{i}, \gamma_{l}\right)\right\} \\
\frac{1}{n^{2}} n V A R\left\{p\left(\mathbf{x}_{i}, \gamma_{l}\right)\right\} \\
\frac{1}{n} V A R\left\{p\left(\mathbf{x}_{i}, \gamma_{l}\right)\right\}
\end{array}
$$

Sabendo que o índice é dado pela soma das variáveis aleatórias $\bar{p}\left(\gamma_{l}\right)$ ao longo dos $\gamma_{l}$ e tendo computado suas variâncias pela Equação 4.6 , pode-se calcular a variância do índice da 


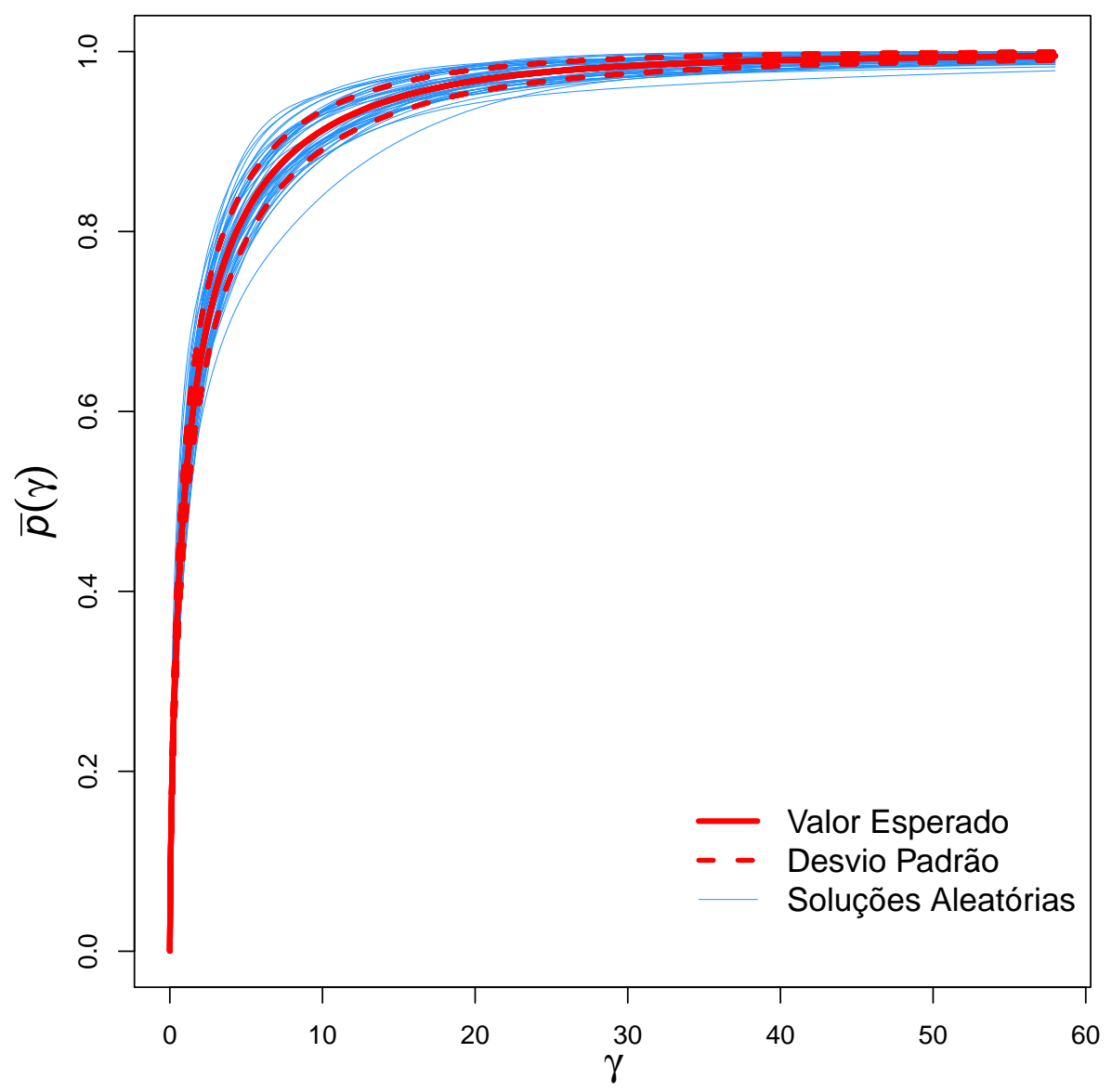

Figura 4.5: Soluções Aleatórias

seguinte forma:

$$
\begin{array}{r}
V A R\{I\}=V A R\left\{\frac{1}{n_{\gamma}} \sum_{l=1}^{n_{\gamma}} \bar{p}\left(\gamma_{l}\right)\right\} \\
\frac{1}{n_{\gamma}^{2}} V A R\left\{\sum_{l=1}^{n_{\gamma}} \bar{p}\left(\gamma_{l}\right)\right\} \\
\frac{1}{n_{\gamma}^{2}} \sum_{l, m}^{n_{\gamma}} \operatorname{COV}\left\{\bar{p}\left(\gamma_{l}\right), \bar{p}\left(\gamma_{m}\right)\right\}
\end{array}
$$

em que a $C O V\left\{\bar{p}\left(\gamma_{l}\right), \bar{p}\left(\gamma_{m}\right)\right\}$ é utilizada para considerar a possível falta de independência de $\bar{p}\left(\gamma_{l}\right)$ ao longo dos diferentes valores de $\gamma_{l}$. De forma similar ao que foi mostrado na Equação 4.6 para a variância da amostra, a covariância da amostra é igual $\operatorname{COV}\left\{\bar{p}\left(\gamma_{l}\right), \bar{p}\left(\gamma_{m}\right)\right\}=$ $\frac{1}{n} C O V\left\{p\left(\mathbf{x}_{i}, \gamma_{l}\right), p\left(\mathbf{x}_{i}, \gamma_{m}\right)\right\}$, sendo a $C O V\left\{\bar{p}\left(\gamma_{l}\right), \bar{p}\left(\gamma_{l}\right)\right\}=V A R\left\{\bar{p}\left(\gamma_{l}\right)\right\}$.

Caso o tamanho da amostra ( $n$ ) não seja muito pequena o Teorema do Limite Central (TLC) garante que, para cada $\gamma_{l}$, a média da amostra $\left(\bar{p}\left(\gamma_{l}\right)\right)$ segue pelo menos aproximadamente uma distribuição Normal, i.e. $\bar{p}(\gamma) \sim \mathcal{N}(E\{\bar{p}(\gamma)\}, V A R\{\bar{p}(\gamma)\})$. Como o índice é dado pela soma de variáveis normalmente distribuídas e sabendo que a soma de variáveis aleatórias normalmente distribuídas é também normalmente distribuída (i.e., se $X \sim \mathcal{N}\left(\mu_{X}, \sigma_{X}^{2}\right)$ e 
$Y \sim \mathcal{N}\left(\mu_{Y}, \sigma_{Y}^{2}\right)$ então $Z=X+Y \sim \mathcal{N}\left(\mu_{X}+\mu_{Y}, \sigma_{X+Y}^{2}\right)$ (Ross, 2009)), tem-se um importante resultado para o índice: como a soma das médias das amostras irá seguir pelo menos aproximadamente uma distribuição Normal de acordo com o TLC, então $I \sim \mathcal{N}(E\{I\}, V A R\{I\})$, com a média $E\{I\}$ e a variância $V A R\{I\}$ computadas de forma exata como descrito nas Equações (4.4) e (4.7) respectivamente.

Em resumo, sabendo a média e a variância da população, pode-se ir além do simples ajuste para aleatoriedade dado pela Equação 4.3 e realizar também uma validação estatística. Se for dado uma certa solução de detecção de outliers, S, e seu correspondente valor de índice ajustado, $I_{a d j}(\mathbf{S})$, pode-se avaliar a significância estatística de $I_{a d j}(\mathbf{S})$ utilizando, por exemplo, o teste $z$ (Schefler, 1988). Neste caso, o $p$-value pode ser trivialmente calculado baseado na comparação entre $I_{a d j}(\mathbf{S})$ e a hipótese nula de uma solução aleatória assumindo a hipótese de normalidade, que é garantida ao menos aproximadamente pelo TLC conforme discutido acima. Mesmo quando esta hipotese não é satisfeita, o teste $z$ se mostra robusto (Boneau, 1960).

\subsubsection{Ajuste Aproximado via Monte Carlo}

O cálculo computacional exato descrito anteriormente assume que $m_{\text {clSize }}=1$. Para diferentes configurações, $p\left(\mathbf{x}_{i}, \gamma_{l}\right)$ não pode mais ser independentemente pré-computado para cada observação $\mathbf{x}_{i} \in \mathbf{X}$, pois agora a separabilidade de uma dada observação também depende da rotulação associada às outras observações da base de dados, para cada possível solução aleatória. Isso mostra que, para um dado $\gamma_{l}$, o tamanho da população finita cresce de $N$ para $\left(\begin{array}{l}N \\ n\end{array}\right)$ e então isto pode facilmente se tornar computacionalmente intratável. Mesmo quando $m_{c l \text { Size }}$ $=1$, pré-computar $N$ termos $p\left(\mathbf{x}_{i}, \gamma_{l}\right)$ para cada $\gamma_{l}$ (i.e., $N \times n_{\gamma}$ no total) pode também ser computacionalmente proibitivo para grandes bases de dados, pois cada um desses termos exige o treinamento de um classificador.

Para tornar o ajuste para aleatoriedade e a validação estatística tratável quando $m_{\text {clSize }}>1$ ou $N$ é muito grande, pode-se utilizar simulações de Monte Carlo para estimar estatísticas ao invés de tentar computá-las de forma exata e exaustiva. A ideia é sortear um número $n_{\mathrm{MC}}$ de soluções aleatórias de detecção de outliers para que o momento estatístico desejado, e. g. $E\{I\}$ em 4.2), possa ser estimado. O tamanho da amostra, $n_{\mathrm{MC}}$, claramente representa um trade-off entre custo computacional e acurácia. Maiores amostras levarão a uma estimação mais acurada, ainda que seja necessário um maior número de classificadores para serem treinados. Para estimação de $E\{I\}$, o tamanho da amostra pode ser automaticamente determinado a partir do intervalo de confiança $(L)$ que se deseja que $E\{I\}$ esteja, utilizando uma estimativa do desvio padrão (s) e um nível de significância $(\alpha)$ (Triola, 2007):

$$
n_{\mathrm{MC}}=\left(\frac{(\alpha / 2) s}{L}\right)^{2}
$$

Quando se deseja também a validação estatística, é necessário estimar a distribuição sob a hipótese nula. Existem diferentes alternativas. Se a normalidade é assumida utilizando TLC, uma abordagem paramétrica é possível baseada na distribuição $t$ de student utilizando um teste 
$t$, que é sabido ser robusto mesmo quando a normalidade não é completamente satisfeita $(\overline{B o-}$ neau, 1960). Alternativamente, $p$-values podem ser diretamente derivados de histogramas observados em uma abordagem não paramétrica (Jain and Dubes, 1988).

\subsection{Algoritmo e Complexidade}

Um pseudo código em alto nível para computação de IREOS para um conjunto $\Omega$ de soluções top- $n$ de detecção de outliers é apresentado no Algoritmo 1. Inicialmente é necessário encontrar o valor $\gamma_{\max }$ para discretizar $\gamma$ em $n_{\gamma}$ valores no intervalo $\left[0, \gamma_{\max }\right]$. Após isso, cada solução $\mathbf{S} \in \Omega$ é avaliada por meio da separabilidade de cada observação $\mathbf{x}_{i} \in \mathbf{S}$ ao longo dos diferentes valores de $\gamma \in \Gamma$. No passo 7 a separabilidade de cada observação $\mathbf{x}_{i} \in \mathbf{S}$ é avaliada para cada $\gamma \in \Gamma$. Utilizando um classificador de máxima margem é calculada a distância de cada observação $\mathbf{x}_{i} \in \mathbf{S}$ para fronteira de decisão traçada pelo classificador para cada $\gamma \in \Gamma$. Conforme discutido na seção 4.3 , apenas uma fração $\beta=\frac{1}{m_{\text {clSize }}}$ da penalidade para violação da margem é aplicada para as observações $\mathbf{x}_{i} \in \mathbf{S}$. No passo 8 é calculada a média das separabilidades das observações $\mathbf{x}_{i} \in \mathbf{S}$ para cada $\gamma \in \Gamma$, para que no passo 9 seja computado o índice IREOS da solução $\mathbf{S}$ dado pela Equação (4.2) a partir da curva média de separabilidade das observações $\mathbf{x}_{i}$ ao longo dos diferentes valores de $\gamma \in \Gamma$. Por fim, no passo 9 é oferecido um ajuste para aleatoriedade opcional, caso o interesse vá além de apenas uma comparação em termos relativos.

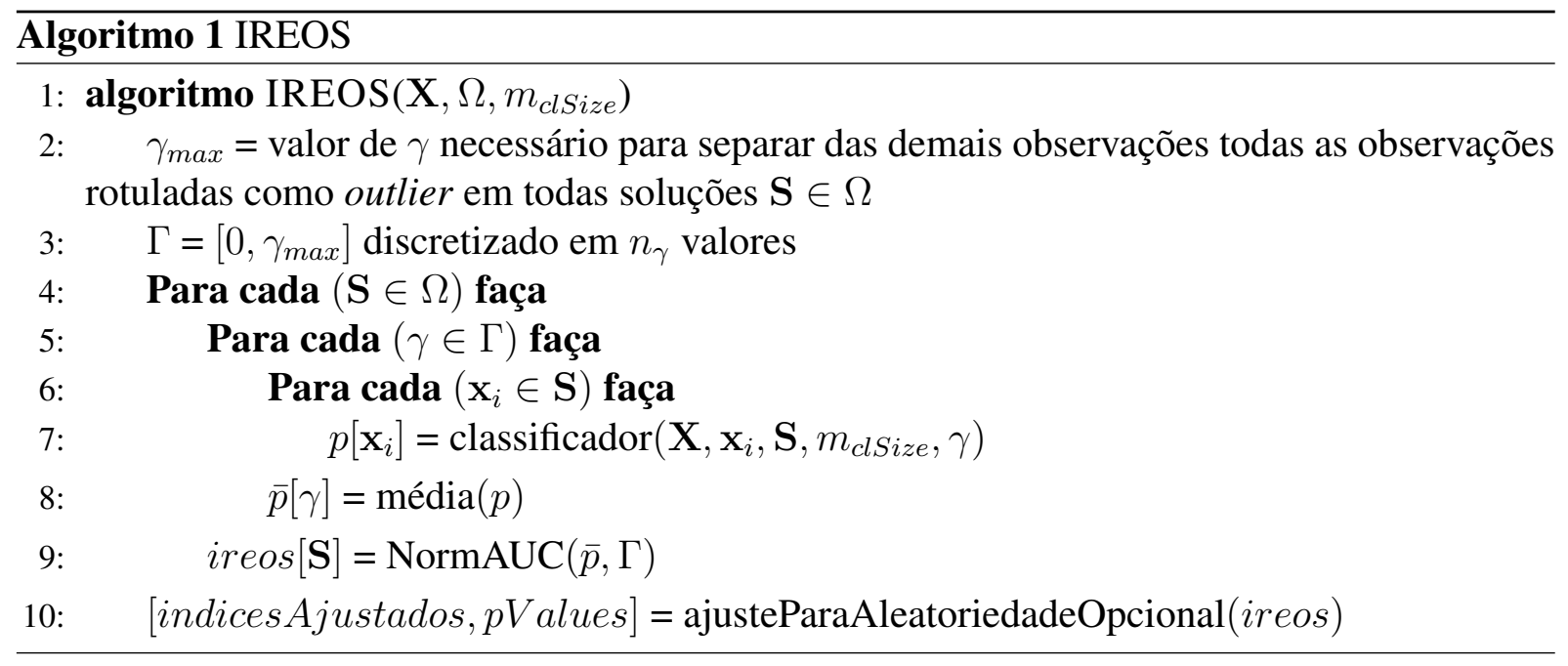

A complexidade computacional do algoritmo depende da complexidade do classificador utilizado, sendo a complexidade do classificador uma função $\mathcal{O}(f(N, d))$ do tamanho da base de dados, $N$, e dimensionalidade, $d$. O cálculo do índice IREOS (Equação 4.2) é realizado para cada uma das soluções candidatas $\mathbf{S} \in \Omega$. Para cada solução avaliada, o cálculo do índice demanda o treinamento de $n \times n_{\gamma}$ classificadores, o que resulta em $\mathcal{O}\left(n \times n_{\gamma} \times f(N, d)\right)$. Quando o índice é ajustado para aleatoriedade é necessário avaliar $n_{\mathrm{MC}}$ diferentes soluções aleatórias via simulações de Monte Carlo para estimar o índice esperado, o que demanda $\mathcal{O}\left(n_{\mathrm{MC}} \times\right.$ $\left.n \times n_{\gamma} \times f(N, d)\right)$. Esta é então a complexidade no caso mais geral. Para casos práticos que um classificador de máxima margem deve ser escolhido, tem-se que a complexidade do 
$\underline{\mathrm{SVM}}$ é de $\mathcal{O}\left(d \times s v \times N^{2}\right)$, em que $s v$ é o número de support vectors, no caso da KLR a complexidade é de $\mathcal{O}\left(d \times N^{3}\right)$, sendo assim, a complexidade da medida utilizando $\mathbf{S V M} \mathrm{e} \mathbf{\mathrm { KLR }}$ seriam respectivamente $\mathcal{O}\left(s v \times d \times N^{2} \times n_{\mathrm{MC}} \times n \times n_{\gamma}\right)$ e $\mathcal{O}\left(d \times N^{3} \times n_{\mathrm{MC}} \times n \times n_{\gamma}\right)$. Note que o custo computacional para geração das soluções a serem avaliadas não é considerado. A redução da complexidade é um tópico interessante para trabalhos futuros, mas apesar disso, pode-se considerar a atual complexidade não é um problema crítico pela seguinte razão: cada classificador pode ser treinado de forma completamente independente. Então, caso se tenha $\mathcal{O}\left(n_{\mathrm{MC}} \times n \times n_{\gamma}\right)$ processadores para processamento paralelo, a complexidade se reduz à complexidade do classificador. Em outras palavras, IREOS é altamente paralelizável e pode ser implementado em ambientes distribuídos usando frameworks para computação paralela, tais como MapReduce (Dean and Ghemawat, 2008). 



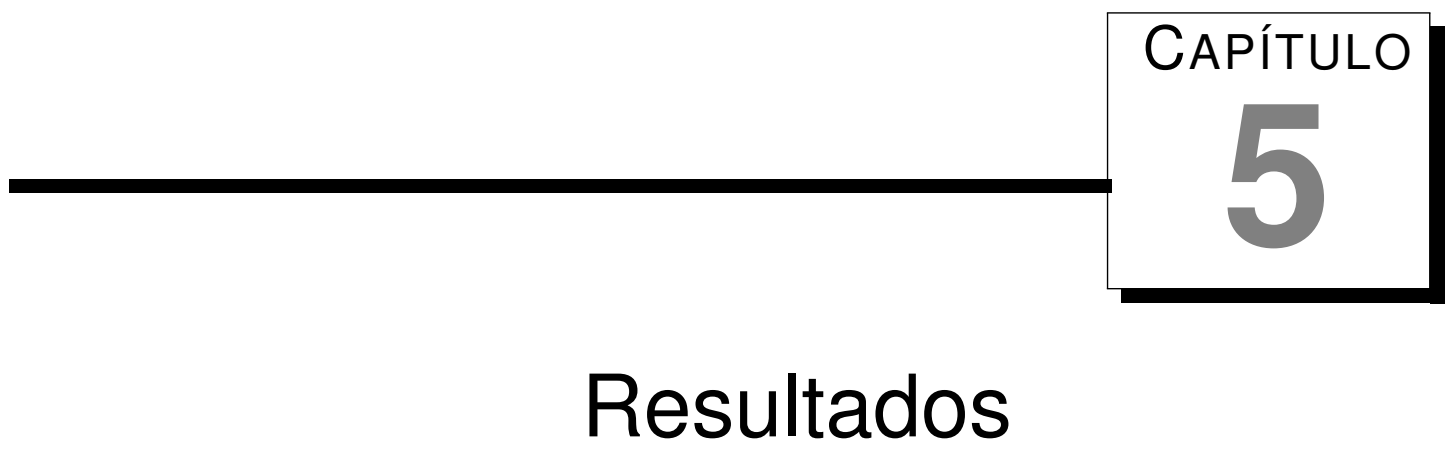

Neste Capítulo são discutidos os resultados dos experimentos envolvendo avaliação e seleção de modelos em diferentes coleções de bases de dados sintéticas e reais para avaliação de IREOS. Na seção 5.1 ambas coleções de bases sintéticas e reais utilizadas nos experimentos são apresentadas. Na seção 5.2 a metodologia utilizada na realização dos experimentos é introduzida, assim como a descrição dos experimentos realizados. Por fim, na seção 5.3 os resultados dos experimentos realizados são apresentados e discutidos.

\subsection{Bases de Dados}

Base de dados rotuladas para problemas de detecção de outliers não são comuns, tipicamente o que se encontra na literatura são bases de dados de classificação que sofrem algum tipo de pré-processamento para a rotulação dos outliers. Existem diferentes procedimentos para a rotulação. Tais procedimentos podem, por exemplo, rotular as observações de acordo com a semântica de outlier ou então utilizando métodos estatísticos. Para realização dos experimentos foram utilizadas bases de dados sintéticas e reais seguindo diferentes procedimentos encontrados na literatura para a rotulação dos outliers. As rotulações em questão são utilizadas aqui apenas como ground truth, ou seja, como referencial ideal de solução ótima. Tais rótulos não são evidentemente utilizados por \REOS ou por algoritmos de detecção não supervisionados que geram soluções a serem avaliadas por \REOS

\subsubsection{Bases Sintéticas}

Foram utilizadas duas coleções de bases de dados sintéticas para a realização dos experimentos, sumarizados na Tabela 5.1 e descritas abaixo: 
- Coleção de bases Zimek et al. (2013) (ZMK): A primeira coleção foi desenvolvida e utilizada para avaliação de métodos de detecção de outliers (Zimek et al., 2013). As bases de dados foram geradas em dois conjuntos independente de 30 bases sintéticas (batch 1 e batch 2). As bases de dados variam independentemente na dimensionalidade $d \in[20,40]$, no número de grupos $c \in[2,10]$ e no número de observações para cada grupo $n_{c i} \in[600,1000]$. Cada grupo foi gerado seguindo uma distribuição Normal com os parâmetros selecionados aleatoriamente e independentemente. Para a rotulação dos outliers foi calculada a distância de Mahalanobis de cada observação para o centro do seu grupo. Sabendo que a distância de Mahalanobis segue uma distribuição $\chi^{2} \operatorname{com} d$ graus de liberdade quando aplicada a dados que seguem uma distribuição Normal, foram rotuladas como outliers as observações que tiveram distância para o centro de seus respectivos grupos maior que o quartil teórico de 0,975 . Seguindo este procedimento é esperado que cerca de $2,5 \%$ dos dados sejam rotulados como outliers.

- Coleção de bases Handl et al. (2005) (HDL): A segunda coleção é composta de 40 bases sintéticas bi-dimensionais, desenvolvida originalmente para avaliação de métodos de agrupamento de dados (Handl et al. 2005). A coleção contém bases com 4, 10, 20 e 40 grupos, o número de observações é selecionado uniformemente entre $[50,500]$ para as bases com 4 e 10 grupos e entre $[10,100]$ para as bases com 20 e 40 grupos. O mesmo procedimento utilizado por (Zimek et al., 2013) (descrito acima) foi utilizado para a rotulação dos outliers, entretanto, para as bases desta coleção os parâmetros das distribuições são desconhecidos, sendo assim calculados a partir dos dados.

\begin{tabular}{ccccccc}
\hline Coleção & Bases & Dimensões & Grupos & Observações & Outliers & \multicolumn{2}{c}{ Referência } \\
\hline HDL & 40 & 2 & {$[4,40]$} & {$[863,3630]$} & {$[17,90]$} & Handl et al. $(2005)$ \\
[ZMK & 60 & {$[20,40]$} & {$[2,10]$} & {$[1359,7730]$} & {$[33,201]$} & Zimek et al. $(2013)$ \\
\hline
\end{tabular}

Tabela 5.1: Bases de dados sintéticas

\subsubsection{Bases Reais}

Além das duas coleções de bases sintéticas, foram utilizadas 7 bases de dados reais. Com exceção da base Brain and Weight 1 , todas as demais estão disponíveis no repositório UCI $\mathrm{Ba}$ che and Lichman, 2013). Esses bases de dados são originalmente utilizadas em problemas de classificação, entretanto, aqui tais bases foram modificadas utilizando procedimentos comuns da literatura, por exemplo, um procedimento comum é a subamostragem de uma das classes para assegurar que as respectivas observações são pouco frequentes com relação às demais classes. Esta classe subamostrada é considerada então como a classe outlier simplesmente porque agora ela é rara, a semântica da classe original não é considerada neste tipo de rotulação arbitrária.

1http://cran.r-project.org/package=robustbase 
Uma abordagem oposta, é utilizar a semântica para escolha das observações que serão consideradas outliers, por exemplo, a escolha de clientes com perfil de consumo elevado. Nesta abordagem, é esperado que haja um desbalanceamento natural entre as proporções de outliers e inliers, que idealmente não precisaria ser artificialmente imposto por um procedimento de subamostragem. Os procedimentos aplicados nas bases de dados utilizadas, assim como breve descrição são sumarizadas na Tabela 5.2 e descritos abaixo:

- Annthyroid: Esta base de dados contém informações médicas, descritas em 6 atributos, relacionadas ao funcionamento da tireoide de 3656 pacientes. O objetivo é determinar se o paciente possui hiperfunção, funcionamento subnormal ou funcionamento normal. Seguindo o procedimento utilizado por Keller et al. (2012) os pacientes que possuem hipertiroidismo foram rotulados como outliers, tal procedimento é baseado na semântica da classe.

- Brain and Weight: Esta base contém dois atributos, formados pelo log do peso do cérebro e pelo log do peso do corpo de 65 diferentes espécies de animais, em que os outliers são espécies que tenham um cérebro pequeno em relação ao peso do seu corpo. 3 espécies de dinossauros (Brachiosaurus, Triceratops e Diplodocus) foram rotuladas como outliers seguindo o procedimento utilizado por (Rousseeuw and Leroy, 1987), aqui a distância de Mahalanobis foi utilizada como procedimento para determinação das observações que seriam rotuladas como outliers, além do procedimento estatístico realizado, pode-se notar que a rotulação de tais observações também possui uma semântica.

- Lymphography: Base de dados contém 148 resultados de exames radiológicos do sistema linfático. A partir dos 18 atributos é possível classificar os exames como: normal, fibrose, maligno ou metástase. Utilizando o procedimento realizado por Lazarevic and $\mathrm{Ku}-$ $\operatorname{mar}(2005)$ as observações pertencentes às classes normal e fibrose foram rotuladas como outliers. Aqui a rotulação das observações como outliers é totalmente contra-intuitivo, a rotulação é baseada simplesmente no fato das classes serem raras, sem nenhuma semântica associada.

- Shuttle: Base de dados contém 9 atributos de dados relacionados a aeronaves. As observações podem ser classificadas em 7 classes diferentes. Para a rotulação dos outliers foi utilizado o procedimento realizado por Zhang et al. (2009): as classes 1, 3, 4, 5, 6, 7 foram utilizadas para representar os inliers e a classe 2 para representar os outliers. Foram subamostrados aleatoriamente para 1000 inliers e 13 outliers. Novamente a rotulação segue o procedimento de subamostragem, em que as observações são consideradas outliers apenas devido ao fato de pertencerem a classe rara.

- Vowel: Base de dados utilizada para reconhecimento de fala de 11 vogais do inglês britânico. Cada vogal representa uma classe que é descrita por 10 atributos. Seguindo o procedimento de Micenkova et al. (2013) a classe 0 foi rotulada como inlier e seguindo o procedimento de subamostragem comumente utilizado, cada uma das outras classes foi 
subamostrada para apenas 1 observação para então representar os outliers pelo fato de serem raros.

- Wisconsin Breast Cancer (WBC): A base de dados possui 223 amostras de tumores de mama descritos por 9 atributos, sendo considerados os tumores malignos como outliers e os tumores benignos como os inliers. Apesar desta base possuir a semântica de outlier, para utilização dela foi realizado o mesmo procedimento feito por Schubert et al. (2012), subamostrando os outliers para apenas 10 observações.

- Wisconsin Diagnostic Breast Cancer (WDBC): Esta base de dados é descrita por 30 características nucleares de 367 diagnósticos de câncer de mama. Novamente os tumores benignos foram considerados inliers enquanto os malignos foram rotulados como outliers e a classe outlier foi subamostrada para somente 10 observações. O procedimento utilizado foi realizado por Zhang et al. (2009).

\begin{tabular}{lcccl}
\hline Base de dados & Dimensões & Observações & Outliers & \multicolumn{1}{c}{ Referência } \\
\hline Annthyroid & 6 & 3656 & 93 & Keller et al. (2012) \\
Brain and Weight & 2 & 65 & 3 & Rousseeuw and Leroy (1987) \\
Lymphography & 18 & 148 & 6 & Lazarevic and Kumar (2005) \\
Shuttle & 9 & 1013 & 13 & Zhang et al. (2009) \\
Vowel & 10 & 100 & 10 & Micenkova et al. (2013) \\
WBC & 9 & 223 & 10 & Schubert et al. (2012) \\
WDBC & 30 & 367 & 10 & Zhang et al. (2009) \\
\hline
\end{tabular}

Tabela 5.2: Bases de dados reais

\subsection{Metodologia}

Os resultados foram avaliados comparando a avaliação feita pelo índice IREOS com a avaliação feita a partir do ground truth. Note que os rótulos do ground truth não são utilizados por IREOS no processo de avaliação da solução de detecção de outliers, tais rótulos são utilizados apenas para comparação entre a medida de qualidade fornecida por IREOS e a medida de qualidade de acordo com o ground truth. Para avaliar a qualidade da solução de acordo com o ground truth foi utilizada a precision-at-n (medida apresentada em maiores detalhes no Apêndice A.1), em que $n$ (número de outliers na solução a ser avaliada) é o mesmo que o número de outliers presente no ground truth. Note que utilizar a área sob a curva $\mathrm{ROC}$ não faz sentido, uma vez que não estão sendo avaliados rankings das soluções, mas sim soluções top- $n$ de detecção de outliers, em que somente a rotulação das $n$ primeiras observações ranqueadas importam.

Dois tipos de experimentos foram realizados:

- Correlação entre Precision-at-n e IREOS: O primeiro é um experimento controlado em que foi produzido para cada base de dados uma coleção de soluções artificiais de detecção de outliers variando a precision-at- $n$ de 0 até 1 . Para isso, foi utilizado o ground 
truth (precision-at- $n=1$ ) como solução inicial e então substituído iterativamente cada outlier do ground truth por um inlier escolhido aleatoriamente, tendo no final uma solução em que todas observações rotuladas como outliers são de fato inliers de acordo com o ground truth (precision-at- $n=0$ ). Desta forma, a cada iteração a precision-at- $n$ é reduzida gradativamente e ao final são geradas $n+1$ soluções para serem avaliadas pelo índice IREOS, Para avaliar a medida de qualidade fornecida por IREOS para cada uma das $n+1$ soluções geradas, foi comparada a precision-at- $n$ com a medida de qualidade fornecida por IREOS. Não é esperado que o valor fornecido por IREOS seja aproximadamente igual a precision-at- $n$, porém é esperado que soluções boas (alta precision-at- $n$ ) sejam melhores avaliadas por IREOS que as soluções ruins (baixa precision-at- $n$ ). Sendo assim, as soluções foram ranqueadas de acordo com a medida de qualidade fornecida pelo índice \REOS e é esperado que as soluções melhores ranqueadas tenham maior precision$a t-n$. Para capturar essa ideia foi computada a correlação de Spearman entre o ranking de acordo com IREOS e ranking de acordo com precision-at- $n$. Este experimento foi realizado para todas as bases apresentadas na seção 5.1, sintéticas e reais.

- Seleção de Modelos: Para as bases de dados reais também foi realizado um experimento mais prático envolvendo seleção de modelos. Para cada base de dados foi gerada uma coleção de soluções candidatas rodando o algoritmo LOF (apresentado na seção 2.2.3 variando o tamanho da vizinhança de $k=2$ até 50 utilizando passos $=3$, gerando ao final 17 soluções candidatas para cada base de dados. Cada solução candidata é composta das top- $n$ observações com maiores scorings de outlier de acordo com o critério utilizado pelo LOF quando rodado o algoritmo com a determinada configuração de $k$ (ou seja, cada solução top- $n$ é gerada binarizando a solução original correspondente gerada por LOF na forma de scorings). A melhor solução avaliada de acordo com \REOS foi então comparada com a melhor solução, com a pior solução e com a solução esperada (média) de acordo com a precision-at- $n$ das soluções candidatas usando o ground truth.

Para todos experimentos realizados, foi utilizado o classificador KLR Apesar de ser possível utilizar qualquer outro classificador de máxima margem, KLR oferece as seguintes vantagens: i) automaticamente fornece $p\left(\mathbf{x}_{i}, \gamma_{l}\right)$ como probabilidade de cada observação $\mathbf{x}_{i}$ pertencer à classe positiva (outlier); ii) esses termos não apenas são fornecidos diretamente pelo classificador, mas são também normalizados (como probabilidade) no intervalo [0,1]; iii) KLR é um classificador conhecido por ser robusto mesmo na presença de classes desbalanceadas e com pequeno número de observações para treinamento.

\REOS foi avaliado utilizando $m_{c l \text { Size }}$ com ambos os extremos do intervalo válido discutido na seção 4.3 , que representa o caso com $\left(m_{\text {clSize }}=n\right)$ e sem $\left(m_{\text {clSize }}=1\right)$ o mecanismo opcional para modelagem dos clumps. O número de valores de $\gamma$ discretizados para o cálculo do índice foi de $n_{\gamma}=100$ em todos os experimentos. Para o valor do custo da penalidade para violação da margem $(C)$, que apenas precisa ser suficientemente grande, foram realizados

\footnotetext{
${ }^{2}$ LOF foi escolhido pelo fato de ser um algoritmo clássico que está entre os mais populares e efetivos métodos da literatura
} 
experimentos com diferentes valores. Conforme esperado, os resultados são muitos similares e as conclusões não se alteram. Um exemplo para o primeiro tipo de experimento descrito nesta seção e aplicado à coleção de bases HDL é mostrado na Tabela 5.3. Note que o resultado das correlações são muito similares para os valores de $C$ de 100 até 800000 . Por esta razão, em todos os demais experimentos foi utilizado apenas $C=1000$.

\begin{tabular}{lcc}
\hline Custo & $m_{\text {clSize }}=1$ & $m_{\text {clSize }}=n$ \\
\hline 100 & $0.996 \pm 0.009$ & $0.997 \pm 0.008$ \\
1000 & $0.998 \pm 0.004$ & $0.994 \pm 0.020$ \\
20000 & $0.998 \pm 0.001$ & $0.995 \pm 0.010$ \\
800000 & $0.997 \pm 0.003$ & $0.996 \pm 0.009$ \\
\hline
\end{tabular}

Tabela 5.3: Correlação de Spearman entre IREOS e precision-at- $n$ variando o Custo $C$ : coleção de bases de dados HDL

\subsection{Experimentos}

Nesta seção são discutidos os resultados dos experimentos descritos na seção anterior.

\subsubsection{Correlação entre Precision-at-n e IREOS}

Os resultados para os experimentos controlados descritos na seção anterior são sumarizados na Tabela 5.4, para ambas coleções de bases reais e sintéticas. Para as coleções de bases sintéticas são apresentados a média e o desvio padrão dos respectivos resultados. Pode-se perceber a partir dessa tabela, com total de 107 bases de dados, que IREOS em quase todos os casos possui correlação extremamente alta com o ground truth (precision-at-n), para ambas configurações de $m_{\text {clSize }}$. Um típico exemplo é apresentado na Figura 5.1, que corresponde a uma das bases de dados da coleção HDL(2d-10c-no2) utilizando IREOS com $m_{\text {clSize }}=1$. As curvas de separabilidade média que são utilizadas para computar IREOS são mostradas para todo o conjunto de soluções candidatas (linhas sólidas), que são coloridas de acordo com a precision-at- $n$. Claramente, pode-se notar que a temperatura da cor é altamente correlacionada com as áreas das curvas. De fato, pode-se ver pela comparação entre os valores de IREOS e precision-at- $n$ (prec@n) (mostrados à direita) que os rankings das soluções de acordo com ambas as medidas (interna e externa) são exatamente os mesmos. A curva que é esperada para uma solução aleatória (tracejada) e mais/menos um desvio padrão (pontilhada) também são mostradas na figura. Essas curvas seguindo a hipótese de aleatoriedade foram computadas da forma exata descrita na seção 4.4 e os valores correspondentes foram utilizados para o ajuste do índice conforme descrito na seção 4.4. Os valores de p-values também foram computados e mostrados para cada solução. Como esperado, soluções com valores de \REOS ajustado próximos de 0 são de fato compostas basicamente de observações selecionadas aleatoriamente e são também as com maiores p-values. 


\begin{tabular}{lcc}
\hline Base de dados & $m_{\text {clSize }}=1$ & $m_{\text {clSize }}=n$ \\
\hline HDL & $0.995 \pm 0.011$ & $0.996 \pm 0.012$ \\
\hline ZMK & $0.998 \pm 0.004$ & $0.994 \pm 0.020$ \\
\hline Annthyroid & 0.999 & 0.999 \\
Brain and Weight & 1.000 & 1.000 \\
Lymphography & 1.000 & 1.000 \\
Shuttle & 0.520 & 0.995 \\
Vowel & 1.000 & 1.000 \\
WBC & 0.972 & 0.972 \\
WDBC & 1.000 & 1.000 \\
\hline
\end{tabular}

Tabela 5.4: Correlação de Spearman entre IREOS e precision-at- $n$

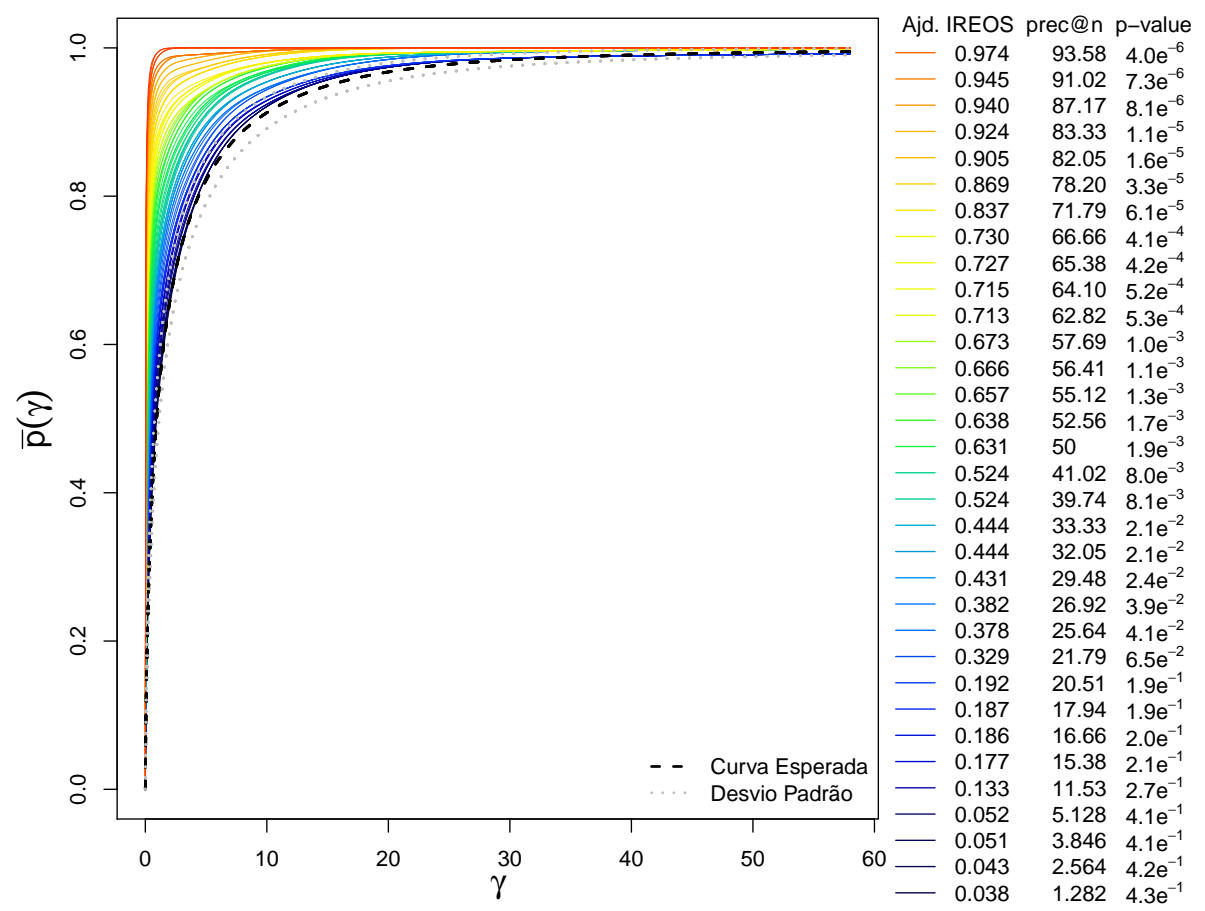

Figura 5.1: Curva de separabilidade para soluções controladas: cores refletem o ground truth (cores quentes com maior precision-at- $n$ )

Para a mesma base de dados da Figura 5.1, foi também avaliado o trade-off entre o custo computacional e a acurácia controlada pelo tamanho da amostra $n_{\mathrm{MC}}$ quando o ajuste para aleatoriedade é realizado de forma aproximada usando simulações de Monte Carlo (ao invés da maneira exata). Foi comparado o resultado entre o valor exato e o valor aproximado do valor esperado do índice $E\{I\}$ utilizando amostras que levam a 1\%,2\%,5\%,10\% e $20 \%$ do número de classificadores necessários para o cálculo exato. Em 30 simulações independentes de Monte Carlo para cada amostra, a diferença absoluta entre o valor exato e o aproximado de $E\{I\}$ no pior caso foram $0.068,0.044,0.018,0.012$ e 0.01 , respectivamente. Como esperado, a estimativa torna-se mais acurada na medida que $n_{\mathrm{MC}}$ aumenta. 


\subsubsection{Seleção de Modelos}

Os resultados para o experimento de seleção de modelos para várias soluções candidatas de LOF são sumarizados na Tabela 5.5, em que a precision-at- $n$ é mostrada para o pior (Min), esperado (Média) e melhor (Max) caso entre as soluções candidatas geradas pelo LOF de acordo com o ground truth; ao lado mostra-se a precision-at- $n$ para a solução selecionada como a melhor de acordo com IREOS. Pode-se ver que usando IREOS com $m_{\text {clSize }}=n$ selecionariase a melhor solução de acordo com o ground truth em 6 das 7 bases de dados. Para IREOS com $m_{\text {clSize }}=1$, essa escolha seria feita em 3 das 7 bases de dados, enquanto para as outras 3, a escolha seria melhor ou competitiva com o caso médio. Em todos os casos as piores soluções são evitadas, o que não poderia ser garantido em uma configuração completamente não supervisionada.

\begin{tabular}{lccccc}
\hline Base de dados & Min & Max & Média & IREOS $\left(m_{\text {clSize }}=1\right)$ & IREOS $\left(m_{\text {clSize }}=n\right)$ \\
\hline Annthyroid & 0.054 & 0.279 & 0.204 & 0.279 & 0.279 \\
Brain and Weight & 0.000 & 1.000 & 0.431 & 0.333 & 1.000 \\
Lymphography & 0.333 & 0.667 & 0.500 & 0.667 & 0.667 \\
Shuttle & 0.077 & 0.385 & 0.181 & 0.308 & 0.385 \\
Vowel & 0.100 & 0.900 & 0.553 & 0.900 & 0.400 \\
WBC & 0.000 & 0.800 & 0.324 & 0.700 & 0.800 \\
WDBC & 0.100 & 0.900 & 0.765 & 0.700 & 0.900 \\
\hline
\end{tabular}

Tabela 5.5: Precision-at-n para soluções de LOF variando $k$

O fato da maioria dos procedimentos adotados na literatura para a adaptação das bases de dados para detecção de outliers rotularem observações que originalmente formam uma classe/grupo como outliers pode explicar o porquê da utilização do $m_{c l \text { Size }}=n$ ter apresentado melhores resultados. O procedimento de rotular a classe minoritária ou subamostrar uma das classes, que é o procedimento adotado nas 5 das 7 bases de dados utilizadas nesse trabalho, pode fazer com que as observações rotuladas como outliers formem clumps entre si, sendo assim, intuitivamente a modelagem desses possíveis clumps deve produzir melhores resultados. As bases de dados Brain and Weight e Vowel são as duas bases de dados que não seguem tal procedimento. Entretanto, nota-se visualmente que na base Brain and Weight (Figura A.1) os outliers formam entre si um clump, o que justificaria o melhor resultado com a utilização do $m_{\text {clSize }}=n$. A base de dados Vowel foi a única que obteve um resultado pior com a utilização do $m_{\text {clSize }}=n$, provavelmente devido ao procedimento adotado para sua adaptação, aqui as observações rotuladas como outliers pertencem cada uma a um grupo diferente, então, intuitivamente tais grupos estão suficientemente separados de forma que quando a observação do grupo é subamostrada para rotulá-la como outlier ela não forme clump com as observações subamostradas dos demais grupos. 


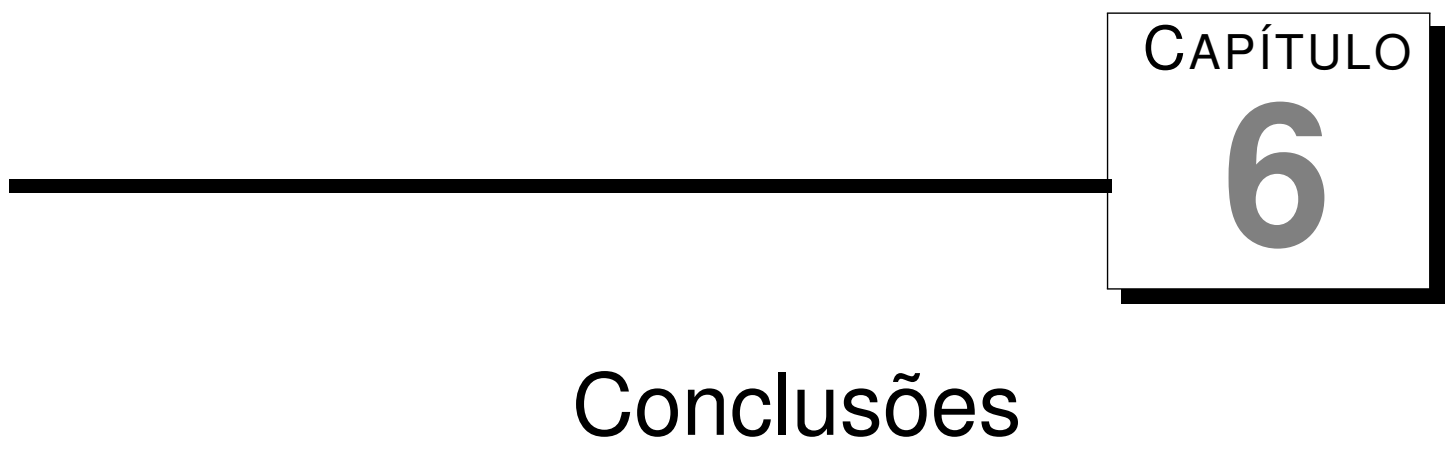

Neste trabalho foram investigados os problemas de seleção de modelos e avaliação (ou validação) de resultados em detecção não supervisionada de outliers, isto é, automaticamente e sem utilizar informações externas (tais como rótulos), selecionar as melhores soluções, que correspondem aos modelos (algoritmos, parâmetros) mais adequados, e avaliar a qualidade dos resultados produzidos por algoritmos não supervisionados de detecção de outliers. Esses problemas têm sido investigados ao longo de décadas na área de agrupamento de dados, mas são raramente mencionados e estavam até então praticamente intocados na área de detecção de outliers. Para solucionar tais problemas foi proposto um índice de validação interna e relativa, chamado IREOS (Internal, Relative Evaluation of Outlier Solutions). IREOS é a primeira medida em detecção de outliers que automaticamente avalia diferentes soluções e consequentemente permite a escolha das mais promissoras sem utilizar qualquer informação externa. Além disso, foram apresentadas propriedades de IREOS, tais como sua estatística, cálculo do $p$-value, ajuste para aleatoriedade e aspectos adicionais desejáveis para uma medida de avaliação interna de qualidade de soluções de detecção que não permite que a medida seja reduzida a mais um método de detecção.

IREOS foi extensivamente avaliado em experimentos envolvendo diferentes coleções de bases de dados sintéticas e reais. Parte dos experimentos envolveram soluções controladas com diferentes níveis de precision-at-n, com o intuito de verificar a correlação entre a avaliação feita pelo índice IREOS (que não utiliza qualquer informação externa) e a avaliação a partir do ground truth. Outra parte dos experimentos envolveu soluções geradas a partir da binarização de rankings produzidos pelo algoritmo clássico LOF, utilizando diferentes valores de parâmetros. Esse experimento teve como objetivo verificar a efetividade de IREOS para seleção de modelos, nesse caso em específico a seleção do parâmetro $k$ (tamanho da vizinhança) do método LOF mais adequado para as bases de dados testadas. Em ambos experimentos os resultados de IREOS apresentaram alta correlação com a qualidade medida a partir do ground truth. 
De forma geral, o índice proposto cumpriu os objetivos propostos neste trabalho com respeito à avaliação e seleção de modelos em detecção não supervisionada de outliers. Os resultados apresentados pelo índice para avaliação e seleção de modelos mostraram alta correlação com os resultados medidos a partir do ground truth. Além disso, o índice apresenta várias propriedades interessantes para uma medida de avaliação interna de qualidade.

\subsection{Limitações e Trabalhos Futuros}

Dentre as principais limitações de \REOS está o alto custo computacional e a impossibilidade de comparar soluções com diferentes números de outliers. Ambas limitações são possíveis temas para trabalhos futuros: a aceleração do tempo computacional utilizando índice espaciais e implementação paralelas e distribuídas, e a extensão do índice para comparação entre soluções com diferentes números de outliers. Além disso, devido à ampla maioria dos algoritmos bem conhecidos de detecção não supervisionada de outliers produzirem soluções em forma de scorings/rankings (ao invés de soluções binárias top- $n$ ), é interessante o desenvolvimento de uma medida para avaliação e seleção de modelos para soluções dadas nessa forma, assim como determinar automaticamente o número de outliers presente na base de dados devido a vários cenários de aplicação em que é necessário que o algoritmo retorne apenas as observações consideradas outliers. Ambas são questões de pesquisa interessante para trabalhos futuros e que ainda permanecem em aberto na literatura. 
APÊNDICE

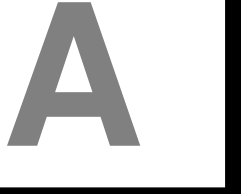

\section{Medidas de Avaliação Externa de Detecção de Outliers}

O procedimento de avaliação de algoritmos de detecção de outliers usualmente adotado na literatura é baseado na utilização de bases de dados previamente rotuladas, nas quais os outliers (segundo alguma intuição particular) são previamente conhecidos. No contexto não supervisionado, os rótulos não são utilizados pelo algoritmo em si, mas para avaliar os resultados produzidos por este. Especificamente, a categorização binária ou o ranking das observações produzidos pelo algoritmo são comparados com a rotulação considerada correta e previamente conhecida (ground truth). Tais procedimentos, conhecidos como avaliação (ou validação) externa, originalmente surgiram nas áreas de classificação de padrões e recuperação de informação onde a suposição de uma base de dados pré-rotulada é consistente, entretanto, em detecção não supervisionada de outliers, onde tal suposição é inconsistente, esses procedimentos de avaliação não são viáveis em aplicações práticas, sendo restritos à experimentos controlados. Neste Apêndice duas das medidas mais utilizadas na literatura de detecção de outliers são apresentadas. Na seção A.1 é apresentada uma medida externa para avaliação de soluções top- $n$ de detecção de outliers e na seção A.2 uma medida externa para avaliação de rankings.

\section{A.1 Precision-at- $n$}

Em um problema top- $n$ de detecção de outliers, em que deseja-se avaliar uma solução $\mathrm{S}$, que consiste de $n$ observações ditas serem outliers, i.e. $|\mathbf{S}|=n$, dado o ground truth $\mathbf{G}$ que são as $n$ observações previamente sabidas serem os corretos outliers, i.e. $|\mathbf{G}|=n$. Precision-at- $n$ (prec@n) mede a fração de outliers no ground truth $\mathbf{G}$ que são detectados como outliers na 
solução S que está sendo avaliada (Equação A.1).

$$
\text { prec@n }=\frac{|\mathbf{S} \cap \mathbf{G}|}{n}
$$

Como a maioria dos algoritmos não produzem uma solução binária e sim um ranking, pode ser de interesse medir prec@2n,prec@3n ou a precision em algum outro ponto do ranking, mas tipicamente a escolha se dá no número de outliers presente no ground truth. A modificação do ponto em que será medido a precision ajuda a resolver uma limitação que ocorre quando os outliers segundo o ground truth são ranqueados logo abaixo das $n$ observações, por exemplo, em um ranking em que os dois únicos outliers aparecem na terceira e quarta colocação terá precision-at- $n$ igual 0 , apesar do algoritmo ranquear bem ambos outliers. Uma segunda limitação apresentada por essa medida é o fato dela, por muitas vezes, avaliar que soluções muito ruins e soluções boas têm a mesma qualidade, vide a Figura A.1, em que a solução da Figura A.1(b) é tão boa quanto a solução A.1(c) de acordo com a precision-at- $n$.

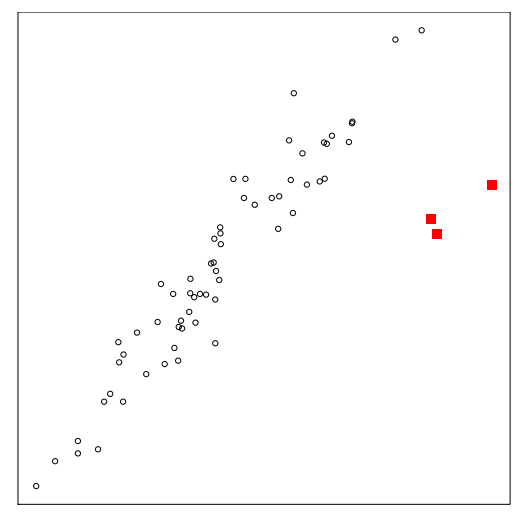

(a) Ground truth

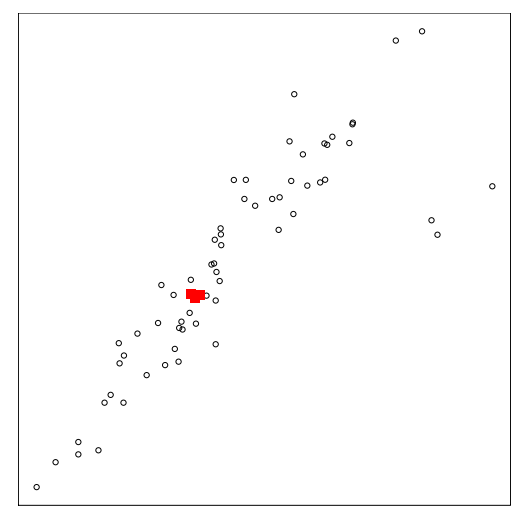

(b) Precision-at $-n=0$

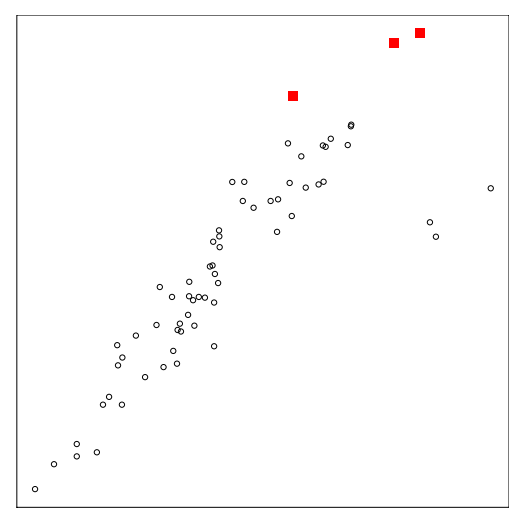

(c) Precision-at $-n=0$

Figura A.1: Ambas soluções com precision-at- $n=0$ de acordo com o ground truth

\section{A.2 Área sob a curva ROC}

Se for dada uma solução que consiste no ranking das $N$ observações da base de dados de acordo com o grau que cada uma delas é considerada outlier, pode-se plotar a curva Receiver Operating Characteristic (ROC) ou sumariza-la pela sua área para comparar diferentes soluções. A curva $\mathrm{ROC}$ avalia o ranking de acordo com o ground truth binário plotando a taxa de verdadeiros positivos ao longo do eixo $y$ pela taxa de falsos positivos ao longo do eixo $x$. Cada ponto ao longo da curva corresponde à variação do limiar que definirá quais observações deveram ser rotuladas como outliers e inliers. Inicialmente assume-se que todas observações da solução sejam outliers, logo a taxa de verdadeiros positivos será igual à 1, pois todas as observações rotuladas no ground truth como outliers terão sido rotuladas como outlier na solução, entretanto, a taxa de falsos positivos também será 1, pois todas observações rotuladas como inliers no ground truth também terão sido rotuladas como outliers. Em seguida esse limiar é aumentado de forma que apenas a última observação do ranking, a observação que menos se 
caracteriza como outlier segundo o ranking, seja considerada inlier, se de fato a observação for inlier no ground truth a taxa de verdadeiros positivos se manterá em 1 e a taxa de falsos positivos diminuirá. Gradualmente esse limiar é aumentado até que todas as observações da solução sejam consideradas inliers, ao contrário do cenário inicial, agora tanto a taxa de verdadeiros positivos quanto a taxa de falsos negativos serão iguais à 0 . Na solução ideal espera-se que a taxa de verdadeiros positivos diminua apenas depois que a taxa de falsos positivos chegue à 0 . Como os eixo $x$ e $y$ estão no intervalo [0,1], área sob a curva ROC pode assumir valores entre 0 e 1 . Na solução ideal a área será igual 1, enquanto em uma solução aleatória a área será próxima de 0,5 .

A curva ROC também possui limitações para avaliar soluções de detecção de outliers. Uma vez que esse procedimento avalia rankings, as informações dos scorings são completamente descartadas. Além disso, para conseguir a área máxima possível é necessário que os outliers sejam ranqueados acima dos inliers, porém existem $n !(N-n)$ ! soluções com a área máxima possível em uma base de dados com $N$ observações e $n$ outliers, todas elas são igualmente perfeitas independentemente de que observações situadas no centro do grupo sejam ranqueadas antes das observações situadas na borda do grupo, ou que observações que se caracterizem mais como outlier sejam ranqueadas depois de observações que se caracterizem menos. 



\section{Bibliografia}

Aggarwal, C. C. (2013). Outlier Analysis. Springer.

Amer, M., Goldstein, M., and Abdennadher, S. (2013). Enhancing one-class support vector machines for unsupervised anomaly detection. In Proceedings of the ACM SIGKDD Workshop on Outlier Detection and Description, ODD '13, pages 8-15, New York, NY, USA. ACM.

Angiulli, F. and Pizzuti, C. (2002). Fast outlier detection in high dimensional spaces. pages 15-26, Helsinki, Finland.

Angiulli, F. and Pizzuti, C. (2005). Outlier mining in large high-dimensional data sets. IEEE Transactions on Knowledge and Data Engineering, pages 203-215.

Bache, K. and Lichman, M. (2013). UCI machine learning repository.

Barnett, V. and Lewis, T. (1994). Outliers in Statistical Data. John Wiley \& Sons, 3rd edition.

Bennett, K. P. and Campbell, C. (2000). Support vector machines: Hype or hallelujah? SIGKDD Explor. Newsl., 2(2):1-13.

Boneau, A. (1960). The effects of violations of assumptions underlying the $t$ test. Psychological Bulletin, 57(1):49-64.

Breunig, M. M., Kriegel, H.-P., Ng, R., and Sander, J. (1999). Optics-of: Identifying local outliers. pages 262-270, Prague, Czech Republic.

Breunig, M. M., Kriegel, H.-P., Ng, R., and Sander, J. (2000). Lof: Identifying density-based local outliers. pages 93-104, Dallas, TX.

Brynjolfsson, E., Hitt, L. M., and Kim, H. (2011). Strength in numbers: How does data-driven decision-making affect firm performance? In Galletta, D. F. and Liang, T.-P., editors, ICIS. Association for Information Systems.

Chandola, V., Banerjee, A., and Kumar, V. (2009). Anomaly detection: A survey. ACM Comput. Surv., 41(3):15:1-15:58. 
Chandola, V., Banerjee, A., and Kumar, V. (2012). Anomaly detection for discrete sequences: A survey. IEEE Trans. on Knowl. and Data Eng., 24(5):823-839.

Dean, J. and Ghemawat, S. (2008). Mapreduce: Simplified data processing on large clusters. Commun. ACM, 51(1):107-113.

Duda, R. O., Hart, P. E., and Stork, D. G. (2001). Pattern Classification. Wiley, 2nd edition.

Ester, M., Kriegel, H.-P., Sander, J., and Xu, X. (1996). A density-based algorithm for discovering clusters in large spatial databases with noise. pages 226-231. AAAI Press.

Faires, J. D. and Burden, R. L. (2012). Numerical Methods. Cengage Learning, 4 edition.

Fan, H., Zaïane, O., Foss, A., and Wu, J. (2006). A nonparametric outlier detection for effectively discovering top-n outliers from engineering data. In Ng, W.-K., Kitsuregawa, M., Li, J., and Chang, K., editors, Advances in Knowledge Discovery and Data Mining, volume 3918 of Lecture Notes in Computer Science, pages 557-566. Springer Berlin Heidelberg.

Fayyad, U. M., Shapiro, G. P., Smyth, P., and Uthurusamy, R. (1996). Advances in Knowledge Discovery and Data Mining. MIT Press.

Gan, G., Ma, C., and Wu, J. (2007). Data Clustering: Theory, Algorithms, and Applications (ASA-SIAM Series on Statistics and Applied Probability). SIAM, Society for Industrial and Applied Mathematics, illustrated edition edition.

Grubbs, F. E. (1969). Procedures for detecting outlying observations in samples. Technometrics, 11(1):1-21.

Hadi, A. S. (1992). Identifying multiple outliers in multivariate data. Journal of the Royal Statistical Society. Series B (Methodological), 54(3):pp. 761-771.

Hadi, A. S., Imon, A. H. M. R., and Werner, M. (2009). Detection of outliers. Wiley Interdisciplinary Reviews: Computational Statistics, 1(1):57-70.

Hair, J. F., Black, B., Babin, B., Anderson, R. E., and Tatham, R. L. (2005). Multivariate Data Analysis. Prentice-Hall, Upper Saddle River, NJ, USA, 6th edition.

Hamel, L. H. (2009). Knowledge Discovery with Support Vector Machines. Wiley-Interscience, New York, NY, USA.

Han, J. and Kamber, M. (2006). Data Mining: Concepts and Techniques. Morgan Kaufmann, 2nd edition.

Han, J., Kamber, M., and Pei, J. (2011). Data Mining: Concepts and Techniques. Morgan Kaufmann, 3rd edition.

Handl, J., Knowles, J., and Kell, D. B. (2005). Computational cluster validation in post-genomic data analysis. Bioinformatics, 21(15):3201-3212. 
Hastie, T., Tibshirani, R., and Friedman, J. (2013). The Elements of Statistical Learning: Data Mining, Inference, and Prediction. Springer-Verlag New York, Inc., 2nd edition.

Hawkins, D. (1980). Identification of Outliers. Chapman and Hall.

Hodge, V. and Austin, J. (2004). A survey of outlier detection methodologies. Artif. Intell. Rev., 22(2):85-126.

Hosmer, D. W. and Lemeshow, S. (2000). Applied Logistic Regression. John Wiley \& Sons, second edition.

Hubert, L. and Arabie, P. (1985). Comparing partitions. Journal of Classification, 2(1):193218.

Jain, A. K. and Dubes, R. C. (1988). Algorithms for clustering data. Prentice-Hall, Inc., Upper Saddle River, NJ, USA.

Jin, W., Tung, A. K. H., and Han, J. (2001). Mining top-n local outliers in large databases. In Proceedings of the Seventh ACM SIGKDD International Conference on Knowledge Discovery and Data Mining, KDD '01, pages 293-298, New York, NY, USA. ACM.

Jin, W., Tung, A. K. H., Han, J., and Wang, W. (2006). Ranking outliers using symetric neighborhood relationship. pages 577-593, Singapore.

Johnson, T., Kwok, I., and Ng, R. (1998). Fast computation of 2-dimensional depth contours. Proc. Int. Conf. on Knowledge Discovery and Data Mining, pages 224-228.

Keerthi, S. S., Duan, K. B., Shevade, S. K., and Poo, A. N. (2005). A fast dual algorithm for kernel logistic regression. Mach. Learn., 61(1-3):151-165.

Keller, F., Müller, E., and Böhm, K. (2012). Hics: high contrast subspaces for density-based outlier ranking. Washington, DC.

Khan, S. S. and Madden, M. G. (2010). A survey of recent trends in one class classification. In Proceedings of the 20th Irish Conference on Artificial Intelligence and Cognitive Science, AICS'09, pages 188-197, Berlin, Heidelberg. Springer-Verlag.

Knorr, E. M. and Ng, R. T. (1998). Algorithms for mining distance-based outliers in large datasets. In Proceedings of the 24rd International Conference on Very Large Data Bases, VLDB '98, pages 392-403, San Francisco, CA, USA. Morgan Kaufmann Publishers Inc.

Knorr, E. M., Ng, R. T., and Tucanov, V. (2000). Distance-based outliers: Algorithms and applications. The VLDB Journal, pages 8(3-4):237-253.

Kriegel, H.-P., Kröger, P., Schubert, E., and Zimek, A. (2009). Loop: local outlier probabilities. pages 1649-1652, Hong Kong, China. 
Kriegel, H.-P., Schubert, M., and Zimek, A. (2008). Angle-based outlier detection in highdimensional data. pages 444-452, Las Vegas, NV.

Lazarevic, A. and Kumar, V. (2005). Feature bagging for outlier detection. pages 157-166, Chicago, IL.

Mahalanobis, P. C. (1936). On the generalized distance in statistics. In Proceedings of the National Institute of Sciences of India, page 49-55.

Micenkova, B., Dang, X.-H., Assent, I., and Ng, R. (2013). Explaining outliers by subspace separability. In Data Mining (ICDM), 2013 IEEE 13th International Conference on, pages $518-527$.

Milligan, G. W. and Cooper, M. C. (1985). An examination of procedures for determining the number of clusters in a data set. Psychometrika, 50:159-179.

Moore, G. (1964). The future of integrated electronics. Fairchild Semiconductor internal publication.

Moore, G. (1965). Cramming more components onto integrated circuits. Electronics Magazine, $38(8)$.

Moore, G. (1975). Progress in digital integrated electronics. Electron Devices Meeting, 1975 International, 21:11-13.

Naisbitt, J. (1982). Megatrends: Ten New Directions Transforming Our Lives. Warner Books.

Nocedal, J. and Wright, S. (2006). Numerical Optimization. Springer, 2 edition.

Orair, G. H., Teixeira, C., Wang, Y., Jr., W. M., and Parthasarathy, S. (2010). Distance-based outlier detection: Consolidation and renewed bearing. Proceedings of the VLDB Endowment, pages 3(2):1469-1480.

Osuna, E., Freund, R., and Girosi, F. (1997). Support vector machines: Training and applications. Technical report, Cambridge, MA, USA.

Papadimitriou, S., Kitagawa, H., Gibbons, P., and Faloutsos, C. (2003). Loci: Fast outlier detection using the local correlation integral. pages 315-326, Bangalore, India.

Patcha, A. and Park, J.-M. (2007). An overview of anomaly detection techniques: Existing solutions and latest technological trends. Comput. Netw., 51(12):3448-3470.

Pham, N. and Pagh, R. (2012). A near-linear time approximation algorithm for angle-based outlier detection in high-dimensional data. In Proceedings of the 18th ACM SIGKDD International Conference on Knowledge Discovery and Data Mining, KDD '12, pages 877-885, New York, NY, USA. ACM. 
Platt, J. C. (1999). Advances in kernel methods. chapter Fast Training of Support Vector Machines Using Sequential Minimal Optimization, pages 185-208. MIT Press, Cambridge, MA, USA.

Pokrajac, D., Reljin, N., Pejcic, N., and Lazarevic, A. (2008). Incremental connectivity-based outlier factor algorithm. In Proceedings of the 2008 International Conference on Visions of Computer Science: BCS International Academic Conference, VoCS'08, pages 211-223, Swinton, UK, UK. British Computer Society.

Ramaswamy, S., Rastogi, R., and Shim, K. (2000). Efficient algorithms for mining outliers from large data sets. pages 427-438, Dallas, TX.

Ross, S. (2009). Introduction to Probability Models. Academic Press, 10 edition.

Rosset, S., Zhu, J., and Hastie, T. (2003). Margin maximizing loss functions. In Advances in Neural Information Processing Systems (NIPS) 15, page 16. MIT Press.

Roth, V. (2006). Kernel fisher discriminants for outlier detection. Neural Comput., 18(4):942960.

Rousseeuw, P. J. and Leroy, A. M. (1987). Robust Regression and Outlier Detection. John Wiley \& Sons, Inc., New York, NY, USA.

Rousseeuw, P. J. and Zomeren, B. C. v. (1990). Unmasking multivariate outliers and leverage points. Journal of the American Statistical Association, 85(411):pp. 633-639.

Ruts, I. and Rousseeuw, P. J. (1996). Computing depth contours of bivariate point clouds. Comput. Stat. Data Anal., 23(1):153-168.

Schefler, W. C. (1988). Statistics: Concepts and Applications. Academic Press.

Schubert, E., Wojdanowski, R., Zimek, A., and Kriegel, H.-P. (2012). On evaluation of outlier rankings and outlier scores. pages 1047-1058, Anaheim, CA.

Tan, P.-N., Steinbach, M., and Kumar, V. (2006). Introduction to Data Mining. Addison Wesley.

Tang, J., Chen, Z., Fu, A. W.-C., and Cheung, D. W. (2002). Enhancing effectiveness of outlier detections for low density patterns. pages 535-548, Taipei, Taiwan.

Tang, Y., Zhang, Y.-Q., Chawla, N. V., and Krasser, S. (2009). SVMs Modeling for Highly Imbalanced Classification. Trans. Sys. Man Cyber. Part B, 39(1):281-288.

Tax, D. M. J. (2001). One-class classification: Concept-learning in the absence of counterexamples. $\mathrm{PhD}$ thesis, University of Delft.

Triola, M. (2007). Elementary statistics. Pearson, 10 edition. 
Vapnik, V. N. (1995). The Nature of Statistical Learning Theory. Springer-Verlag New York, Inc., New York, NY, USA.

Vapnik, V. N. (1998). Statistical Learning Theory. Wiley-Interscience, New York, NY, USA.

Vendramin, L., Campello, R. J. G. B., and Hruschka, E. R. (2010). Relative clustering validity criteria: A comparative overview. Statistical Analysis and Data Mining, 3(4):209-235.

Zhang, J. and Mani, I. (2003). KNN Approach to Unbalanced Data Distributions: A Case Study Involving Information Extraction. In Proceedings of the ICML'2003 Workshop on Learning from Imbalanced Datasets.

Zhang, K., Hutter, M., and Jin, H. (2009). A new local distance-based outlier detection approach for scattered real-world data. pages 813-822, Bangkok, Thailand.

Zhang, T., Ramakrishnan, R., and Livny, M. (1996). Birch: an efficient data clustering method for very large databases. SIGMOD Rec., 25(2):103-114.

Zhu, J. and Hastie, T. (2001). Kernel logistic regression and the import vector machine. In Journal of Computational and Graphical Statistics, pages 1081-1088. MIT Press.

Zimek, A., Gaudet, M., Campello, R. J., and Sander, J. (2013). Subsampling for efficient and effective unsupervised outlier detection ensembles. In Proceedings of the 19th ACM SIGKDD International Conference on Knowledge Discovery and Data Mining, KDD '13, pages 428436, New York, NY, USA. ACM.

Zimek, A., Schubert, E., and Kriegel, H.-P. (2012). A survey on unsupervised outlier detection in high-dimensional numerical data. Stat. Anal. Data Min., 5(5):363-387. 